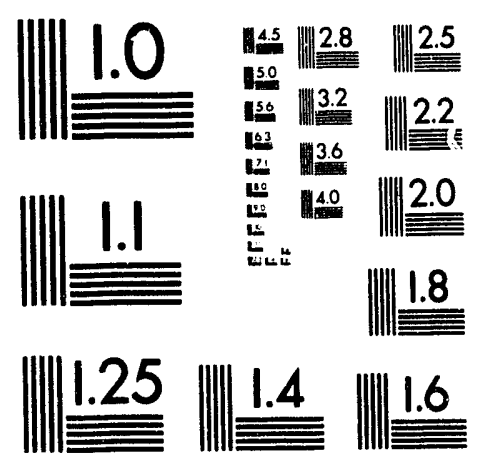



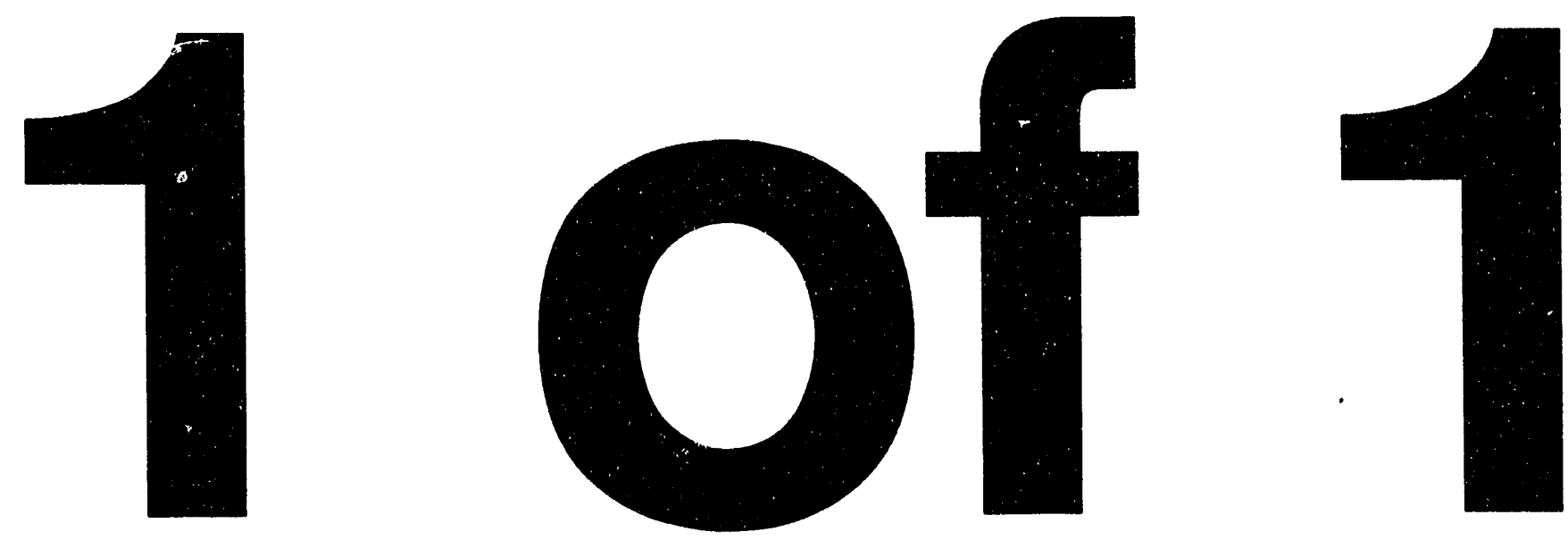


\section{ESTIMATES FOR PU-239 LOADINGS IN BURIAL GROUND CULVERTS BASED ON FAST/SLOW NEUTRON MEASUREMENTS (U)}

by

W. G. Winn

Westinghouse Savannah River Company

Savannah River Site

Aiken, South Carolina 29808

R. C. Hochel

WSRC

K. J. Hofstetter

WSRC

R. A. Sigg

WSRC

A document prepared for:

requested by:

Mary Cunningham

Information Store, San Francisco, CA

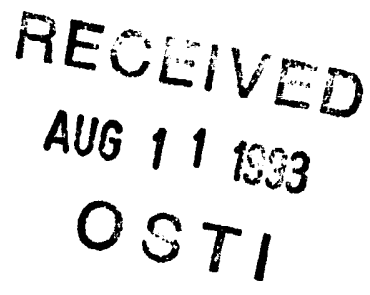

\section{DOE Contract No. DE-AC09-89SR18035}

This paper was prepared in connection with work done under the above contract number with the U.S.

Department of Energy. By acceptance of this paper, the publisher and/or recipient acknowledges the U.S.

Government's right to retain a nonexclusive, royalty-free license in and to any copyright covering this paper, along with the right to reproduce and to authorize others to reproduce all or part of the copyrighted paper. 


\section{DISCLAIMER}

This report was prepared as an account of work sponsored by an agency of the United States Government. Neither the United States Government nor any agency thereof, nor any of their employees, makes any warranty, express or implied, or assumes any legal liability or responsibility for the accuracy, completeness, or usefulness of any information, apparatus, product, or process disclosed, or represents that its use would not infringe privately owned rights. Reference herein to any specific commercial product, process, or service by trade name, trademark, manufacturer, or otherwise does not necessarily constitute or imply its endorsement, recommendation, or favoring by the United States Government or any agency thereof. The views and opinions of authors expressed herein do not necessarily state or reflect those of the United States Government or any agency thereof.

This report has been reproduced directly from the best available copy.

Available to DOE and DOE contractors from the Office of Scientific and Technical Information, P. O. Box 62, Oak Ridge, TN 37831; prices available from (615) $576-8401$.

Available to the public from the National Technical Information Service, U. S. Department of Commerce, 5285 Port Royal Rd., Springfield, VA 22161. 


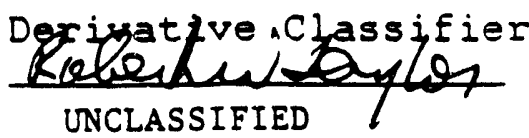

KEYWORDS

Criticality

Burial Ground

TRU Waste

Pu- 239

Neutron Counters

Estimations

Statistical Models

- i. icty

Lifetime Retention

August 15, 1989

\footnotetext{
TO: M.A. EBRA WJW H.

FROM: W.G. WINN, R.C. HOCHEL,

K.J. HOFSTETTER, R.A. SIGG
}

\section{Estimates for Pu-239 Loadings in Burial Ground Culverts Based on Fast/Slow Neutron Measurements ( $i l$ )}

The above WSRC-RP, which follows this cover sheet, includes a Table of Contents, Main Text, and Appendicies A - C. The data are tabulated to aliow easy appraisal of estimated pu-239 upper limit loadings for comparison with criticality limits.

\section{SRP}

L.M. Papouchado, 703-A

R.G. Garvin, 703-H

J.E. Haywood

S.S. Cathey

W.E. Stewart

J.R. Shappell

H.H. Rowland, 703-F

T.A. Reilly, 707-H

S.J. Mentrup, 724-7G

R.E. Hanvey

C.C. Robbins

D.W. Murdock
SRL

H.D. Harmon, 773-A

A.L. Boni

C.E. Coffey

G.T. Wright

C.W. Jenkins

K.A. Andringa, 773-41A

D.R. Finch

D.A. Orth

M.D. Boersma

R.W. Taylor, 735-A 
TABLE OF CONTENTS

MAIN TEXT

INTRODUCTION $\ldots \ldots \ldots \ldots \ldots \ldots \ldots \ldots \ldots \ldots$

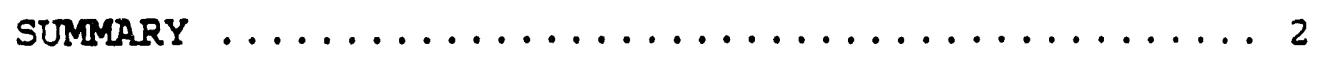

MEASUREMENTS AND DATA SOURCES $\ldots \ldots \ldots \ldots \ldots \ldots$

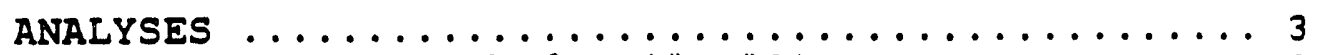

Direct $\mathrm{m} / \mathrm{p}$ Methods $(1,12) \ldots \ldots \ldots \ldots \ldots \ldots$

$(\# 3, \# 4, \# 5) \ldots \ldots \ldots \ldots \ldots \ldots$

Statistical Methods $(\# 6, \# 7) \ldots \ldots \ldots \ldots \ldots \ldots$

$(\# 8, \# 9) \ldots \ldots \ldots \ldots \ldots \ldots$

Applicability to Maximum Drum ...........6

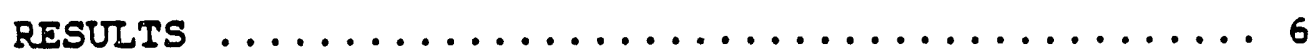

Preferred Methods ................. 6

Other Methods ..................... 7

DISCUSSION ........................

Appraisal of Preferred Methods .......... 7

$\mathrm{m} / \mathrm{p}$ Method (Methoo 5 ) ............

Statistical Method (Method 9 ) ........

$\mathrm{m} / \mathrm{p}$ vs Statistical Method ............

Applicability to Remaining Culverts ....... 10

Need for Realistic Criticality Limits ...... 10

ACKNOWLEDGEMTNTS ................... 10

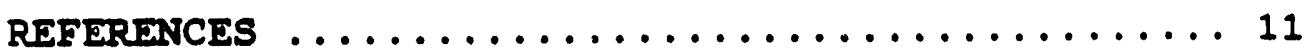

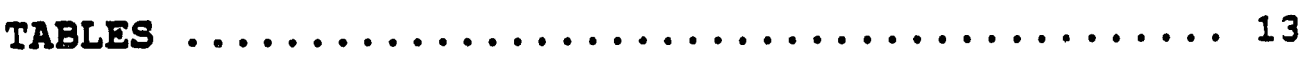

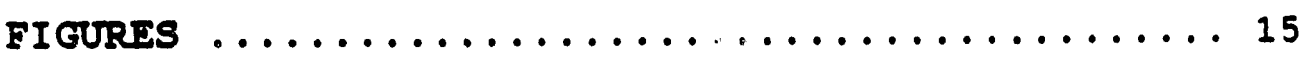

\section{APPENDICIES}

A. Development of New Analysis Methods ........ A-1

B. Comparisons from Better known Culverts ...... B-1

C. Tables for Pu-239 Estimates ............. C-1 


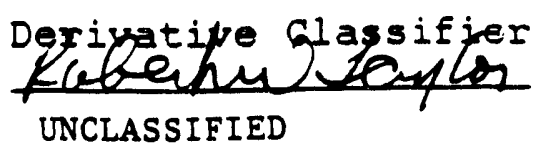

CC: Distribution (coversheet)

August 15, 1989
TO: M.A. EBRA, JhW Wet
FROM: W.G. WINN, R.C. HOCHEL
K.J. HOFSTETTER, R.A. S:GG

Estimates for Pu-239 Loadings in Burial Ground Culverts Based on Fast/Slow Neutron Measurements

\section{INTRODUCTION}

This report provides guideline estimates for Pu-239 mass loadings in selected burial ground culverts. The relatively high recorded Pu-239 contents of these culverts have been appraised as suspect relative to criticality concerns, because they were assayed only with the solid waste monitor (SWM) per gamma-ray counting [ref 1]. After 1985, subsequent waste was also assayed with the neutron coincidence counter (NCC), and a comparison of the assay methods showed that the NCC generally yielded higher assays than the SWM [ref 2]. These higher NCC readings signaled a need to conduct non-destructive/non-intrusive nuclear interrogations of these culverts, and a technical team conducted scoping measurements to illustrate potential assay methods based on neutron and/or gamma counting [ref 3 ].

A fast/slow neutron method has been developed to estimate the Pu-239 in the culverts [ref 4]. In addition, loading records include the SWM assays of all pu-239 cuts of some of the culvert drums [ref 5], and these data are useful in estimatins the corresponding NCC drum assays from NCC vs SWM data [ref 2]. Togther, these methods yield predictions based on direct measurements and statistical inference. 


\section{SUMDARY}

Detailed Pu-239 estimates are given for 118 suspect culverts on pads 6,10 , and 13 . A total of 9 estimate methods were examined, and one based on direct measurements and one based on statistical inference are adopted as the most appropriate guides. For arbitrary Pu-239 loading limits of $1000 \mathrm{~g}$ per drum and $2500 \mathrm{~g}$ per culvert, the direct method predicts that 82 culverts comply, and the statistical method predicts that $a 11118$ comply.

Interferences from non-Pu-239 neutron sources cause some of the non-compliance cases in the direct method. Measurements on 36 culverts with better known pu loadings imply that refinements for the Pu-238 contribution would allow 111 culverts to comply, using the direct method. These measurements also indicate that the SWM provides a better - albeit lower - estimate than the NCC, and thus currently accepted (NCC+SWM)/2 values are conservative on average. Gamma-ray measurements will provide additional information on some of the culverts. Ultimate compliance will depend on criticality loading iimits, which are being evaluated and adopted for this work.

There are 93 suspect culverts that were not appraised in this study, because an overburden of soil rendered them inaccessable. However, their recorded SWM assays are much lower than those examined in the present work. Thus, compliance for these culverts may be demonstratable without direct measurements.

\section{MEASUREMIENTS AND DATA SOURCES}

Measurements were conducted with the fast/slow neutron method, as described in detail earlier [ref 4]. Briefly, a fast and a slow neutron detector were centered atop each culvert and counted for $200 \mathrm{sec}$. The measured neutron rates were corrected for backgrounds for the adjacent culverts and general area. Each measured neutron rate was compared with a projected neutron rate based on culvert calibrations, which address neutron source location and drum moderator. These rate calibrations were convoluted with the SWM recorded Pu-239 for each drum per location, to yield the projected rate. The ratio of measured to projected neutron rates, designated $\mathrm{m} / \mathrm{p}$, reflects the agreement between the actual and recorded Pu-239 loadings. Multiplication of $\mathrm{m} / \mathrm{p}$ by the recorded mass yields an estimate of the actual Pu-239 in the culvert.

Earlier work [ref 4] had already measured the 71 suspect culverts on pad 13 , and the present study measured the 30 suspect culverts on pad 6 and the 17 on pad 10 . Thus, results for a total of 118 culverts are presented in this report. There are 93 more culverts that still need to be appraised; however, they were inaccessable in this work due to a soil overburden. Also, it may be possible to cancel measurements on these pending the status of the 118 , as the 93 have much lower SwM recorded Pu-239. 
The present work also includes measurements on 36 "check" culverts that have better information on their Pu loadings, as both SWM and NCC data were available. These culvert measurements provide further appraisal of the fast/slow neutron method. In particular, they give better information on the effect of pu- 238 . These culverts include 33 from pad 10 and 3 from pad 13. A total of 18 have only Pu-239; the other 18 have both Pu-238 and Pu-239.

Further data sources are from records of individual cuts of Pu-239. The cuts are assayed and packaged into the drums, and data on these suggest that most drums are loaded with 10-20 cuts of relatively small amounts of Pu-239 [ref 6]. This further implies that the accumulative percent error in the sum of these SWM assays (per drum loading) will be smaller than the error in a single assay of all these cuts. Given cut data for each drum, NCC vs SWM fluctuation data [ref 2] exist for predicting these errors and thus their upper limit excursions. Unfortunately, cut data for all drums were not available; only data for 68 drums could be examined for these fluctuations [ref 5]. The consistency of these predictions could be tested with the NCC and SWM data for the 36 "check" culverts.

\section{ANALYSES}

Two analyses, an $\mathrm{m} / \mathrm{p}$ measurement method and one based on statistical inference, were considered most appropriate. These evolved from a total of nine different analyses that were examined. Five were described earlier [ref 4] and four now ones have evolved recently. All methods are summarized below, as a framework for discussing the two preferred methods. Each method is given a number and name for easy reference to analysis results, as summarized in Tables in Appendix C. The first five methods are based directly on the measured $\mathrm{m} / \mathrm{p}$ ratios. The last four utilize statistical models. As will be discussed in further detail in the the REsuLTS section, Method $\$ 5$ is adopted as the preferred $\mathrm{m} / \mathrm{p}$-method, and Method $\% 9$ is the preferred statistical method. The direct methods and statistical methods leading to the preferred ones are described below.

\section{Direct $\mathrm{m} / \mathrm{p}$ Methods - Method 5 Preferred}

Methods 11 - 15 directly estimate Pu-239 by multiplying each inventory value by its culvert ratio of measured/projected neutron rates. Method $\$ 5$ is identified as the preferred direct method.

(1) $\mathrm{m} / \mathrm{p} \times$ Inventory Pu-239. [Ref 4 Method \#3]. The estimate is defined by its title.

(2) $\mathrm{m} / \mathrm{p} \times 35 i g \times$ Inventory Pu-239. [Ref 4 Method " 4 ] . Estimate of Method 11 increased to account for upward 3-sigma fluctuations. The sigma includes all $\mathrm{m} / \mathrm{p}$ measurements. 
(3) $\mathrm{m} / \mathrm{p}($ Pu-239) $\mathrm{x}$ Inventory Pu-239. [Ref 4 Method \#5].

Estimate is defined by its title, where $\mathrm{m} / \mathrm{p}(\mathrm{Pu}-239)$ is based on culverts that only have Pu-239 and no other interferring neutron sources. The $\mathrm{m} / \mathrm{p}$ values for these pure Pu-239 cases were low (average $\sim 1$ ) relative to earlier NCC/SWM values (average 1.40); thus, $\mathrm{m} / \mathrm{p}$ values were normalized to 1.40 to be conservative. Later measurements with the check culverts showed that this conservative factor was unnecessary.

(4) $\mathrm{m} / \mathrm{p}(\mathrm{Pu}-239) \times 3 S i g(P u-239) \times$ Inventory Pu-239. [Ref 4 Method \#6]. Estimate of Method \#3 increased to account for upward 3-sigma fluctuations. The sigma includes $\mathrm{m} / \mathrm{p}$ measurements for culverts having only Pu-239 neutron sources.

(5) $\mathrm{m} / \mathrm{p} \times 3$ Sig (Pu-239) $x$ Inventory Pu-239.... Preferred $\mathrm{m} / \mathrm{p}$ Method. [New Method]. Estimate uses measured $\mathrm{m} / \mathrm{p}$ ratio (as in Methods 1 and $\# 2$ ) increased to account for 3-sigma Pu-239 fluctuations (as in Method \#4). The average $\mathrm{m} / \mathrm{p}$ ratio for the check culverts agrees well with 1.0 for check culverts containing only Pu-239, and the 3-sigma Pu-239 fluctuations are appropriate for upper limit estimates of their Pu-239. The

check culverts that contain both Pu-238 and Pu-239 yield $\mathrm{m} / \mathrm{p}$ values that are biased high; thus, using the 3-sig(Pu-239) for the upper limit Pu-239 estimate for these culverts should yield conservatively high results.

\section{Statistical Methods - Method 9 Preferred}

Methods \#6 - \#9 use statistical inference to estimate the Pu-239 loadings. Method 9 is identified as the preferred statistical method.

(6) $13 / \sqrt{n} \times$ Inventory Pu-239. [Ref 4 Method 2 ]. This method takes credit for the cut averaging effect in $\mathrm{m} / \mathrm{p}$ estimates, which lowers the fluctuations by a factor of $\sqrt{n}$. The $n$ is an effective number of recorded Pu-239 cuts of a culvert loading, based on measured log-Normal distribution data. For a single cut $(n=1)$, a maximum factor of 13 gives the 3-sigma upper limit [ref 4]. The effective $n$ is shown to be proportional to the recorded mass loading. The development is based on culverts having only pu-239 neutron sources, and uses those with SWM that cluster about $248 \mathrm{~g}$ and $926 \mathrm{~g}$, as shown in Figure 1. Appendix A provides further details.

(7) Refined $13 / \sqrt{n} \times$ Inventory Pu-239. [New Method]. This method is the same as Method 6 , except that the individual data points of Figure 1 are fitted to the model instead of using two averaged point clusters. This refined approach results in somowhat larger effective $n$ (lower accumulative fluctuations) than afforded by the 
point cluster approach. This is expected because the variation in SWM values with the point clusters

introduces additional uncertainty in derived NCC values. Mathematical details for this method are discussed in Appendix A.

(8) Cut Model $x$ Inventory Pu-239. [New Method]. This method uses the data for the 68 drums with detailed cut information and the NCC vs SWM correlation. Figure 2 reproduces the NCC vs SWM correlation from an earlier study [ref 2]. The correlation shows that $\ln (\mathrm{NCC})$ and its error increase linearly with ln(SWM). Using the SWM recorded for each cut, the correlated NCC and error is calculated. The cut NCCs are then summed for each drum and their accumulated error is also determined. The resulting 3-sigma excursion upper limits for the 68 drums are plotted in Figure 3. The figure also includes an envelope curve that is conservatively higher than all measured NCC excursions. This envelope of NCC excursion vs drum SWM is also used to predict the culvert NCC excursion limits. Specifically, the correlated NCCs for the drums and their errors, as determined from the envelope curve, are sumed to yield a culvert NCC and its corresponding accumulated error. From this, the 3-sigma excrusion limits for the culverts are determined. The mathematical details for this method are given in Appendix A, where the predictions are shown to be consistent with observations for the 36 check culverts.

(9) Conservative Cut Model x Inventory Pu-239.... Preferred Statistical Method. [New Method]. This method yields results intermediate to those of Methods $\$ 7$ and $\#$. Method 7 is thought to yield a high estimate, be-suse it uses neutron rate fluctuations to infer fluctuations in the pu-239 loadings. Here, the neutron rate

contribution from drums in the bottom of the culvert can be diminished relative to rates from drums in the top; thus, all Pu-239 is not equally represented in the rates and their effective $\mathrm{n}$ from rates is lower (larger fiuctuations). By contrast. Method \#8 can yield low Pu-239 estimates. In Method 8 , the cut model only uses 68 drums to predict the NCC (upper limit) vs SWM envelope curve for drums, and all values are accumulated from cuts with SWM less than 30 g. At the same time, Appendix A shows that these predictions are consistent with NCC and SWM measurements for the 36 check culverts, which have SWM cuts of somewhat larger mass. Yet the possibility of very large SWM cuts in the suspect culvert drums cannot be ignored, although they are less likely [ref 6]. Thus, Method \#8 should be treated as a possibly low estimate. The Conservative Cut Model

increases the drum envelope (Figure 3 ) by $\times 1.5$, to yield the culvert results in Figure 4. The excursion estimates agreo with Method $\$ 8$ for the lowest SWM loadings, where 
the lowest probability for a large Pu-239 cut exits: they agree with Method \#7 for the largest SWM loadings. where the highest probability for a large Pu-239 cut exists. The estimates increase monotonically with SWM between these limits.

\section{Applicability to Maximum Drum of a Culvert}

The above methods were used to estimate both the drum contents and the culvert contents. The $\mathrm{m} / \mathrm{p}$ methods are not as suitable for the individual drums, because these methods only measure rates for the culvert. However, the projected rates ( $p$-factor of $\mathrm{m} / \mathrm{p}$ ) do depend on the recorded SWM values for the drums, and modeling the projected rates with the drum SWM and distributional data does reduce the fluctuations in the $\mathrm{m} / \mathrm{p}$ measurements [ref 4]. Also, in most culverts, the SWM of the highest drum is substantially larger than the SWM of the next highest drum, so the $\mathrm{m} / \mathrm{p}$ of the culvert is heavily influenced by the highest drum. Because the highest drum is appraised relative to a criticality limit, multiplication of its SWM by the culvert $\mathrm{m} / \mathrm{p}$ yields a useful guideline estimate for examining the drum compliance.

For the statistical methods, which are based on the effect of accumulative errors on the sums of cuts, the estimate for both drums and culverts are based on the same models, and thus the above concern for distinguishing between individual drums is not an issue.

\section{RESURTS}

\section{Preferred Methods}

Table 1A gives the Pu-239 estimates for the preferred $\mathrm{m} / \mathrm{p}$ method, which is Method $\$ 5$. Assuming example loading limits of $1000 \mathrm{~g} / \mathrm{drum}$ and $2500 \mathrm{~g} / \mathrm{culvert.} \mathrm{Table} 1 \mathrm{~A}$ projects that 82 of the 118 culverts would be in compliance. Table $1 B$ reduces these estimates by including a special Pu-238 correction, which is described in the DISCUSSION section. Table 1B projects that 111 of the culverts would be in compliance with the above example limits.

Table 2 gives the Pu-239 estimates for the preferred statistical method, which is Method "9. Relative to the example limits of $1000 \mathrm{~g} / \mathrm{drum}$ and $2500 \mathrm{~g} /$ culvert. Table 2 projects that all 118 culverts would be in compliance.

These tables are designed to allow rapid appraisal of the estimates against realistic criticality limits, which are yet to be certified. Each table is like a scatter plot, where the culvert estimates are ordered monotonically in the third column (vertical axis), and their corresponding maximum drum estimates are monotonically spaced and printed to the right along respective rows (horizontal axis). The first column gives the 
table entry number, and the second column identifies the culvert number.

An example of how these tables are used is as follows. Using Table 1A, again suppose Pu-239 limits of $1000 \mathrm{~g} / \mathrm{drum}$ and $2500 \mathrm{~g} /$ culvert. Then Table $1 \mathrm{~A}$ has 88 culverts with $<2500 \mathrm{~g}$. which is easily determined from columns 1 and 3 . Of these, 6 can be easily identified as having maximum drum estimates that are as high as $1000 \mathrm{~g}$. Thus, a total of $88-6$ or 82 of these culverts and their drums meet the criteria. Using the table as a scatter plot. one would have drawn a horizontal line under the highest culvert estimate that is less than $2500 \mathrm{~g}$ (entry 88) and a vertical line just to the right of the highest drum estimate that is less than $1000 \mathrm{~g}$. Then, the acceptable cases are those having both culvert estimates above the horizontal line and drum estimates to the left of the vertical line.

\section{Other Methods}

The results for all nine estimato methods are presented in similar tables in Appendix $C$, which in addition includes tables that order the data by culvert number for easy reference. Although the preferred methods are recommended at present, the over-conservatism in some of these alternative methods may become attractive, should their estimates be in compliance with the to-be-established criticality limits.

\section{DISCUSSION}

\section{Appraisal of Preferred Methods}

The preferred analysis methods are considered reasonable and conservative for several reasons. Both methods utilize estimates that are coupled with 3-sigma upper-limit fluctuations. The corresponding $0.1 \%$ probability for these limits needs to be appraised in terms of the probability of critical configurations, and preliminary studies [ref 7] indicate that these probabilities should be less than $10^{-5}$ so that current methods would render these probabilities to be less than 10\%. Other conservative aspects for the preferred methods are discussed below.

preferred $\mathrm{m} / \mathrm{p}$ Method (Method 5 ). The results from the 36 check culverts support Method $\$ 5$ as the preferred $\mathrm{m} / \mathrm{p}$ method. The (NCC+SWM) / 2 values for the 18 culverts containing only Pu-239 yield a low $\mathrm{m} / \mathrm{p}$ geometric average of $0.74 \pm 0.09$. When the SWM values are used. this average is $0.95 \pm 0.11$, which is consistent with the desired value of 1 . Becalse culvert calibrations in the laboratory used a well-known Pu-239 source [ref 4 ], the above result implies that the SWM measurements are generally more accurate than the NCC measurements. Appendix B details the analysis for these observations. 
For the 18 check culverts containing both Pu-238 and Pu-239. the $\mathrm{m} / \mathrm{p}$ values tend to be significantly greater than 1 , yielding a geometric average of 1.78. Although a correction for Pu-238 contribution was developed [ref 4], the check culvert data show that as Pu-238 becomes a larger fraction of the total Pu, the $\mathrm{m} / \mathrm{p}$ ratio is biased higher, which makes the correction conservatively high. Appendix B examines this Pu-238 bias trend and develops a bias correction factor $R$. An $R$ factor was calculated for each of the 118 culverts under study, and each $\mathrm{m} / \mathrm{p}$ estimate for Pu-239 was divided by its $R$, to yield the corrected Pu-239 estimates given in Table 1B. With these corrections, 111 of the 118 culvorts meet the example criteria of $1000 \mathrm{~g} / \mathrm{drum}$ and $2500 \mathrm{~g} /$ culvert.

The Preferred $\mathrm{m} / \mathrm{p}$ Method is also conservative due to subcrit.ocal multiplication arguments. Measurement of the $\mathrm{m} / \mathrm{p}$ values assumes that the ratio is entirely related to the ratio $\mathrm{m} / \mathrm{m}$. of actual Pu-239 to recorded Pu-239. If a criticality concern exists, noticeable subcritical multiplication $M$ should also be a factor in the $\mathrm{m} / \mathrm{p}$ ratio $\mathrm{r}$, so that

$$
m / p=r=M m / m
$$

An estimate for $M$ is given by

$$
M=\frac{1}{1-k_{0.0}}=\frac{r m}{m}
$$

where k... is the effective criticality constant for the culvert, such that k... = 1 for the critical (infinite multiplication) case. Solving Equation 2 for kop yields

$$
\text { k.r. }=1-m_{0} / m_{r} r=1-m_{0} / m_{0} 0
$$

where $m_{0}=\mathrm{mr}$ is the Pu-239 estimated as the upper excursion (3-sigma limit) value of $\mathrm{m} / \mathrm{p} x$ SWM in Method 5 . From Equation 3 , it is clear that for k.p to be near the critical value of 1 , the actual Pri-239 or mo must be small relative to the $\mathrm{m} / \mathrm{p}$ SWM estimate mo. However, there has to be a realistic lower limit on mo because small amounts of Pu-239 cannot produce much multiplication to yield a substantial kop. For example, suppose the Pu-239 of a drum were estimated as $\mathrm{m} / \mathrm{p}$ swM $=1000 \mathrm{~g}=\mathrm{m}$... Then, if the actual mass were $m_{0}=500 \mathrm{~g}$, which is the minimum possible critical mass, the kop would be 0.5 . For lower actual masses, criticality would be impossible, and for higher actual masses, ker. would be less than 0.5 . Realistic critical configurations for the culverts would involve actual critical masses that are greater than the 5008 minimum considered here, which would render that even greater $\mathrm{m} / \mathrm{p}$ SWM estimates could be in compliance with criticality concerns. It might be beneficial to examine individual cases using these concepts, to demonstrate compiiance when the realistic cIitical limits become ayailable. 
In any event, Method $\# 5$ does not take credit for the subcritical multiplication offect, and its estimated masses can only be conservatively high with respect to its assumption of nonmultiplication $(M=1)$.

Preferred Statistical Method (Method \#9). This method uses statistical modeling to infer the effect of individual cuts, which are summed to give the drum and culvert Pu-239 loadings. As described in the ANALYSES section, this method yields results that are intermediate to Method $\# 7$, which can produce cverestimates, and Method 8 , which can produce underestimates. The possible underestimates of Method $\$ 8$ are for NCC excursion limits, as predicted from corresponding recorded SWM values. Because these NCC excursion limits exceed the SWM reading, the assay (NCC+SWM) $/ 2$ that would have been obtained by current policies would be lower than that of the NCC estimates of Method \#8. Thus, although Method \#8 may yield a low estimate, it could be even lower if credit for this averaging effect were included. In fact, data for the 36 check culverts indicate that $\mathrm{NCC} /[(\mathrm{SWM}+\mathrm{NCC}) / 2]=1.22$, as shown in Appendix B. Thus, Mothod $\# 8$ is conservative relative to this effect. Method 9 uses a modification of Method 8 , in which the drum NCC estimates are increased by $\times 1.5$ to force agreement with the higher loadings that are conservatively estimated by Method $\# 7$, as shown in Figure 4. Thus, Method \#9 appears to be both a reasonable and conservative statistical method.

Figure 5 compares the preferred statistical method with the current accepted policy of using (NCC+SWM)/2 estimates. Here, the statistical estimates for the 118 suspect culverts and the (NCC+SWM) $/ 2$ values for the 36 check culverts are both plotted against their respective SWM values. Because the statistical estimates cluster well above the scatter for the (NCC+SWM)/2 values, the preforred statistical method is quite conservative, implying that probabilities considerably lower than $0.1 \%$ really correlate with the above-defined $0.1 \%$ upper 1 imit estimates. Actually, Method 8 appears to yield fairly accurate $0.1 \%$ upper limit estimates of NCC, as illustrated by a similar plot in Appendix $\mathrm{A}$; however, the data are inadequate for addressing fluctuations of large cuts, which are less likely. Thus, the conservatism of Method 9 makes it more favorable than Method $\$ 8$.

preferred $\mathrm{m} / \mathrm{p}$ Method vs Preferred Statistical Method . The $\mathrm{m} / \mathrm{p}$ Method senerally predicts higher estimates than the

Statistical Method. The $\mathrm{m} / \mathrm{p}$ ratio can be $\mathrm{high}$ due to contributions from neutron sources other than Pu-239. Although the analysis includes a correction for some of these neutron sources, the overail results include a conservative bias that is attributed to these sources [ref 4]. Thus, estimates by the $\mathrm{m} / \mathrm{p}$ Method can be unduly high. The Pu-238 bias factor R provides a correction for this effect. By contrast, the statistical Method is based on culverts that contain only pu-239 neutron sources and drum cut data for Pu-239 alone; thus, it is not biased by other neutron sources. Although these considerations favor use of the statistical Method, it will be prudent to closely examine some of 
the higher estimate cases of $\mathrm{m} / \mathrm{p}$ Method, as a guide to their acceptance. Gamma-ray measurements for these can confirm whether the high estimates are caused by sources other than Pu-239.

\section{Applicability to Remaining Culverts}

The Statistical Method may be applicable for screening the remaining 93 suspect culverts that were inaccessable due to soil overburden. If so, actual measurements would not be necessary. These remaining culverts have SWM recorded Pu-239 loadings that are much lower than many of those analyzed in the present work. For example, the present study appraised 20 culverts with SWM recorded Pu-239 of 500-1200 g, and the largest loading for the remaining culverts is only $363 \mathrm{~g}$. In addition, their individual drum loadings tend to be smaller. Further detailed data could enhance these appraisals. In particular, additional NCC and SWM duta for culvert loadings would be useful to refine the correlations presented in this work. In particular, these data would be transformed to $(\mathrm{NCC}+S W M) / 2$ values, which are accepted for current assays.

\section{Need for Realistic Criticality Limits}

The results of the present work are presented in a way that acceptable culverts can easily be identifiod relative to critical loading limits for pu-239. An effort [ref 8) has been underway to establish realistic limits for these culverts, because the present limits are based on general conditions for a postulated worst possible situation. Thus, the present limits are overly conservative relative to known moderator and geometry conditions of these culverts.

The realistic criticality limits are also needed to s. ide the completion of these appraisals. In particular, gamma-iy studies are being conducted only for culverts that are considered to be unacceptable from neutron measurements alone, and identification of these culverts is governed by the criticality limits. Because each gamma-ray measurement/analysis of a culvert can involve extensive time and effort, only culverts that absolutely require this appraisal should be studied.

\section{ACKNOKLEDGEMITNTS}

J.R. Shappell has provided much data from culvert/drum records, including the detailed cut records and updated culvert loading information. S.J. Mentrup has helped assure smooth field measurements, by providing assistance from services in the burial ground. 


\section{REFERMNCES}

(1) O.M. Morris, "Meeting Minutes - Suspect FB-Line TRU Waste", Memorandum to Distribution, December 17, 1987.

(2) E.P. Shine, "Analysis of Large Differences between Neutron Coincident and Gamma Measurements for FB-Line TRU Waste Cuts", Memorandum to W.E. Stewart, October 7, 1988.*

(3) R.C. Hochel, K.J. Hofstetter, R.A. Sigg, and W.G. Winn, "TRU Waste Culvert Monitoring Study",DPST-88-606, June 14, 1988.

(4) W.G. Winn, R.C. Hochel, K.J. Hofstetter, R.A. Sigg, "Fast/Slow Neutron Method for Appraising Pu-239 Waste in Burial Ground Culverts", DPST-89-346, March 6, 1989.

(5) J.R. Shappell, transmittal of culvert data below:

(a) Pu-239 cut data (SWM) for 68 drums from drum waste inventory worksheets.

(b) Data for suspect culverts - Culvert Log Book data on drum contents vs location, appended to COBRA inventory records referenced by:

W.J. Jaegge, "Pu-239 Inventory in Culverts with pre-11/16/85 FB Line Waste", Memorandum to G.H. Street, J.N. Chen, and J.R. Shappell, April 6, 1988.

(c) Data for 36 "check" culverts with NCC and SWM loadings Culvert Log Book Data on drum contents (NCC \& SWM) and location, appended to COBRA inventory records referenced by:

K.S. Weirzbicki, "Burial Slips and Completed Procedures for Culverts Containing FB-Line and TRU Waste", Memorandum to T.H. Fisher, February 28, 1989.

(6) D.W. Murdock, E-Area Separations Department, "FB-Line Solid TRU Waste Analysis", Memorandum to J.K. McKibbin and R.E. Hanvey, August 4, 1988.

* Data in this report are consistent with an overall average NCC/SWM bias of 1.40 , although recent measurements suggest this may be higher. The overall bias depends on the size distribution of the cuts investigated; thus, the detailed correlated data of this report of $\ln (N C C)$ vs $\ln (S W M)$ is considered the most reliable. 
REFERENCES - continued

(7) R.C. Hochel, K.J. Hofstetter, R.A. Sigg, and W.G. Winn, "Probabilistic Assessment of Culvert Nuclear Safety", DPST89-383. April 10, 1989.

(8) R.C. Hochel, K.J. Hofstetter, R.A. Sigg, and W.G. Winn, "Nuclear Safety of Plutonium/Polyethylene Waste in TRU Culverts", DPST-88-1014, December 12, 1988. 
Table 1. Preferred a/p Analysis - Method us

A. Base Analyais

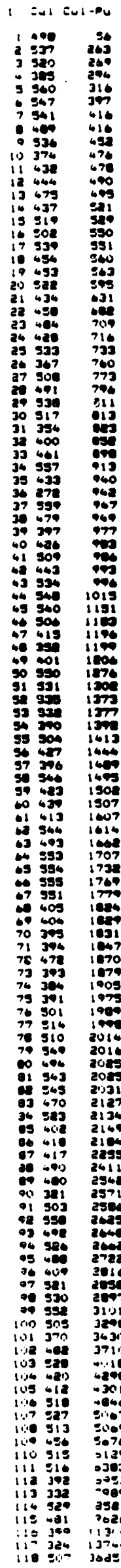

B. Analysis with Pu-238 Correction

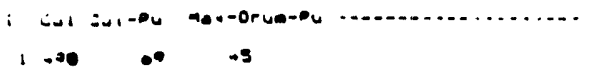

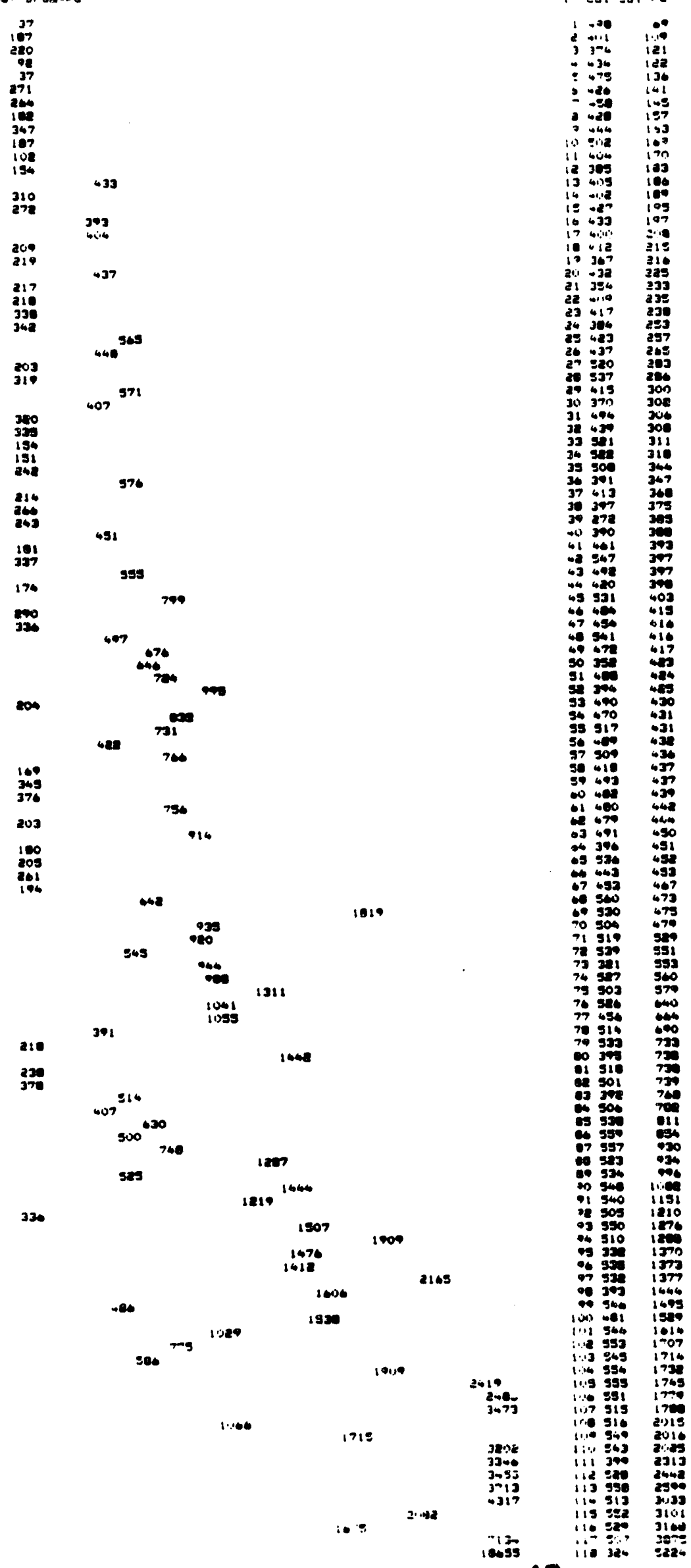

13 
Table 2. Preferred Statistical Analysis - Method

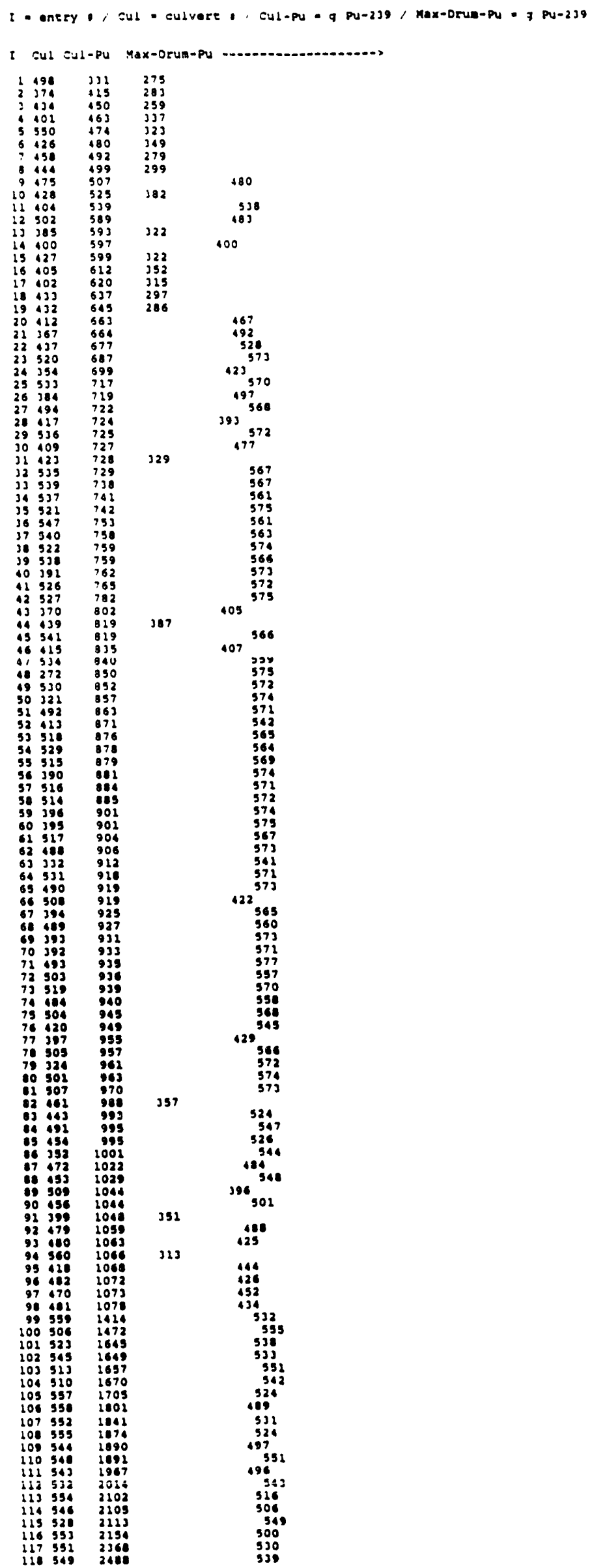




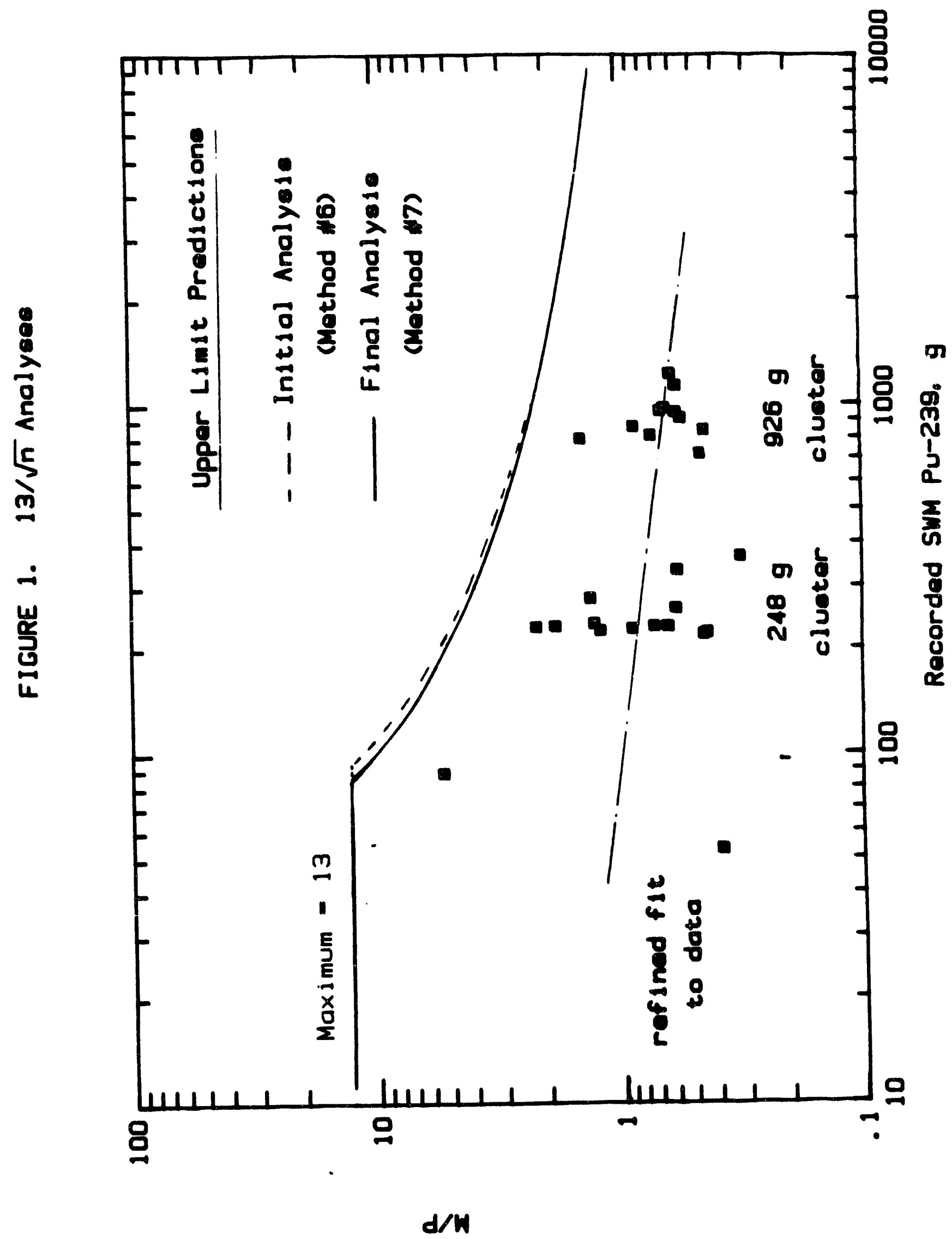


FIGURE 2. NCC vs SWM Measurements of Cuts

(From E.P. Shine, ref 2)

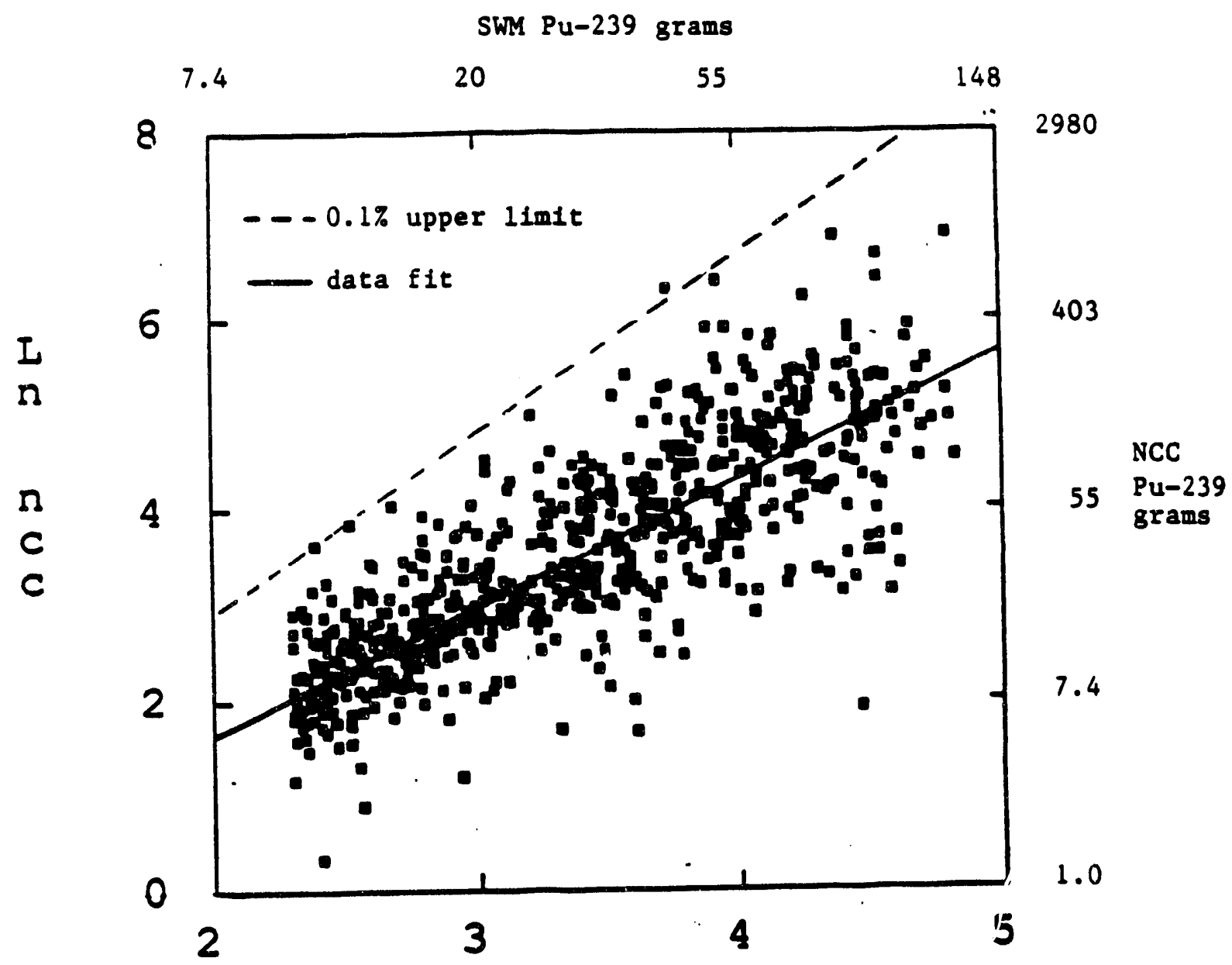

In (swmi)

Fit:

$$
\begin{aligned}
\ln (N C C)=-0.9019 & +1.309 \ln (\text { SWM }) \\
& \pm(\ln (\text { SWM } / 5)(0.9287)
\end{aligned}
$$




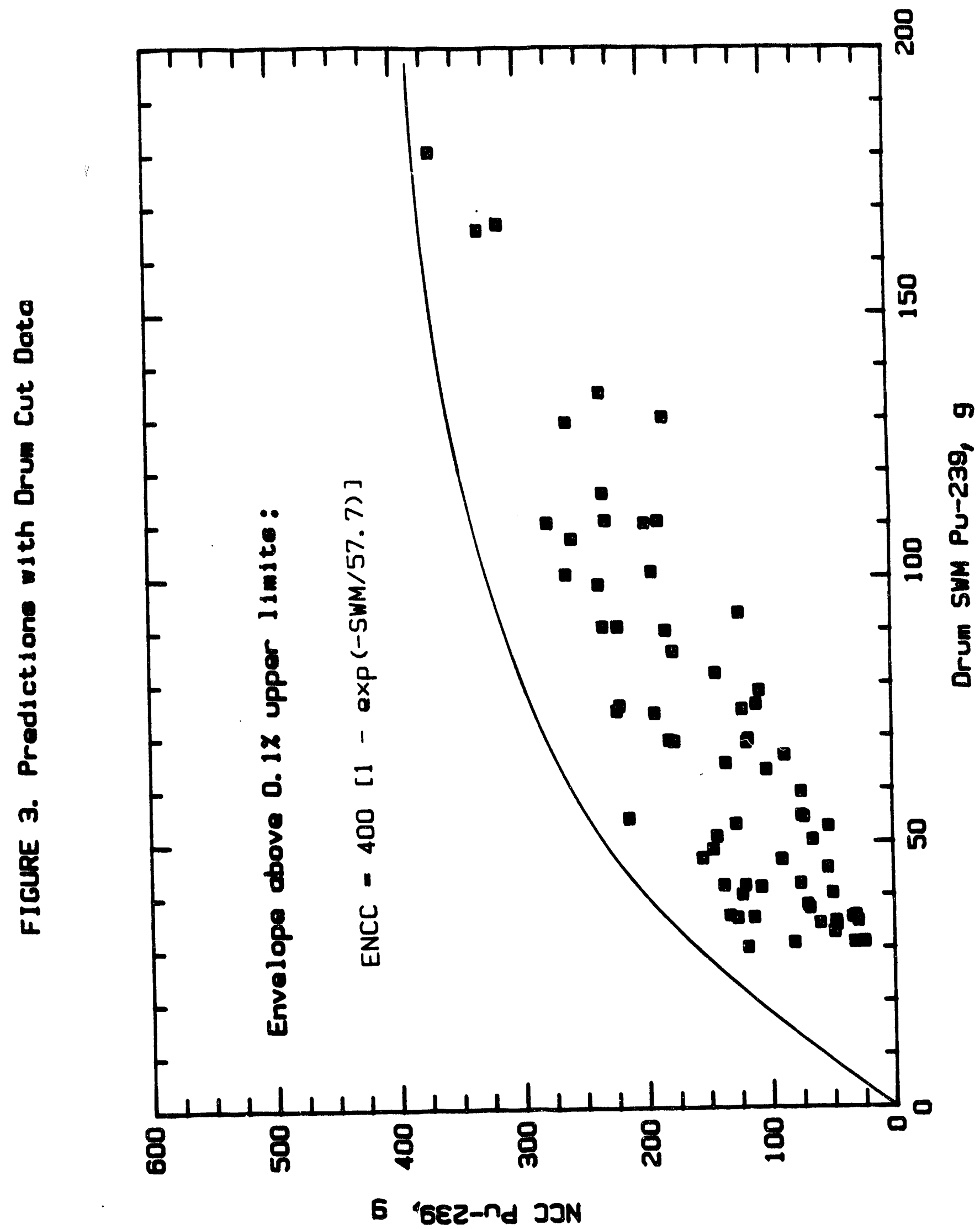




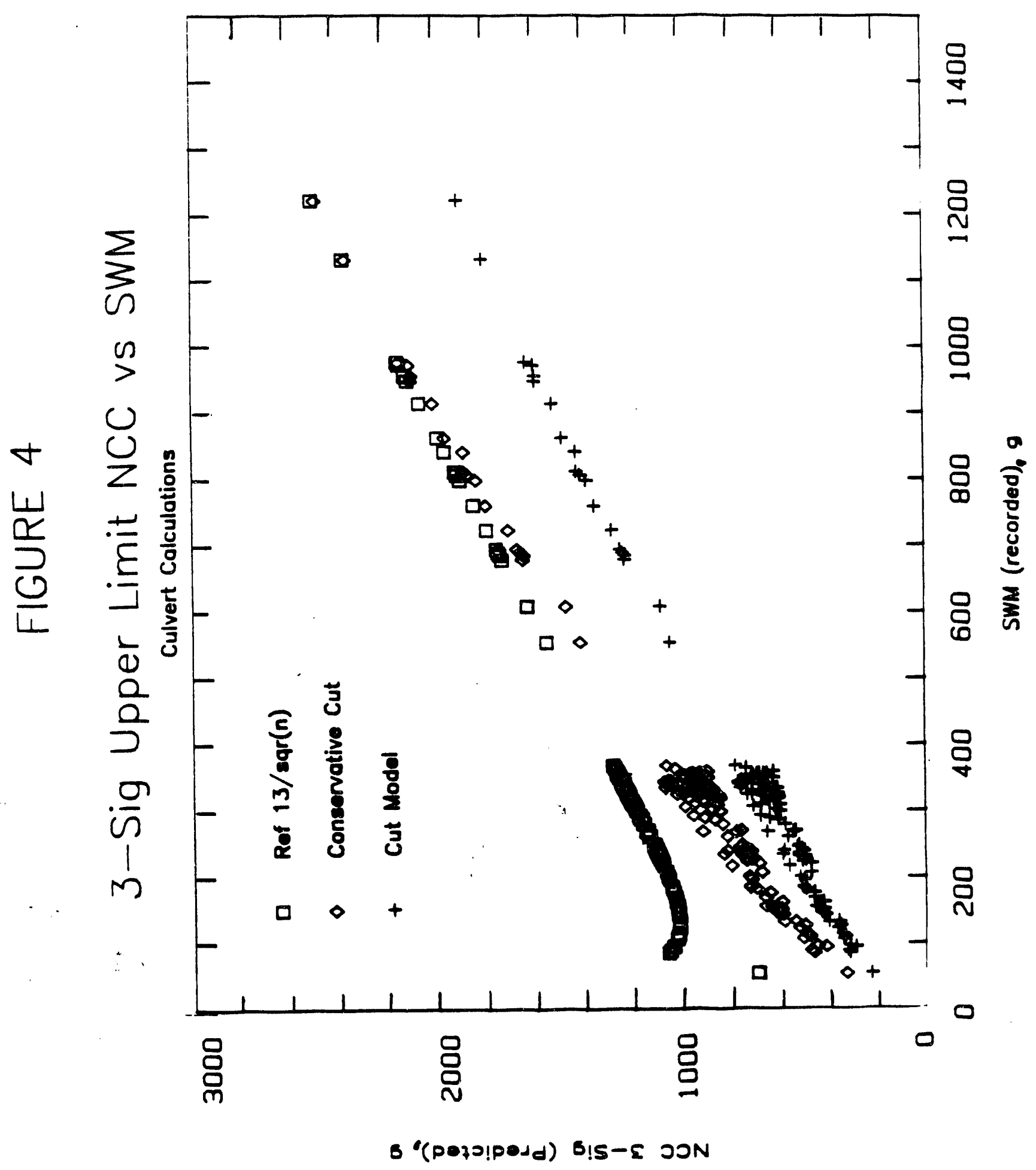




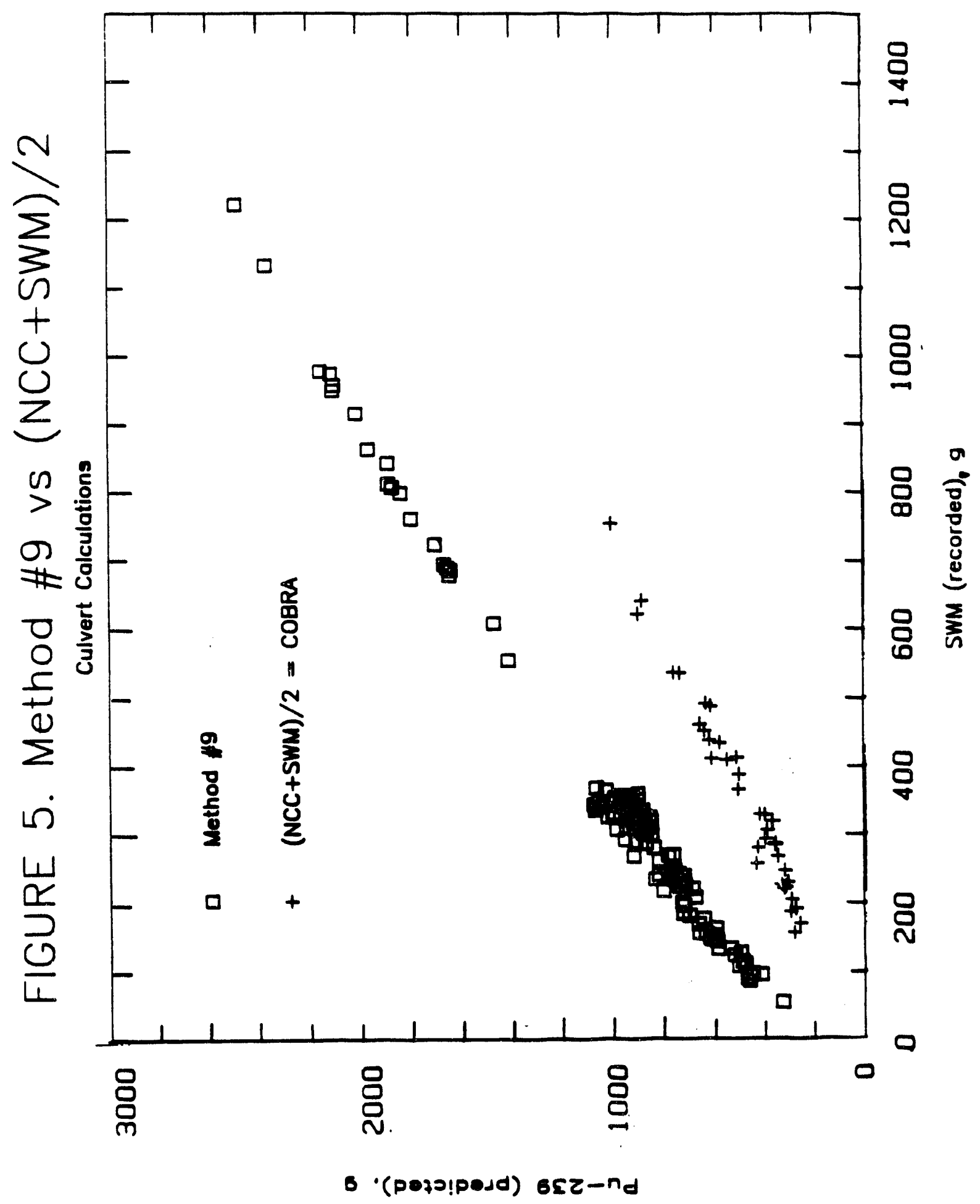




\section{APPENDIX A}

Development of New Analysis Methods

This appendix develops the basis of three of the new analysis methods introduced in this report. These are (1) the Refined $13 / \sqrt{n}$ Method, (2) the Cut Model Analysis, and ( 3 ) the Conservative Cut Model Analysis, which is a combination of the first two. Each method is developed in detail below.

\section{Refined $13 / \sqrt{n}$ Mothod (Method $\# 7$ )}

An earlier report [ref 4] showed that the meas/proj values for culverts having only Pu-239 neutron sources were log-normally distributed with distribution sigma of

$$
\sigma_{0}=\sigma_{0}(1) / \sqrt{n}
$$

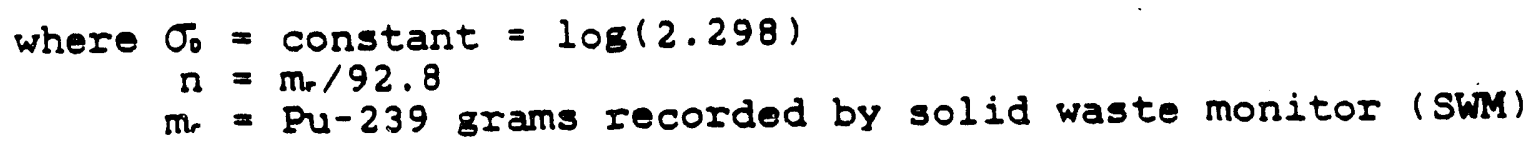

The relationship between $n$ (the effective number of pu-239 components in the recorded total) and $\mathrm{m}_{\mathrm{r}}$ was deduced using data that clustered about $\mathrm{m}=248 \mathrm{~g}$ and $\mathrm{mr}=926 \mathrm{~g}$, per data plotted in Figure 1. (Two additional points have been added since the earlier work). Using data from this figure, the $n$ and $\sigma_{0}$ of each cluster was determined using the formalism of the earlier work [ref 4], viz:

$$
\sigma_{i}^{*}=\sigma_{0}^{2}+\sigma_{r}^{2}+\sigma_{*}^{*}+\sigma_{8}^{2}
$$

where individual sigmas are given by

$\sigma_{T}=$ total sigma of meas/proj distribution

$\sigma_{\text {. }}$ error in chemical form of Pu-239= $\sigma_{f}(1) / \sqrt{n}=108(1.577) / \sqrt{n}$

$\sigma_{n}=$ error in meas/proj analysis model $=\log (1.158)$

$\sigma_{t}=$ error in rocorded $\mathrm{Pu}-238$ and other neutron sources $=0$

In the analysis, $\sigma_{0}$ was calculated with Equation A-1, by substituting the value of $n$ deduced from Equation $A-2$, with its above defined terms:

$$
\begin{gathered}
\sigma_{r}^{*}=\sigma_{0}^{*}(1) / \mathrm{n}+\sigma_{r}^{*}(1) / \mathrm{n}+\sigma_{n}^{*} \\
\mathrm{n}=\frac{\sigma_{0}^{*}(1)+\sigma_{*}^{*}(1)}{\sigma_{r}^{*}-\sigma_{n}^{*}}
\end{gathered}
$$


Upon applying Equation A-3 to Equation A-1, the $\sigma_{0}$ for the two m. $\left(248 \mathrm{~g}\right.$ and $926 \mathrm{~g}$ ) clusters indicated that $n=\mathrm{m}_{\mathrm{r}} / 92.8$. This is

Method \#6 of the main text.

A refinement of this method takes into account that meas/proj decreases slightly with $\mathrm{m}_{\mathrm{r}}$, as seen in Figure 1 . The Eigure shows a $\log (\mathrm{meas} / \mathrm{proj})$ vs $\log (\mathrm{mr})$ linear least-squares fit, in which calculated $1 / \sigma_{r}^{2}$ weight each point. The difference between the Eitted $\log \left(\right.$ meas/proj) $=Y_{\text {, }}$ and its measured value $Y$ : is its residual $\Delta Y_{1}$. For a good fit, chi-square considerations yield

$$
\sum_{i=1}^{N} \frac{\left(\Delta Y_{1}\right)^{2}}{\left(\sigma_{T}\right)^{2}}=N-2 \quad(A-4)
$$

where there are $\mathrm{N}-2$ degrees of freedom after $\mathrm{N}$ points are fitted to a straight line. Calculating the $\left(\sigma_{i}\right)$, from Equations $A-1$ and $A-3$ with $n=m \cdot 92.8$ yields fair agreement for Equation $A-4$. By choosing $n=m_{r} / 82.3$, the agreement is exact; thus, this latter formula for $n$ is used in the Refined $13 / \sqrt{n}$ Method. The fitted results of Figure 1 are also consistent with this $n$.

In summary, the $\sigma_{0}$ for the Refined $13 / \sqrt{n}$ Method is defined by the above $n$ and Equation $A-1$ as

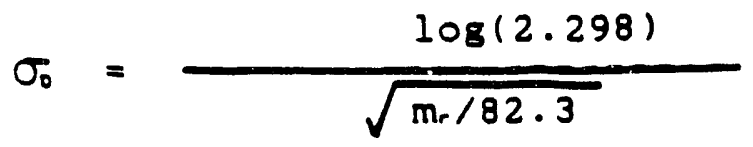

which corresponds to error factor $E=10^{\circ}[$ or $\exp (\sigma)$ for $[n]$ of

$$
E_{0}=(2.298) \sqrt{82.3 / \mathrm{m} r}
$$

The $0.1 \%$ probability for an upper-limit excursion corresponds to a lovel $=\left(\right.$ geo ave meas/proj) $\times \mathrm{E}_{0}{ }^{3}=(1.071) \times \mathrm{E}_{0}{ }^{3}$, as consistent with the earlier treatment [rof 4]. This assures that the excursion is $\times 13$ for the lowest $(n=1)$ inferred integral mass $(82.3 \mathrm{~g})$. For lower mass loadings, the oxcursion is conservatively defined as $\times 13$. These calculated excursions are also conservatively high relative to the observed meas/proj. 


\section{Cut Model Analysis (Method $* 8$ )}

This model uses Pu-239 cut data for individual drums to predict their 0.1\%-probability excursion levels of Pu-239. Then these drum results are combined to predict the $0.1 \%$-probability excursion levels for individual culverts. The major development of this approach is discussed first. Then a section supporting the mathematical considerations follows. A final section appraises the reliability of the method.

\section{Major Development}

Detailed data for Pu-239 cut loadings of 68 drums were provided [ref 5 ], and a sample data sheet is given in Figure A-1. These cut values were measured by the solid waste monitor (SWM), which was later determined to read low relative to the neutron coircidnnce counter (NCC). Because the higher NCC readings are conservatively applied to assure that Pu-239 loadings are safely belew criticality levels, the NCC readings are treated as a reliably safe upper-limit indicator of Pu-239. E.P. Shine [Ref 2] has examined NCC vs SWM readings shown in Figure 2, and deduced the correlation

$$
\ln (N C C)=-0.9019+1.309 \ln (S W M) \pm(\ln (S W M) / 5)(0.9287)(A-5)
$$

Thus, given an SWM measurement, the upper-limit excursion ENCC with. 0.1\%-projability corresponds to a level given by

$$
\begin{aligned}
\ln (\text { ENCC }) & =\ln (\text { NCC })+3 \sigma \\
& =-0.9019+1.309 \ln (\text { SWM })+3(\ln (\text { SWM }) / 5)(0.9287)
\end{aligned}
$$

These NCC predictions for cuts or a drum are combined to yield a drum ENCC. Each measured SWM $=x$ predicts NCC $=y$ and an excursion $3 \sigma=\Delta y$, as deduced by Equations $A-5$ and $A-6$. The In(NCC) with $\pm \sigma$ is assumed to be distributed as a Gaussian; thus, the $\operatorname{ENCC}=I_{Y}=y \exp (3 \sigma)$, and the corresponding $y$ distribution is not Gaussian. If a set of Gaussian variables z, were added, the excursion of their sum would be

$$
\text { Ezave }=\sum z_{1}+\sqrt{\sum 3\left(\sigma_{21}\right)^{2}}
$$

Although the $y$ are not Gaussian, a formula analogous to this was used for the sum of the cuts in a drum, viz

$$
\text { Ey.ue }=\sum y_{1}+\sqrt{\sum\left[y_{1} \exp \left(3 \sigma_{1}\right)-y_{1}\right]^{*}}
$$

This formula Eor Eyou is shown to be a conservative estimate in the next section, which develops pure mathematical considerations in more detail. 
The excursions Eyou for each drum with cut data were calculated using Equation $A-8$, as defined by $y_{1}$ and $\sigma_{1}$ values determined from Equations $A-5$ or $A-6$. The results are shown in Figure 3, which is a scatter plot of ENCC vs SWM for the 68 drums. It is noted that The ENCC values all lie beneath an envelope curve defined as

$$
\begin{aligned}
& \operatorname{ENCC}(\text { drum })_{\text {.nveloo. }}=400[1-\exp (-\operatorname{SWM} / 57.7)] \\
& \operatorname{ENCC}(\text { drum })_{\text {.nvol...0 }}=400\left[1-\exp \left(-m_{0} / 57.7\right)\right]
\end{aligned}
$$

where in this application $S W M=m_{r}$, which is the recorded Pu-239 mass of the drum.

A scatter plot of $\sum y_{1}$ vs $\sum x_{1}$ (NCC vs SWM) for the drums is given in Figure A-2, and yields the correlation

$$
\sum y_{1}=0.85 \sum x_{1}
$$

This NCC/SWM $=0.85$ is consistent with the fact that the individual cuts for drums examined are generally small, and Equation A-5 predicts NCC/SWM $\leq 1$ for SWM $\leq 18.8$ g. The equation predicts an NCC/SWM of 2.04 for the largest possible cut in this work, which corresponds to a drum loading of $187 \mathrm{~g}$. The available cut distributions and loadins data indicate that it is unlikely that a single drum has a clt with this high a SWM value. For example, if the $187 \mathrm{~g}$ were composed of $\sim 10$ cuts, which is typical, the average cut would have $\sim 20 \mathrm{~g}$ Pu-239, which is in the range of the correlation used in this work. Ideally, the cut data for each drum/culvert in question should be analyzed using Equations $A-5, A-6$, and $A-8$; however, these data do not appear to be available. Thus, the drum estimates provided by Equations $A-9$ and $A-10$ are used in the Cut Model Analysis For the culverts.

The culvert NCC excursions are calculated by summing the drum predictions for each culvert. The individual drum data, EY $=\operatorname{ENCC}(d r u m)_{\text {onvelono }}$ and $Y=\sum Y_{1}$ are calculated using Equations $A-9$ and $A-10$, to yield the corresponding $3 \sigma$-deviations of EY-Y. Then the culvert NCC excursions ars calculated as

$$
\begin{aligned}
& \operatorname{ENCC}(\text { culvert })=\sum Y_{1}+\sqrt{\sum\left(E Y_{1}-Y_{1}\right)} \quad(A-11) \\
& \text { ENCC (culvert) }=0.85 \mathrm{SWM}+\sqrt{\sum_{0}(400[1-\exp (-\operatorname{SWM} / 57.7)]-0.85 \mathrm{SWM})^{\circ}} \\
& \operatorname{ENCC}(\text { culvert })=0.85 \mathrm{mr}+\sqrt{\sum_{0}\left\{400\left[1-\exp \left(-\mathrm{m}_{0} / 57.7\right)\right]-0.85 \mathrm{mro}\right\}^{2}}
\end{aligned}
$$

where SWM $=\mathrm{m}$ is the total recorded Pu-239 for the culvert and $\mathrm{m} . \mathrm{is}$ the pu-239 per individual drum. The coefficient 0.85 is again used, and it is tempting to increase it to at least 1.0 . However, increasing it has little effect on micc(culvert), because increases in the first term of Equation A-11 tend to be cancelled by decreases in its second term. Thus, the 0.85 coefficient derived from Figure $A-2$ was used for Method 8. 


\section{Mathematical Considerations}

The above development depends on features of the log-Normal distribution and the Central Limit Theorem. First, the moments of the distribution are examined, so that the variance and mean are available. Then the Central Limit Theorem is applied to these parameters. Finally, the application of these concepts to the present work is discussed.

Moments. A variable $x$, which has a log-Normal distribution, has a Gaussian distribution with variable $z=\log (x)$. Because such a distribution applies for $x$ with its 108 to any base, the convenient choice of $z=\ln (x)$ is used in the development that follows. Specifically, it is desired to find the moments $\left\langle x^{\circ}\right\rangle$ as

where

$$
\left\langle x^{*}\right\rangle=\int_{-\infty}^{\infty} x^{\bullet} f(x) d x
$$

$$
f(x) d x=\frac{1}{\sqrt{2 \pi} \sigma} \exp (-[\ln (x)-\ln (c)]=/ 2 \sigma \cdot) \operatorname{dn}(x)
$$

and $\ln (c)$ denotes the maximum of the $\ln (x)$ distribution and $c$ is its geometric mean. To derive the moments in detail, note that $x^{*}=\exp [\operatorname{mln}(x)]$, and suiostitute explicitly into Equation $(A-12)$,

$$
\left\langle x^{\circ}\right\rangle=\frac{1}{\sqrt{2 \pi} \sigma} \int_{-\infty}^{\infty} \exp \left(-[\ln (x)-\ln (c)] \% / 2 \sigma^{\prime}+\ln \ln (x)\right) d \ln (x)
$$

Upon completing the square in the expl, factor,

$$
\begin{aligned}
&\left\langle x^{0}\right\rangle=\frac{1}{\sqrt{2 \pi} \sigma} \int_{-\infty}^{\infty} \exp \left(-\left[\ln (x)-\left\{\ln (c)+m \sigma^{*}\right\}\right] * / 2 \sigma^{*}\right) \\
& \exp \left(-\left[\ln (c) \cdot-\left\{\ln (c)+m \sigma^{*}\right\}^{*}\right] / 2 \sigma^{*}\right) \operatorname{dln}(x)
\end{aligned}
$$

The above integral includes a Gaussian factor which has variable $\ln (x)$ and seometric mean $\ln (c)+m \sigma^{\prime}$. The other factor is a constant. Thus the integral yields the exp(constant) factor, which is reduced to yield

$$
\begin{aligned}
& \left\langle x^{\bullet}\right\rangle=\exp \left(\left[m^{2} \sigma^{\cdot}+2 m \sigma^{\cdot} \ln (c)\right] / 2 \sigma^{*}\right)=\exp \left(m^{2} \sigma^{*} / 2+m \ln (c)\right) \\
& \left\langle x^{\bullet}\right\rangle=c^{\bullet} \exp \left(m^{2} \sigma^{*} / 2\right) \quad(A-13)
\end{aligned}
$$

Variance. The variance $s^{*}$ is calculated using the first two moments $\langle x\rangle$ and $\left\langle x^{e}\right\rangle$ defined by Equation A-13.

$$
\begin{aligned}
& \langle x\rangle=c \exp \left(\sigma^{2} / 2\right) \\
& \left\langle x^{2}\right\rangle=c^{2} \exp \left(2 \sigma^{2}\right)
\end{aligned}
$$


Using these moments, the variance for a single measurement $x_{1}$ is

$$
\begin{aligned}
s^{2}=\left\langle x^{2}\right\rangle & -\langle x\rangle^{2} \\
& =c^{2}\left[\exp \left(2 \sigma^{2}\right)-\exp \left(\sigma^{2}\right)\right] \quad(A-14)
\end{aligned}
$$

Central Limit Theorem. If $N$ values of $x_{1}$ are summed, the Central Limit Theorem predicts that this sum (or average $=\Sigma x_{1} / N$ ) will have a Gaussian distribution that has a variance composed of the sum of the individual variances (or for the average, the variance $=1 / N \sum_{1}\left[s_{1} / N=s^{2} / N\right.$ ). This can be true even for $x_{1}$ that have different distributions:. The Gaussian prediction becomes more dependable as $\mathrm{N}$ increases.

Present Application. The Central Limit Theorem indicates that the sum of cuts in a drum should be approximately normally distributed. However, the drum excursions defined by Equation A-8 differ from those that are predicted by the log-Normal treatment above. The excursions are compared below for these cases, where the average (sum/N) values are used:

Sum Averas:

General

Log-Normal

Present Work

\section{$0.1 \%$ Probability Excursion Value}

$$
\begin{gathered}
\sum x_{1} / N+3 s / \sqrt{N} \\
c \exp \left(\sigma^{*} / 2\right)+3 c \sqrt{\left[\exp \left(2 \sigma^{\prime}\right)-\exp \left(\sigma^{\prime}\right)\right]} / \sqrt{N} \\
c+\left[c \exp \left(3 \sigma^{\prime}-c\right] / \sqrt{N}\right.
\end{gathered}
$$

By calculating the ratio of the Present Work and Log-Normal cases, it is recognized that the Present Work is conservatively

\begin{tabular}{|c|c|c|c|c|c|}
\hline Cuts & $\begin{array}{c}\text { Data } \\
0\end{array}$ & $\begin{array}{l}\text { Sum Average } \\
\text { Present Wor }\end{array}$ & $\begin{array}{l}\text { Excursion V } \\
\text { sk LOB-Nor }\end{array}$ & $\begin{array}{l}\text { Jalue } \\
\text { cmal }\end{array}$ & $\frac{\text { Present Work }}{\text { Los-Normal }}$ \\
\hline 10 & $\begin{array}{l}0.4 \\
0.8 \\
1.2\end{array}$ & $\begin{array}{r}1.73 \mathrm{C} \\
4.17 \mathrm{C} \\
12.25 \mathrm{C}\end{array}$ & $\begin{array}{l}1.51 \\
2.61 \\
5.55\end{array}$ & $\begin{array}{l}c \\
c \\
c\end{array}$ & $\begin{array}{l}1.15 \\
1.60 \\
2.21\end{array}$ \\
\hline 20 & $\begin{array}{l}0.4 \\
0.8 \\
1.2\end{array}$ & $\begin{array}{l}1.52 \\
3.24 \\
8.96\end{array}$ & $\begin{array}{l}1.39 \\
2.25 \\
4.53\end{array}$ & $\begin{array}{l}c \\
c \\
c\end{array}$ & $\begin{array}{l}1.10 \\
1.44 \\
1.98\end{array}$ \\
\hline 30 & $\begin{array}{l}0.4 \\
0.8 \\
1.2\end{array}$ & $\begin{array}{l}1.42 \\
2.82 \\
7.50\end{array}$ & $\begin{array}{l}1.33 \\
2.09 \\
4.07\end{array}$ & $\begin{array}{l}c \\
c \\
c\end{array}$ & $\begin{array}{l}1.07 \\
1.35 \\
1.84\end{array}$ \\
\hline
\end{tabular}
high relative to the Log-Normal one. This is illustrated low for cases ranging up to $\sigma=1.2$, which corresponds to ind idual cut excursions of NCC/SWM that exceed the maximum of 13 observed earlier [ref 4].

* K.V. Bury, Statistical Models in Applied Science, John Wiley and Sons, 1974, P. 69. 
Thus, in the analysis for the present work, each excursion calculated for the sum of cuts by Equation A-8 and A-11 is an overestimate, even though the excursion for each individual cut is well represented by Equation $A-6$.

\section{Comparison with Culverts with known NCC vs SWM Values}

Subsequent to the analysis for Method \$8, NCC and SWM data from 36 culverts loaded after 1985 were made available, as discussed in Appendix $B$. These data are plotted in Figure A-3, along with the predictions of the above analysis. The NCC vs SWM data fit the straight line NCC $=1.583 \mathrm{SWM}$ and the scatter about this line is much smaller than Equation A-5 would project for individual cuts with these SWM values; this is expected since each culvert contains many individual cuts and their individual NCC/SWM relative fluctuations statistically average lower when the cuts are summed to yield the culvert inventory. Figure $A-3$ shows that the upper limits of this scatter barely reach the ENCC (culvert) $3 \sigma$ upper limit excursions of NCC projected by Method 8 above. Thus, the projections by Method 8 are

consistent with measurements on culverts having known NCC and SWM values.

It should be recalled that acceptable current inventories are defined as (NCC+SWM)/2 in post-1985 COBRA listings [ref 5 ]. Thus, instead of projecting NCC vs SWM values, the COBRA vs SWM values should be examined, viz:

$$
\text { COBRA }=(N C C+S W M) / 2=(1.583 \mathrm{SWM}+\mathrm{SWM}) / 2=1.29 \mathrm{SWM}
$$

A plot of COBRA vs SWM in Figure A-3 shows that Method \#8 is conservatively high relative to COBRA. Also, the point scatter (not plotted) Eor COBRA is only $1 / 2$ that for NCC alone.

One concern about the comparison of Method 8 with the culvert data for NCC vs SWM is that Mothod 8 uses fluctuations about NCC $=0.85$ SWM and the culvert data fluctuate about NCC = 1.583 SWM. The discrepancy is probably due to the average size of the cuts involved in the analysis data. For example, Equation A-5 for individual cuts predicts SWM $=11 \mathrm{~g}$ Pu-239 for NCC/SWM $=0.85$ and SWM $=82 \mathrm{Pu}-239$ for NCC/SWM $=1.58$. Actually, each case should be evaluated as the sum of cuts to yield an $\langle x\rangle$ value, as developed in Equation A-13. Substituting NCC and its $\sigma$ firom Equations $A-5$ as the $c$ and $\sigma$ in Equation $A-13$ yields SWM $=10 \mathrm{~g}$ for $\langle N C C\rangle / S W M=0.85$ and SWM $=39$ B fOr $\langle N C C\rangle / S W M=1.58$. As explained in the precedine section, Method 8 is already mathematically conservative relative to this summing scenario. Fortunately. it is sufficiently conservative to accomodate sums of both the smaller and larger cuts, as evidenced by Figure A-3. Thus, the above discrepancy in NCC/SWM averases has no impact on the overall usefulness of these predictions. 


\section{Method Reliability}

Overall, the method appears to be reasonable. However, dispite its many conservatisms, the method does not address the possibility that a large cut of Pu-239 is included in a drum. As discussed earlier, the available cut data for developing the drum excursions shown in Figure 3 are relatively low (SWM <30 g). The cuts for the 36 check culverts plotted in Figure A-3 are somewhat larger (average consistent with $S W M=39 \mathrm{~g}$ ), but quite higher cuts are possible (SWM $=187 \mathrm{~g}$ for drum maximum), although very unlikely relative to cut distribution data [ref 6]. Clearly, additional cut data for drums would be useful, particularly for the culvert/drums of the present study. Should these become available, the Cut Model Analysis can be refined.

Dispite the above concern about actual cut sizes, it is worthwhile to appreciate various conservatisms imbedded in this analysis. The analysis does not take credit for the fact that present assays use the average of the SWM and NCC values, which tends to be lower than the NCC value alone. Thus, the present predictions will tend to be high since only the NCC values are used. The fact that the excursions for summed cuts are overestimated has already been elaborated upon in the preceding section, which shows that the present analysis is conseryative relative to more realistic predictions for log-Normal combinations using the Central Limit Theorem. Finally, the envelope curve for drum excursions is higher than any excursion actualiy observed. 


\section{Conservative Cut Model (Method 9 )}

A combination analysis intermediate to the Refined $13 / \sqrt{n}$ Method and the Cut Model Analysis is developed. The Refined $13 / \sqrt{n}$ Model is thought to be conservatively high, because neutrons from drums in the lower half of the culvert are shielded by the upper drums. Thus, the averaging effect for all pu-239 in the culvert may not be witnessed in the measured neutron rates. The Cut Model Analysis is conservative in general, but an individual large cut in a drum is not addressed with this method. Thus, it is wise to allow that this method can give an underestimate for Pu-239. clearly, a well-chosen analysis yielding predictions intermediate to the above two cases should be more realistic.

For the intermediate analysis, called the Conservative Cut Model, the drum envelope for cuts is increased by $\times 1.5$, and the cut model analysis of section II is repeated, yielding the plot in Figure 4. This analysis agrees with the Refined $13 / \sqrt{n}$ Method for the most heavily loaded culverts, where the chance of large cuts is more likely. It agrees better with the Cut Model Analysis for the culverts with lighter loadings, where the probability for large cuts is smaller. As shown in Figure 4, the predictions gradually increase toward the Refined $13 / \sqrt{1}$ Method values, as the SWM loadings increase over the culvert range.

The results for the Conservative Cut Model are also plotted in Figure 5, where the predictions are well above the scatter of $(\mathrm{NCC}+\mathrm{SWM}) / 2$ values for the 36 check culverts. Thus, the method should be quite conservative relative to presently accepted (NCC+SWM) $/ 2$ values in general. Also, the $\mathrm{m} / \mathrm{p}$ results of the present work indicate that the SWM is more accurate than the (NCC+SWM) $/ 2$ value on the average, and the Conservative Cut Model is even more conservative relative to SWM predictions. The $0.1 \%$ upper limit excursions of the Cut Model (Mothod 8 ) are fairly consistent with the check culvert NCC excursions; therefore, the Conservative Cut Model excursion limits should be associated with a probability significantly lower than $0.1 \%$. 
FIGURE A-1. Example Drum Inventory Worksheet

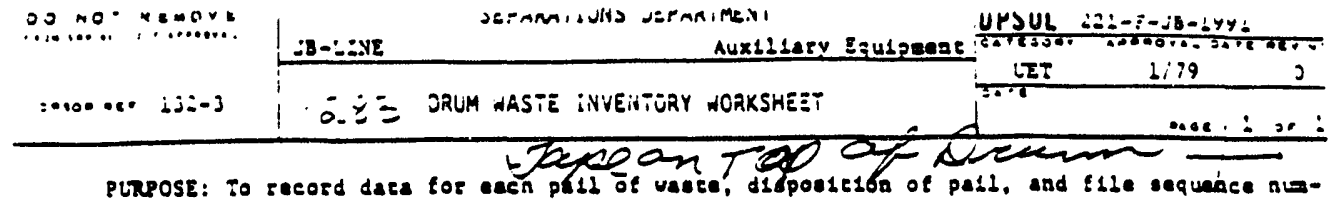

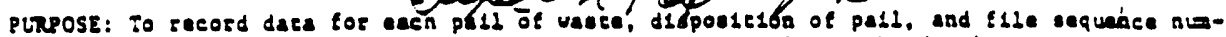

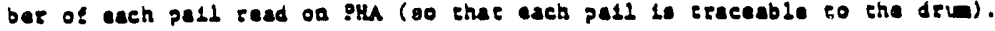

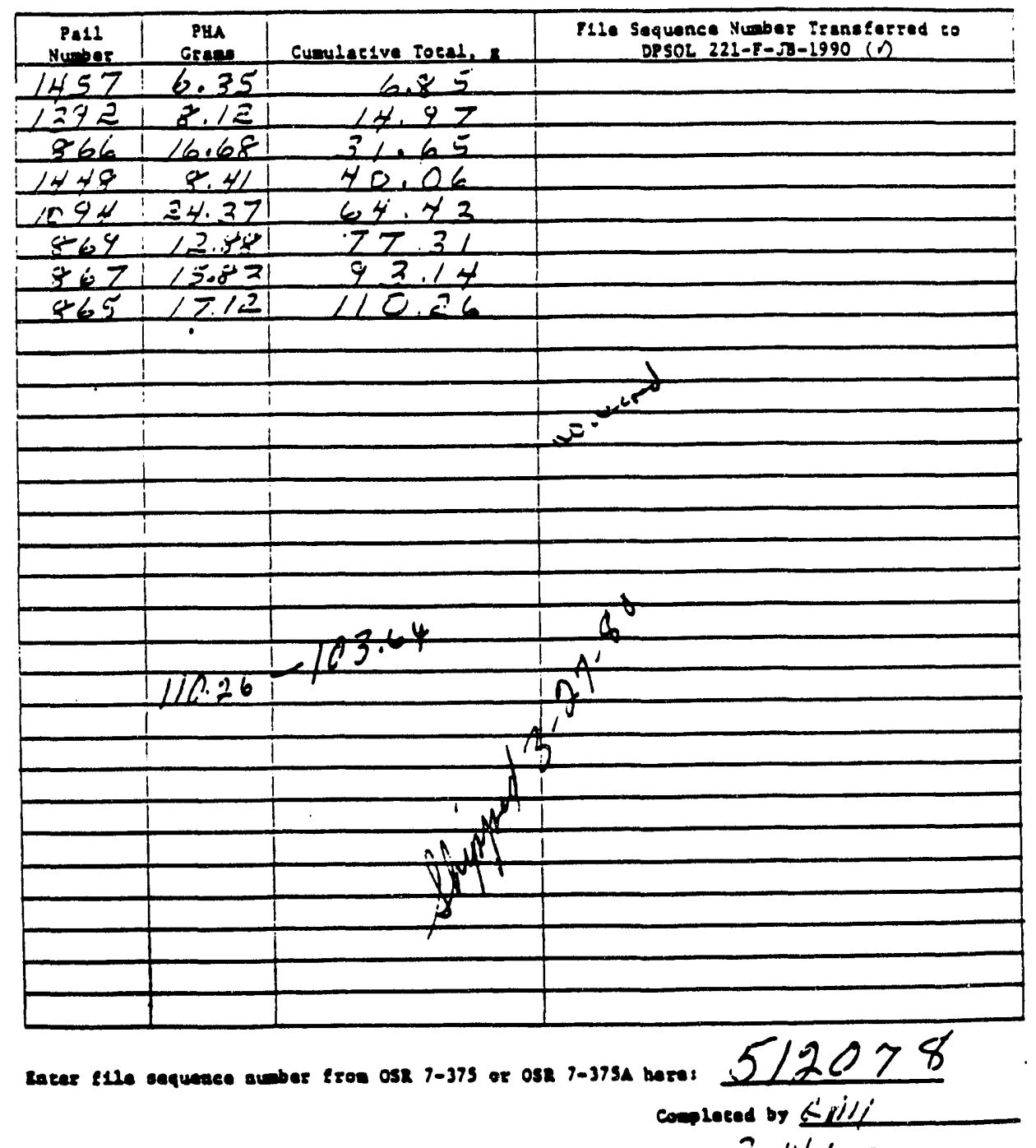

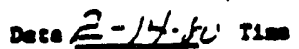




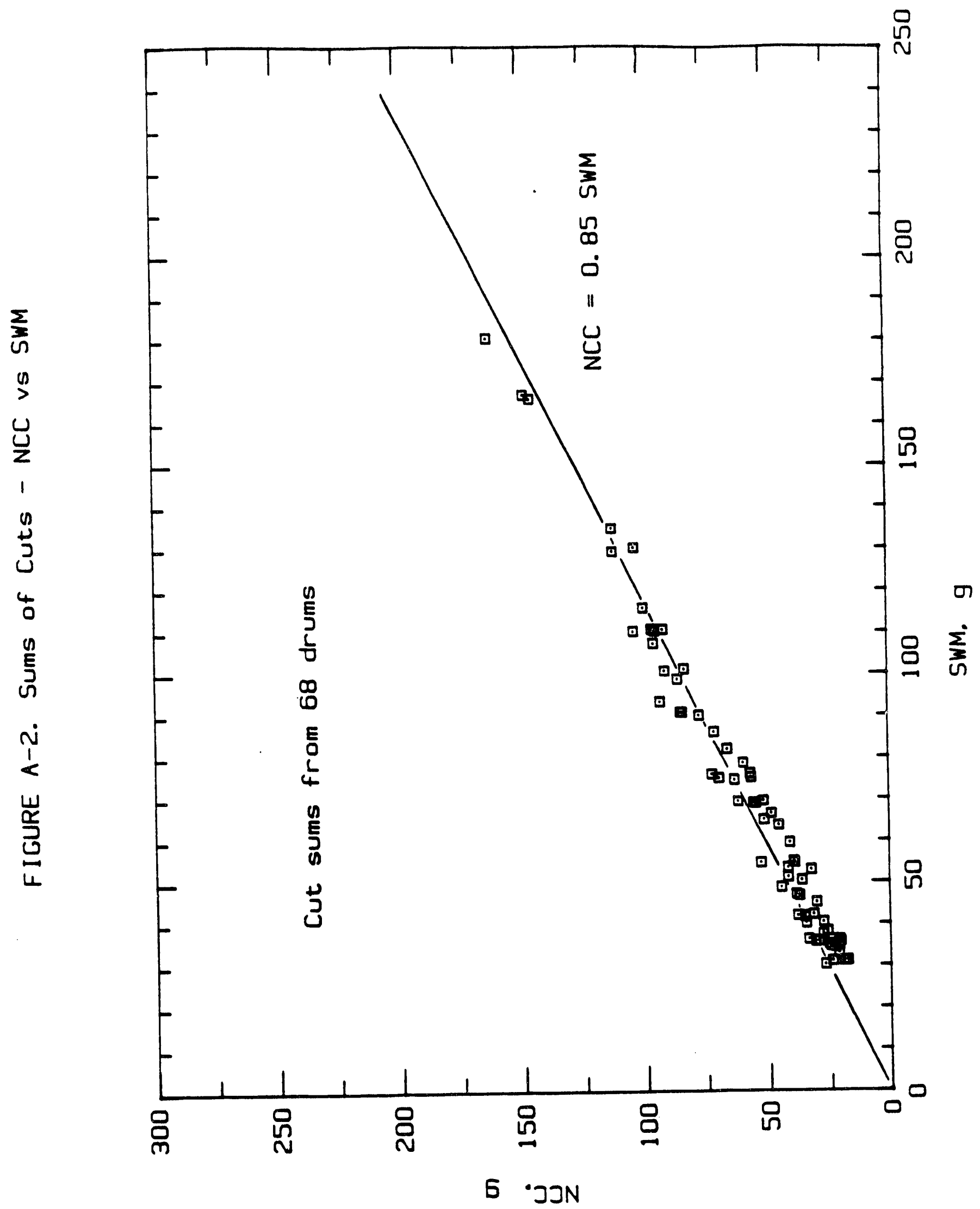

$A-i 1$ 


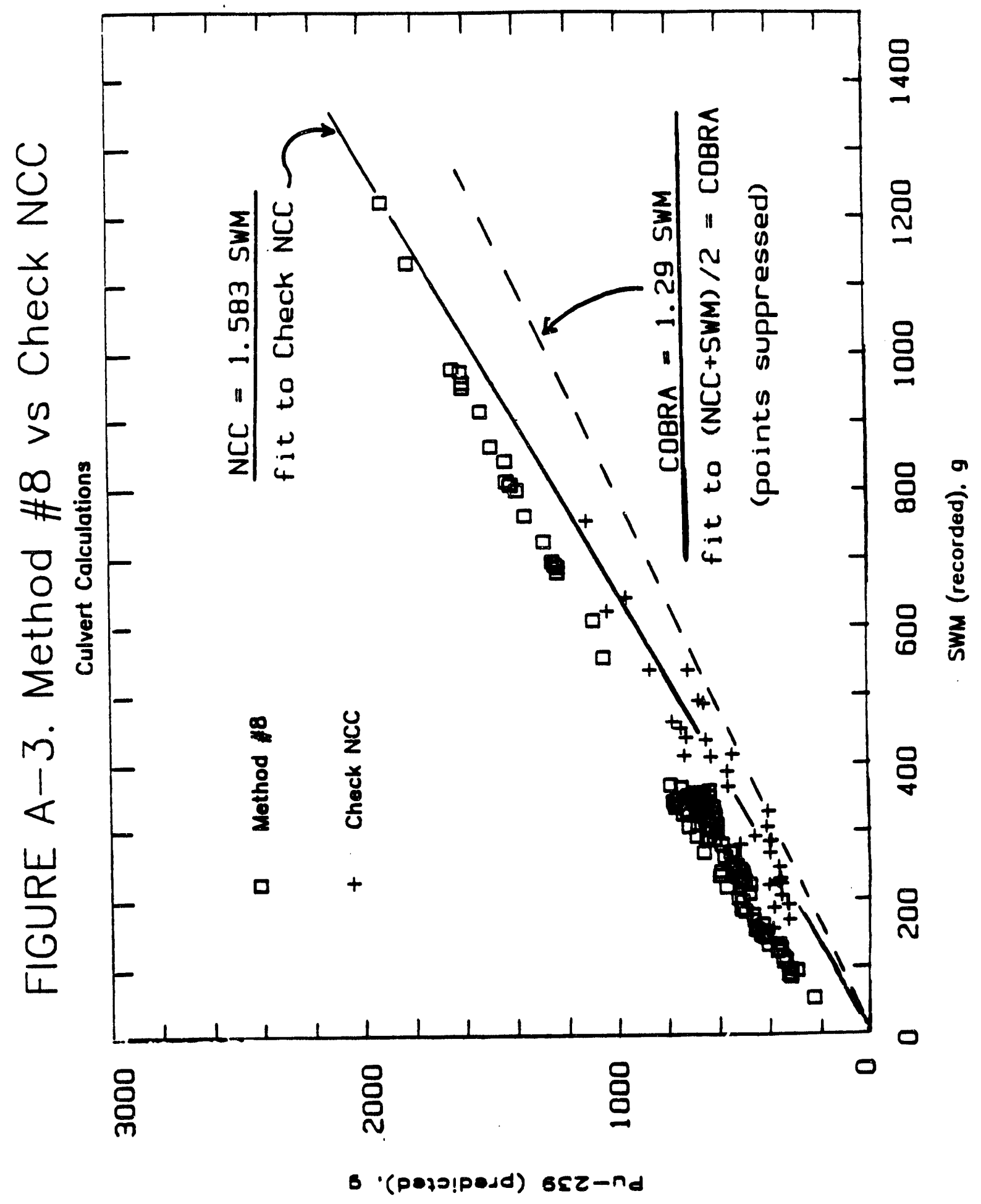




\section{Appendix B. Comparisons using Better Known Culverts}

After 1985, culvert loadings have used values of (NCC+SWM)/2 for $\mathrm{Pu}$ inventory in the COBRA files (Ref 5), as these are thought to be better known than the earlier COBRA values, which were based only on SWM measurements. Measurements on 36 culverts inventoried with these later estimates served as a check on the in-the-field measurements program. The results of these check measurements are summarized in Tables $B-1$ and $B-2$, and their implications are discussed below. The tables include the raw NCC and COBRA values provided [ref 5]. All check culvert data were transformed to isotopic pu-239 values for plots in this report, by using the COBRA (isotopo) and COBRA(quantity) values of these tables.

Table B-1 includes culverts for which only Pu-239 neutron sources are present. There were 18 of these, and the table illustrates that a representative geometric average of their measured/projected neutron rates $\mathrm{m} / \mathrm{p}$ is $0.74 \pm 0.09$. This average should be 1.00 if the projected rates were accurate: thus, the neutron rates projected by $(N C C+S W M) / 2$ estimates are too lange. In order to examine the results for raisi projected for SWM estimates, the plot in Figure B-1 was used. Here, NCC is plotted against COBRA $=(N C C+S W M) / 2$ for the check culverts, yielding a least squares fit of $\mathrm{NCC}=1.2225 \mathrm{COBRA}$. From this, one can solve for SWM as:

$$
\text { SWM }=2 \text { COBRA }-N C C=2 \text { COBRA }-1.2225 \text { COBRA }=0.7775 \text { COBRA }
$$

Thus, if the SWM were used instead of the COBRA value, the above average $\mathrm{m} / \mathrm{p}$ would be divided by 0.7775 to yield $0.95 \pm 0.11$, which is in good agreement with 1.00. Thus, on average, the SWM values are more accurate, and the later COBRA values of $(\mathrm{NCC}+$ SWM $) / 2$ serve as a conservative overestimate.

Table B-2 summarizes 18 check culverts that include neutron sources from both Pu-238 and Pu-239. The $\mathrm{m} / \mathrm{p}$ ratios for these culverts are calculated using the COBRA $=(\mathrm{NCC}+S W M) / 2$ values and the ratio of the tabulated Pu-238/Pu-239 is also recorded.

Figure B-2 plots the $\mathrm{m} / \mathrm{p}$ vs $\mathrm{Pu}-238 / \mathrm{Pu}-239$ and illustrates that as Pu-238/Pu-239 increases, the $\mathrm{m} / \mathrm{p}$ is increasingly larger than 1.00. Although the correlation has some scatter, the trend is apparent and implies that the pu-238 wasto may contain Puo. that has oxygen non-depleted in 0-17, which is a prominent target for $(\alpha, n)$-production of neutrons. (The Pu-238 oxide standards used in calibrations at the Fab Lab were purportedly depleted in 0-17). In any event, the trend gives a basis for correcting some of the high $\mathrm{m} / \mathrm{p}$ values to lower values, yielding better compliance with critical loading limits. The plotted curve of Figure $B-2$ is given by:

$$
m / p=R(C O B R A)=0.7775+0.032[100 \text { Pu238/Pu239(COBRA) }]
$$

where $\mathrm{m} / \mathrm{p}$ is determined using the Pu239 from COBRA. To transform 
to SWM units, the substitutions of $R(S W M)=R(C O B R A) / 0.7775$ and Pu239(COBRA) = Pu239(SWM) $/ 0.7775$ are made to yield:

$$
R(S W M)=1.00+0.02488[100 \text { Pu238/Pu239(SWM) }]
$$

The $R$ (SWM) for the 118 suspect culverts used this $R$ (SWM) factor to correct for $\mathrm{Pu}-238$. Specifically, the $R$ was calculated for the recorded Pu-238 and Pu-239 for each culvert and then divided into the corresponding estimate for Method \#5, yielding the results in Table 18.

In the present study, $R$ (SWM) corrected the Pu-239 estimates of Method 5 as follows:

$$
\text { Pu-239 } \begin{aligned}
\text { (Corrected) } & =\text { Pu-239 (Method } \# 5) / R(S W M), \text { in general } \\
& =\text { Pu-239 (Method } \# 5) / 20, R(S W M)>20 \\
& =1.29 \text { Pu-239 (SWM) if > above cases }
\end{aligned}
$$

Thus, the general formula applies between limits. If $R(S W M)>20$, then $R(S W M)=20$ is used to be conservative relative to extrapolated values in Figure B-2. If the correction yields a value less than COBRA $=($ NCC + SWM $) / 2=1.29$ SWM, then it is set equal to 1.29 SWM to yield predicted agreement with currently accepted values. 
TABLE B-1. Check Culverts with no Pu-238

\begin{tabular}{|c|c|c|c|c|c|}
\hline Pad & Culvert & $\begin{array}{l}\text { Quant } \\
\text { NCC }\end{array}$ & EY & $\begin{array}{l}\text { Isotope, } 8 \\
\text { COBRA }\end{array}$ & $\begin{array}{c}m / p \\
\text { COBRA }\end{array}$ \\
\hline 13 & $\begin{array}{l}565 \\
567 \\
568\end{array}$ & $\begin{array}{r}1202.7 \\
610.2 \\
668.3\end{array}$ & $\begin{array}{r}1008.5 \\
504.92 \\
552.36\end{array}$ & $\begin{array}{l}933.96 \\
461.60 \\
517.84\end{array}$ & $\begin{array}{l}0.763 \\
0.529 \\
1.280\end{array}$ \\
\hline 10 & $\begin{array}{l}570+ \\
571+ \\
582 \\
583 \\
584 \\
585 \\
586 \\
587 \\
588 \\
589 \\
590 \\
591 \\
592 \\
593 \\
594\end{array}$ & $\begin{array}{l}396.4 \\
367.7 \\
373.5 \\
408.45 \\
412.5 \\
342.4 \\
378.7 \\
405.9 \\
420.79 \\
380.0 \\
417.3 \\
420.0 \\
412.0 \\
350.7 \\
393.3\end{array}$ & $\begin{array}{l}396.43 \\
367.67 \\
295.38 \\
287.21 \\
334.58 \\
261.19 \\
311.51 \\
302.14 \\
327.57 \\
321.30 \\
351.05 \\
361.17 \\
358.26 \\
278.78 \\
320.86\end{array}$ & $\begin{array}{l}372.64 \\
318.65 \\
277.66 \\
269.98 \\
294.41 \\
245.51 \\
292.82 \\
284.01 \\
307.91 \\
302.02 \\
329.98 \\
339.49 \\
336.77 \\
257.03 \\
287.77\end{array}$ & $\begin{array}{l}0.462 \\
0.417 \\
0.503 \\
1.261 \\
1.424 \\
0.142 \\
0.698 \\
0.615 \\
0.747 \\
2.272 \\
0.657 \\
0.415 \\
0.783 \\
0.497 \\
1.027\end{array}$ \\
\hline
\end{tabular}

Analysis of $\mathrm{m} / \mathrm{p}$ Ratios

\section{Analysis}

All values

All less +

All less*

A11 less +,*

Representative
Geometric Averase of Ratios (NCC+SWM) / 2
$0.68 \pm 0.10$
$0.88 \pm 0.13$

$0.72 \pm 0.11$

$0.93 \pm 0.15$

$0.75 \pm 0.09$

$0.96 \pm 0.11$

$0.80 \pm 0.10$

$1.03 \pm 0.13$

$0.74 \pm 0.09$

$0.95 \pm 0.11$

Note: $S W M=0.7775(N C C+S W M) / 2=0.7775$ COBRA $($ post-1985)

+ Culvert loaded before 1986, SWM values likely.

* Low value not included in some averages above. 
TABLE B-2. Check Culverts with Pu-238

(All culverts on Pad 10)

\begin{tabular}{|c|c|c|c|c|c|c|}
\hline slvert & $\begin{array}{l}\text { Que } \\
\text { NCC }\end{array}$ & $\begin{array}{l}\text {-ity, } 8 \\
\text { COBRA }\end{array}$ & $\begin{array}{c}\text { Isotope, } \\
\text { COBRA }\end{array}$ & $\begin{array}{l}\text { I sotope, } 8 \\
\text { COBRA }\end{array}$ & $\begin{array}{l}\text { Pu-238* } \\
\text { Pu-239 }\end{array}$ & $\begin{array}{c}m / p \\
\text { COBRA }\end{array}$ \\
\hline $\begin{array}{l}459 \\
562 \\
569 \\
572 \\
573 \\
575 \\
576 \\
577 \\
578 \\
579 \\
580 \\
581 \\
596 \\
597 \\
600 \\
601 \\
602 \\
604\end{array}$ & $\begin{array}{r}735.6 \\
786.7 \\
549.9 \\
796.3 \\
841.8 \\
581.7 \\
443.6 \\
706.3 \\
480.1 \\
695.2 \\
774.6 \\
827.7 \\
589.4 \\
941.4 \\
1064.3 \\
457.7 \\
598.6 \\
1127.1\end{array}$ & $\begin{array}{l}635.646 \\
613.906 \\
425.628 \\
639.701 \\
736.87 \\
512.01 \\
389.979 \\
616.167 \\
395.856 \\
581.338 \\
621.483 \\
658.68 \\
433.12 \\
761.55 \\
887.33 \\
417.256 \\
505.215 \\
902.12\end{array}$ & $\begin{array}{l}582.869 \\
570.745 \\
395.802 \\
596.746 \\
624.490 \\
476.580 \\
354.677 \\
570.295 \\
371.823 \\
539.142 \\
580.392 \\
619.131 \\
401.810 \\
702.020 \\
801.582 \\
363.257 \\
474.878 \\
828.93\end{array}$ & $\begin{array}{c}4.862 \\
16.662 \\
9.141 \\
2.42 \\
20.30 \\
34.20 \\
22.632 \\
0.838 \\
26.356 \\
0.147 \\
6.976 \\
53.42 \\
83.8 \\
23.3 \\
8.20 \\
45.673 \\
49.376 \\
8.30\end{array}$ & $\begin{array}{r}0.83 \\
2.92 \\
2.31 \\
0.41 \\
3.25 \\
7.18 \\
6.38 \\
0.15 \\
7.09 \\
0.03 \\
1.20 \\
8.63 \\
20.86 \\
3.32 \\
1.02 \\
12.57 \\
10.40 \\
1.00\end{array}$ & $\begin{array}{r}1.449 \\
2.015 \\
0.576 \\
0.963 \\
3.095 \\
0.864 \\
1.683 \\
0.169 \\
0.234 \\
0.431 \\
0.396 \\
7.619 \\
14.925 \\
2.008 \\
1.136 \\
7.013 \\
5.387 \\
0.731\end{array}$ \\
\hline
\end{tabular}

Analysis of $\mathrm{m} / \mathrm{p}$ Ratios

Analysis

All values
Geometric Averase of Ratios $(\mathrm{NCC}+\mathrm{SWM}) / 2$

SWM

$1.38 \pm 0.40 \quad 1.78 \pm 0.51$

Note: $\operatorname{SWM}=0.7775(\mathrm{NCC}+$ SWM $) / 2=0.7775$ COBRA $($ post-1985)

* Values given as Pu-238/Pu-239 x 100\%. 


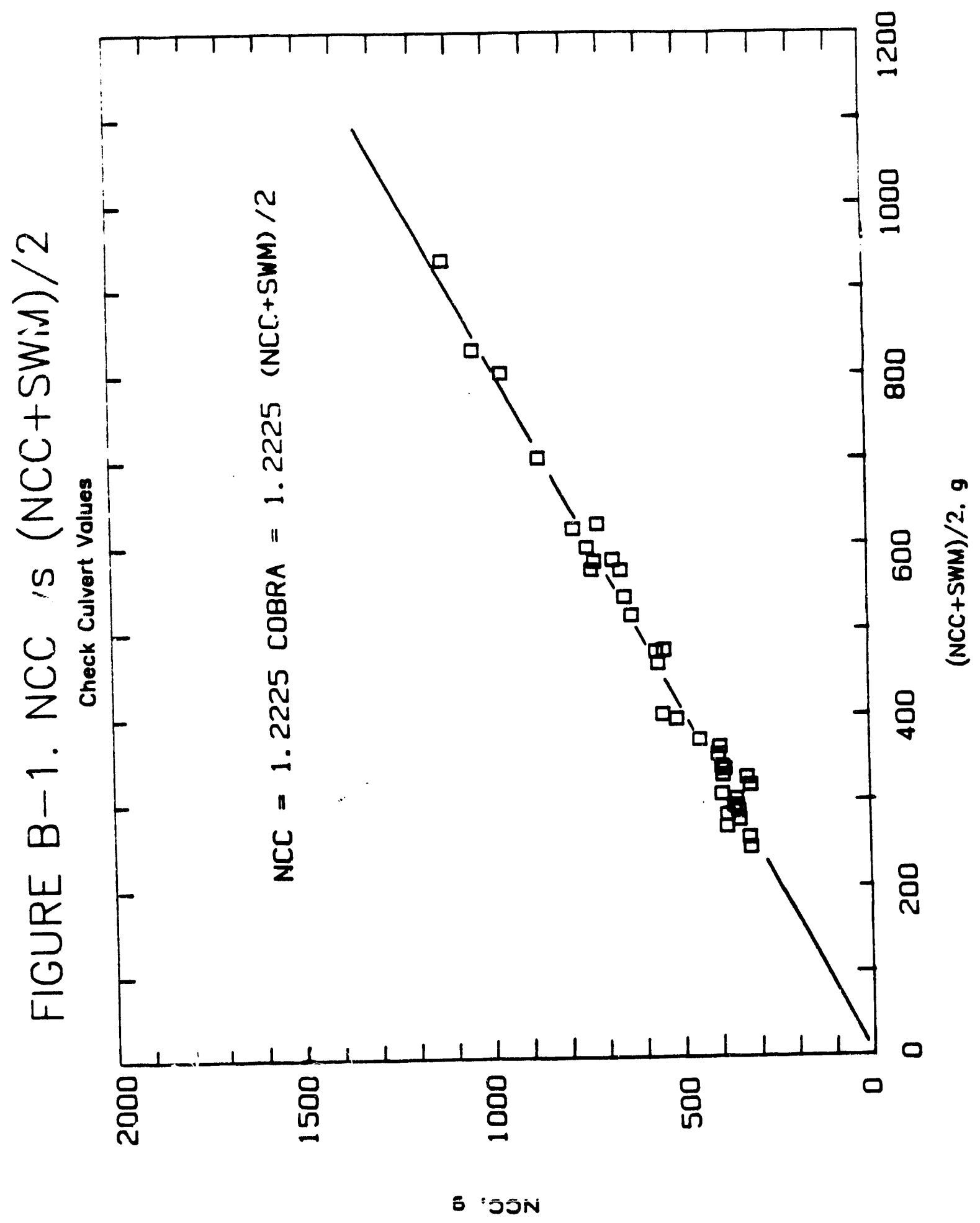

B-5 


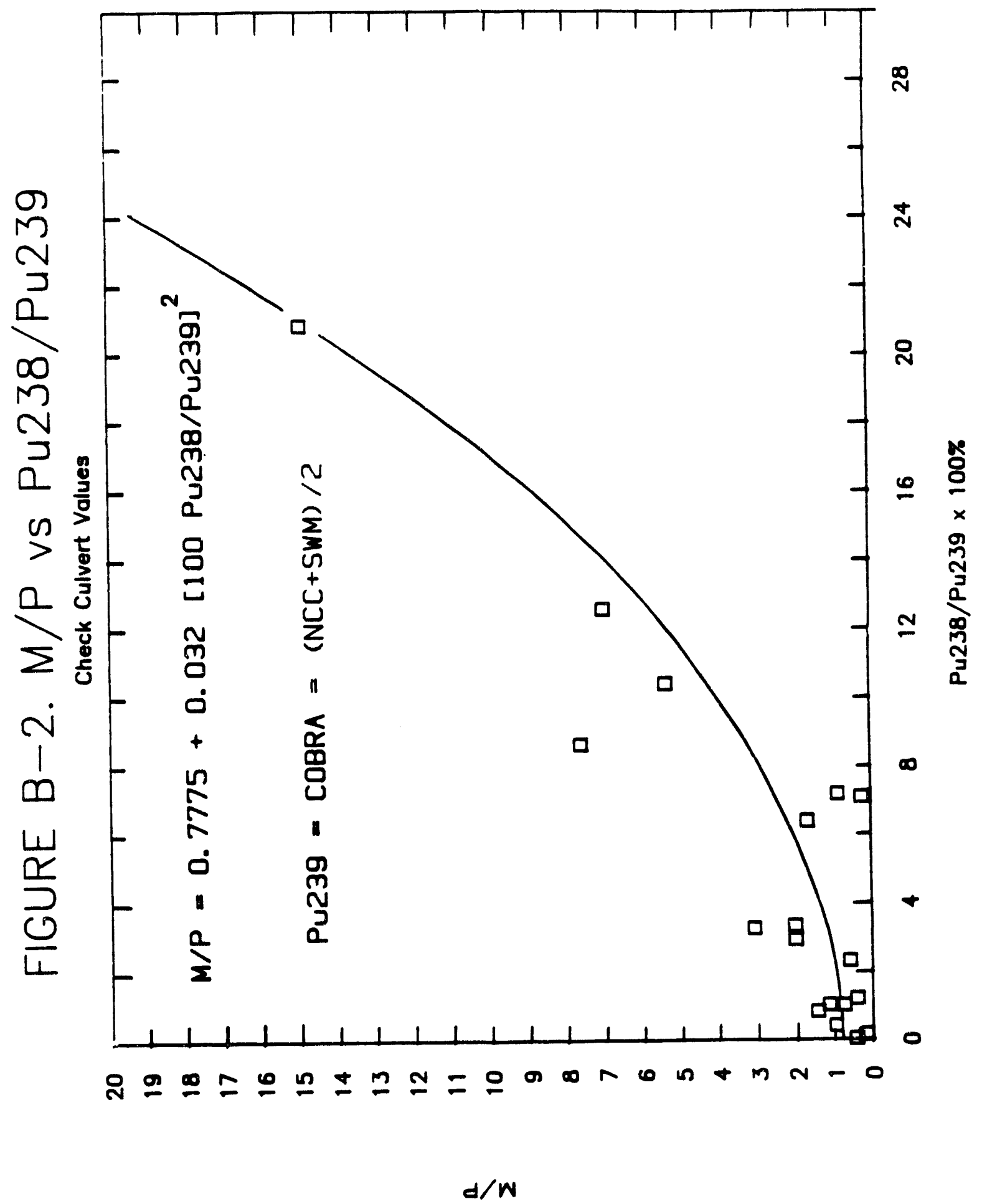




\section{APPENDIX C \\ Pu-239 Estimates for Each Analys is Method}

Table C-1 summarizes the Pu-239 predictions for Method \#1 thru Method 19 , as defined in the main text. The table format is similar to that of Tables 1 and 2 , where the culvert and max drum estimates are monotonically arrayed so that they may be easily appraised against their critcality limits. Table C-2 includes the same data, but here all estimates are ordered according to culvert number.

A summary of the Pu-239 estimation formulae used in the different methods is given below. Some methods yield direct estimates and others are $0.1 \%$ upper limit excursions. This distinction is made below and in the tables, to guide proper interpretation by the user. Variables in the formula below are: $\mathrm{m} / \mathrm{p}=$ measured/projected neutron rates; SWM = solid waste monitor Pu-239, in grams; $3 \mathbf{s i g}$ factors $=E^{2}$, where $E$ is error factor per log-Normal $\sigma=\log (E)$.

$\mathrm{m} / \mathrm{p}$ Mothods

(1) $\mathrm{m} / \mathrm{p} \times$ Inventory Pu-239

Direct estimate

Pu-239 $=\mathrm{m} / \mathrm{p}$ SWM

(2) $\mathrm{m} / \mathrm{p} \times 33 i s \times$ Inventory Pu-239

$0.1 \%$ upper limit excursion

$$
\text { Pu-239 }=m / p(1.46)^{2} \text { SWM }=3.12 \mathrm{~m} / \mathrm{p} \text { SWM }
$$

(3) $\mathrm{m} / \mathrm{p}(\mathrm{Pu}-239) \times$ Inventory Pu-239

Direct mothod

Pu-239 $=(1.40 / 0.989 \mathrm{~m} / \mathrm{P}) \mathrm{SWM}=1.416 \mathrm{~m} / \mathrm{P} \mathrm{SWM}$

(4) $\mathrm{m} / \mathrm{p}(\mathrm{Pu}-239) \times 391 \mathrm{~B}(\mathrm{Pu}-239) \times$ Inventory Pu-239

$0.1 \%$ upper limit excursion

Pu-239 $=(1.40 / 0.989 \mathrm{~m} / \mathrm{p})(1.395) \cdot \mathrm{SWM}=3.84 \mathrm{~m} / \mathrm{p}$ SWM

(5) $\mathrm{m} / \mathrm{p} \times 391 \mathrm{~g}(\mathrm{Pu}-239) \times$ Inventory Pu-239 ... Preforred $\mathrm{m} / \mathrm{p}$

$0.1 \%$ upper limit excursion

Pu-239 $=\mathrm{m} / \mathrm{p}(1.395)^{\circ}$ SWM $=2.71 \mathrm{~m} / \mathrm{p}$ SWM 
Statistical Methods

(6) $13 / \sqrt{n} \times$ Inventory

$0.1 \%$ upper limit excursion

$$
\begin{aligned}
P_{u-239} & =1.071(2.298)^{\sqrt[3]{92.8 / \text { SWM }}} & \text { SWM } & \text { SWM }>92.8 \\
& =13 \text { SWM } & & \text { SWM } \leq 92.8
\end{aligned}
$$

(7) Refined $13 / \sqrt{h} \times$ Inventery

$0.1 \%$ upper limit excursion

$$
\begin{array}{rlrl}
\text { Pu-239 } & =1.071(2.298)^{3 \sqrt{82.3 / \text { SWM }}} & \text { SWM } & \text { SWM }>82.3 \\
& =13 \text { SWM } & \text { SWM } \leq 82.3
\end{array}
$$

(8) Cut Model x Inventory Pu-239

$0.1 \%$ upper 1 imit excursion

Pu-239 $=0.85 \mathrm{SWM}+\sqrt{\sum_{0}\{400[1-\exp (-\operatorname{SWM} / 57.7)]-0.85 \mathrm{SWM}\}^{2}}$

(9) Conservative Cut Model x Inventory Pu-239 ... Preferred statistical Method

$0.1 \%$ upper limit excursion

Pu-239 $=0.85 \operatorname{SWH}+\sqrt{\sum\left\{(600[1-\exp (-\operatorname{SWL} / 57.7)]-0.85 \text { SWM }\}^{2}\right.}$ 

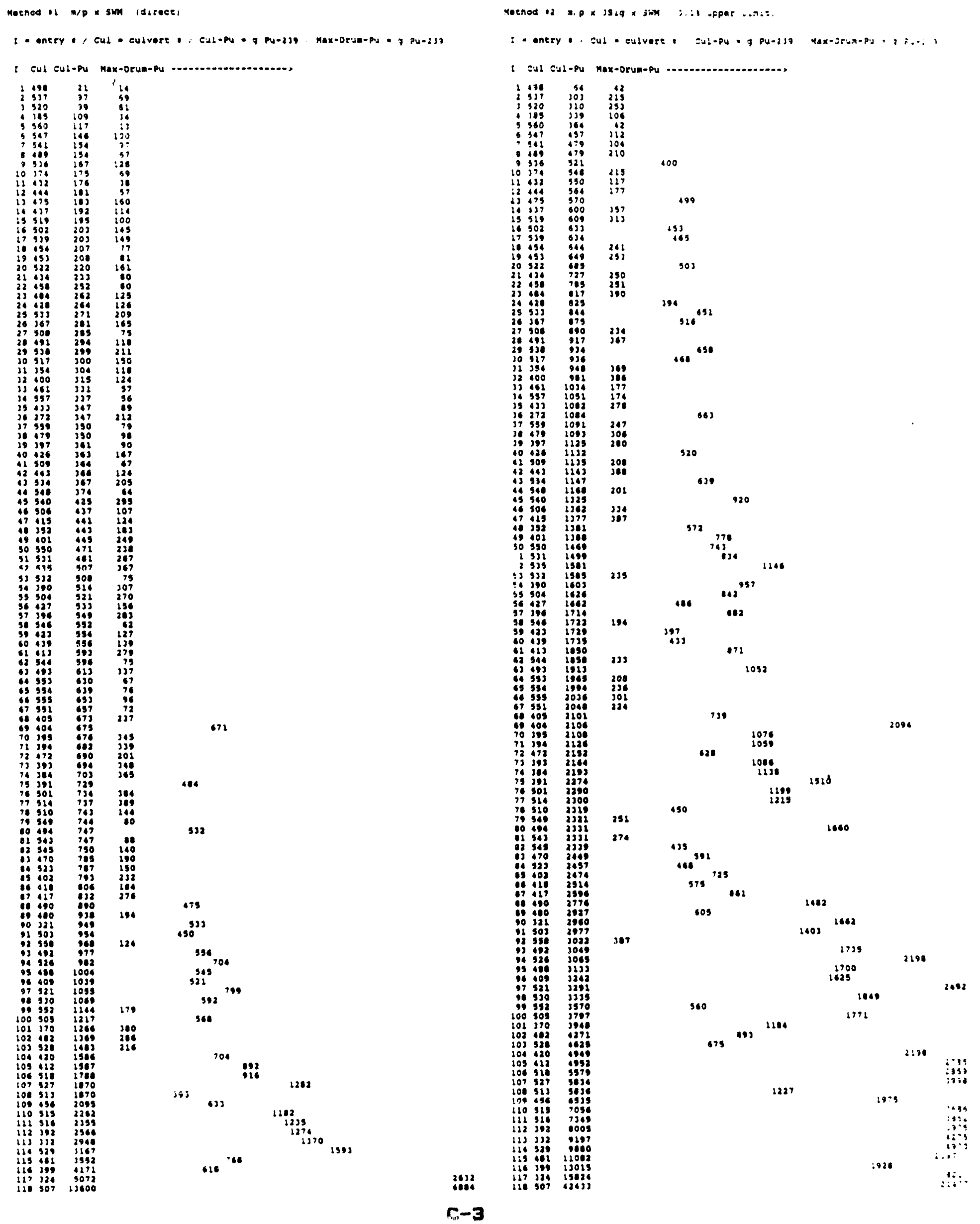


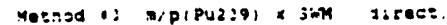

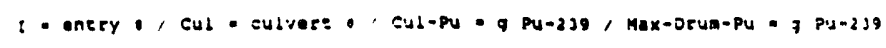

[ Sul Eul-pu Max-Drua-pu

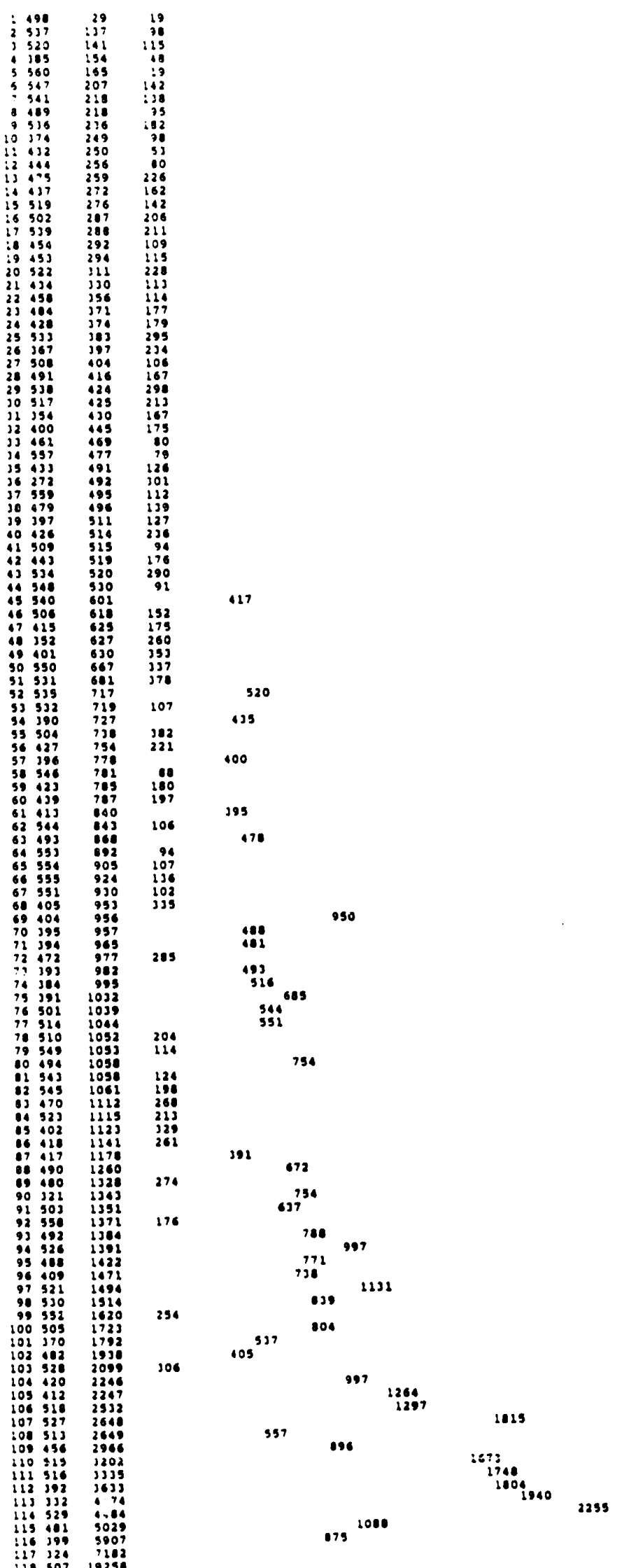

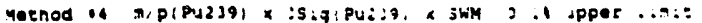

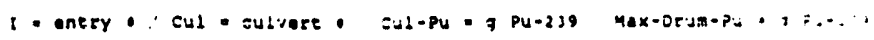

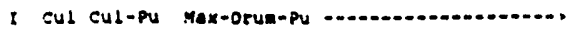

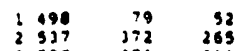

$\begin{array}{lll}320 & 311 & 265 \\ 3115 & 116 & 110 \\ 360 & 147 & 52\end{array}$

360
647

541
149 $390 \quad 374$

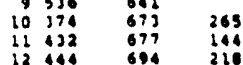

i2 445 794 218

$14+37$

16 $502 \quad 799$

$3045 \quad 792 \quad 396$

20322

21434

23 494

29333

27500

3049

3is 350

13

39.

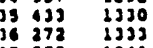

39.9

ㅁ.

a

a.

is 3900

7.49

\$月.

, 31,312

31. 3300

$36.27 \quad 2004$

97390

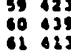

63 493 23095

64 $353 \quad 2417$

a. 559

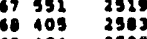

304

$71394 \quad 2619$

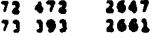

73042007

ii 30123010

70310 2152

70

300

300
337

205

$439^{614}$

557

610

307

287

is9

$633^{100}$

$452 \quad 009$

454

317

398

256

247

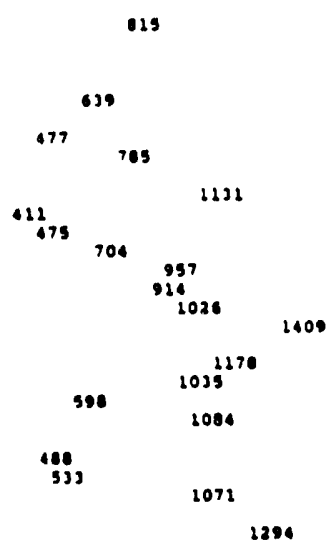

255
291
370
275

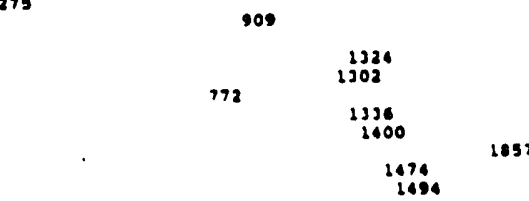

35)

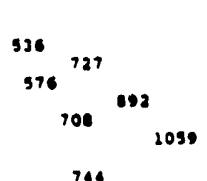

476

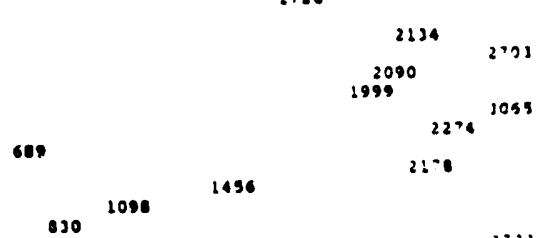

1501

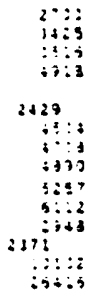




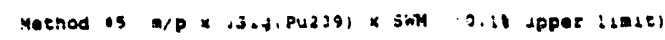

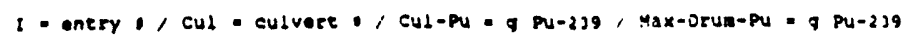

I Cul Cul-ps Mar-orum-pu

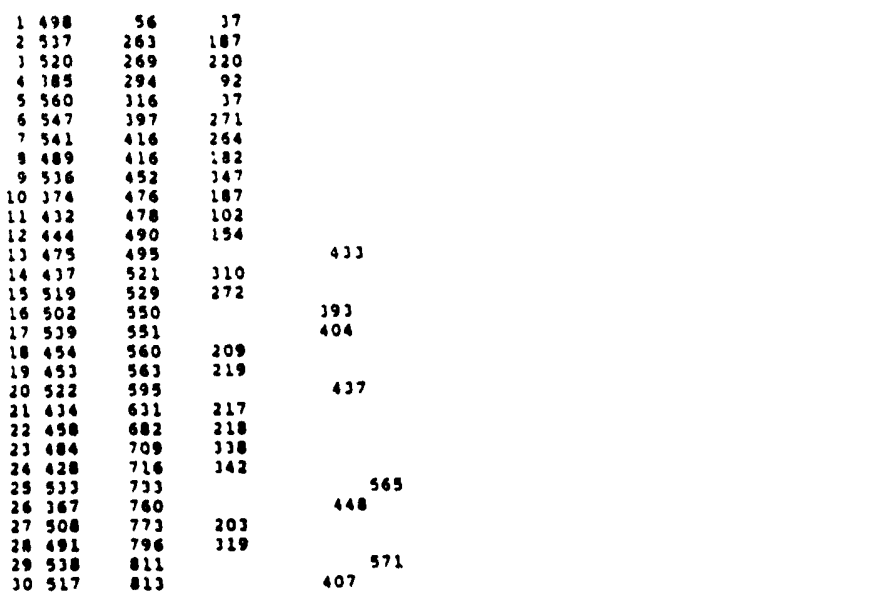

(1)

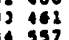

3727

3

40220

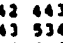

if 540

it 300

$9 \begin{array}{lll}402 & 2200 \\ 30 & 350 & 1270\end{array}$

51 53121302

उ3 33

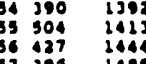

S6 3968

39423

615

63 (9)

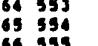

66555

60.05

70 395

72472

74304

765021909

$7910 \quad 2014$

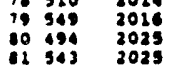

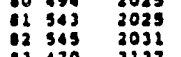

is 17002127

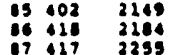

$98490 \quad 2611$

$90 \quad 2942$

$\begin{array}{lll}91 & 503 & 2526 \\ 9 & 558 & 2623\end{array}$

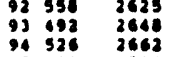

95 980 2722

979002310

$02 \quad 312 \quad 370$

$103328 \quad 0018$

$105412 \quad 390$

$107529 \quad 3006$

1005135009

$109436 \quad 9670$

11 316

112 392

iid 329

its 392

117
1124
1107
316049
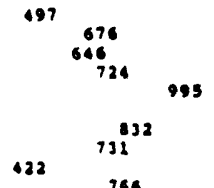

369

203

200
205
262

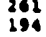

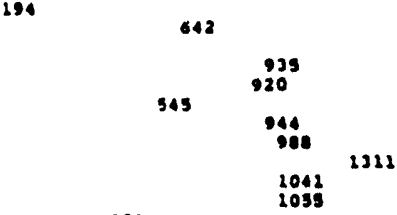

392

323

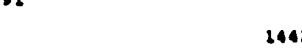

1019

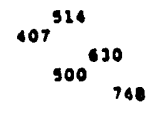

1442

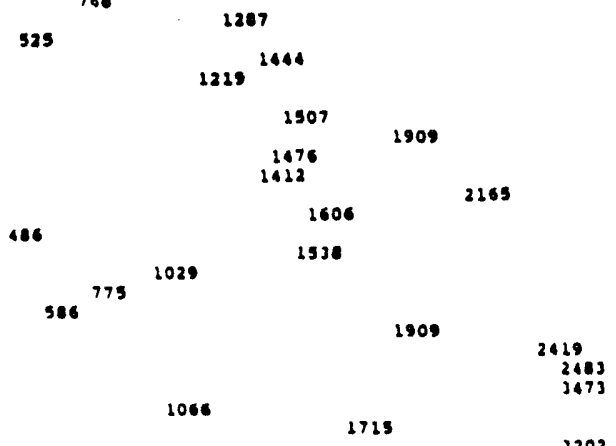

2002

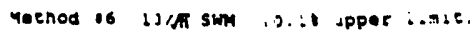

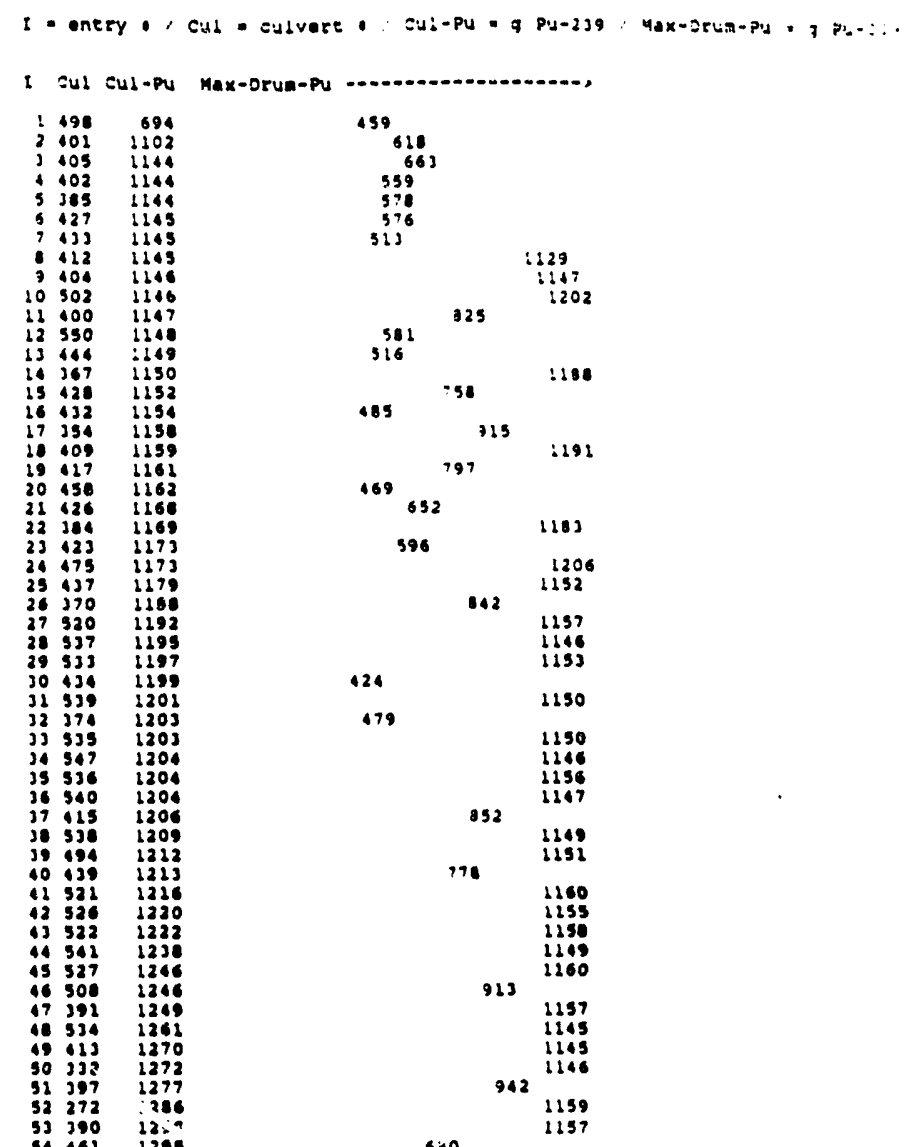

3202
3361
3633
316

,

C-5 


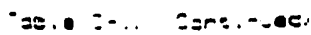

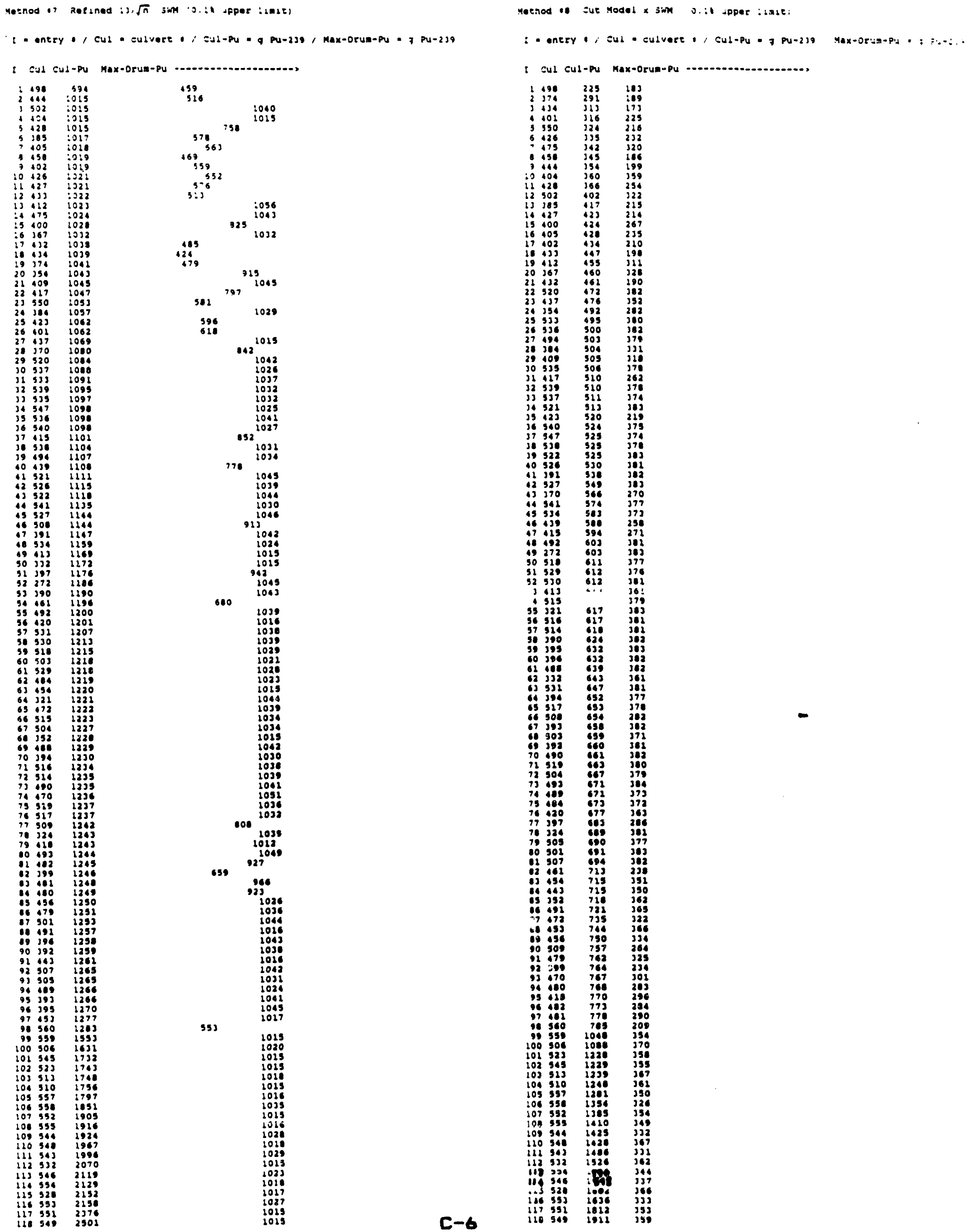




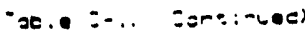

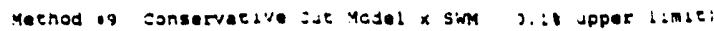

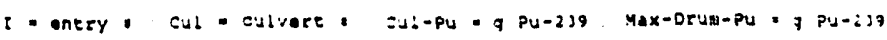

: Cul Cul-pu Max-Drdm-Pu -...................,

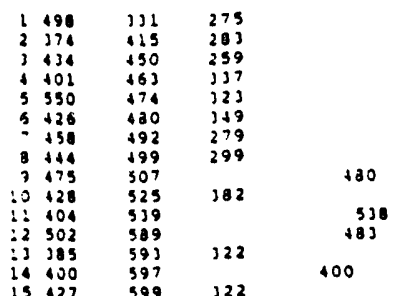

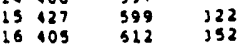

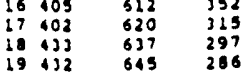

20412

$\begin{array}{lll}21 & 167 \\ 22 & 437\end{array}$

23520

23333

27.94

29336

3143

32335

38532

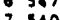

393528

$\begin{array}{ll}40392 \\ 41 & 326\end{array}$

$42 \quad 327$

44496

45942

at 372

4930

$\begin{array}{lll}52 & 13 \\ 53 & 310\end{array}$

54529

390

58318

60195

o2 480

64531

66500

69

39

72303

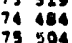

7640

77397

73

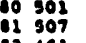

12402

is 498

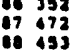

at 909

91393

9340

94
95
950

96462

979701079

$\begin{array}{lll}90559 & 141 \\ 000 & 506 & 147\end{array}$

102523

(0)

og $557 \quad 1709$

$107552 \quad 1002$

00
0.555
340

340 iass

1i. 5332

iis 928

117 551

467
492

922
928
373

490
4760

$393 \quad 372$

329

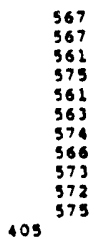

387

407

$07^{366}$

940
90
392

335
575
572

57

542
565
564

574

572
578
975

567
573
544
371
573

422

565
560

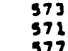

57
557
570
55
560
545

429.560

397

573

313

524
947
526
344
644
548
396

501

425

404
426
452
614

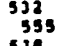

(3)

,

3924

:

518

2154
2360

C-7 
TARLE :-2. Py-239 Estuastes Ordered by Culvert/ Methods 11,0

\begin{tabular}{|c|c|c|c|c|}
\hline \multirow{2}{*}{\multicolumn{2}{|c|}{ Culvert Pad }} & \multicolumn{3}{|c|}{ Recorded Mass } \\
\hline & & Culvert & Max Drue & Meas/Proj \\
\hline 1 & 1 & 9 & 9 & 1 \\
\hline 272 & 13 & 299.027 & 182.810 & 1.162 \\
\hline 321 & 10 & 323.805 & 181.850 & 2.930 \\
\hline 324 & 13 & 339.472 & 176.200 & 14.940 \\
\hline 332 & 13 & 288.188 & 133.940 & 10.229 \\
\hline 352 & 6 & 329.263 & 136.420 & 1.344 \\
\hline 354 & 6 & 180.841 & 70.360 & 1.680 \\
\hline 367 & 6 & 167.871 & 99.010 & 1.671 \\
\hline 370 & 6 & 216.070 & 64.800 & 5.857 \\
\hline 374 & 6 & 93.848 & 36.880 & 1.870 \\
\hline 384 & 6 & 195.460 & 101.420 & 3.596 \\
\hline 385 & 6 & 142.240 & 44.460 & 0.763 \\
\hline 390 & 6 & 301.462 & 180.100 & 1.704 \\
\hline 391 & 6 & 269.640 & 179.010 & 2.703 \\
\hline 392 & 6 & 351.124 & 174.380 & 7.307 \\
\hline 393 & 6 & 356.008 & 178.760 & 1.948 \\
\hline 394 & 6 & 330.690 & 164.650 & 2.061 \\
\hline 395 & 6 & 358.680 & 183.100 & 1.884 \\
\hline 396 & 6 & 350.357 & 180.210 & 1.568 \\
\hline 397 & 6 & 291.585 & 72.480 & 1.237 \\
\hline 389 & 6 & 342.056 & 50.670 & 12.195 \\
\hline 400 & 6 & 161.460 & 63.460 & 1.948 \\
\hline 401 & 6 & 84.780 & 47.540 & 5.248 \\
\hline 402 & 6 & 146.709 & 43.020 & 5.404 \\
\hline 404 & 6 & 131.873 & 131.150 & 5.118 \\
\hline 405 & 6 & 144.970 & 50.990 & 4.644 \\
\hline 409 & 6 & 182.690 & 91.590 & 5.687 \\
\hline 412 & 6 & 154.470 & 86.860 & 10.275 \\
\hline$\$ 13$ & 6 & 286.100 & 134.610 & 2.073 \\
\hline 415 & 6 & 233.380 & 65.510 & 1.891 \\
\hline 417 & 6 & 184.890 & 61.320 & 4.500 \\
\hline 418 & 6 & 340.000 & 77.820 & 2.370 \\
\hline 420 & 6 & 309.360 & $: 37.390$ & 3.127 \\
\hline 423 & 6 & 199.780 & 45.830 & 2.774 \\
\hline 426 & 6 & 109.327 & 50.190 & 3.319 \\
\hline 427 & 13 & 151.346 & 44.290 & 3.520 \\
\hline 428 & 13 & 122.034 & 58.290 & 2.166 \\
\hline 432 & 13 & 175.290 & 37.290 & 1.006 \\
\hline 433 & 13 & 153.204 & 39.430 & 2.263 \\
\hline 434 & 13 & 94.980 & 32.600 & 2.453 \\
\hline 437 & 13 & 206.270 & 122.620 & 0.932 \\
\hline 439 & 13 & 239.610 & 59.840 & 2.321 \\
\hline 443 & 13 & 352.340 & 119.450 & 1.040 \\
\hline 444 & 13 & 126.380 & 39.710 & 1.431 \\
\hline 453 & 13 & 363.432 & 141.570 & 0.572 \\
\hline 454 & 13 & 323.667 & 120.880 & 0.638 \\
\hline 456 & 13 & 344.396 & 104.080 & 6.092 \\
\hline 458 & 13 & 113.037 & 36.090 & 2.226 \\
\hline 461 & 13 & 305.770 & 52.270 & 1.084 \\
\hline
\end{tabular}

Method 11
$1 / 0 \times$ SHA

Culvert Max Drue

347.469212 .425

$948.749 \quad 532.821$

5071.7129632 .428

2947.8791370 .072

$442.529 \quad 183.348$

$303.813 \quad 118.205$

$280.512 \quad 165.446$

$1265.522 \quad 379.534$

$175.496 \quad 68.966$

$702.874 \quad 364.706$

$108.529 \quad 33.923$

$513.691 \quad 306.890$

$728.837 \quad 483.864$

2565.6631274 .195

$693.504 \quad 348.224$

$681.552 \quad 339.344$

$675.753 \quad 344.960$

$549.360 \quad 282.569$

$360.691 \quad 89.658$

$4171.373 \quad 617.921$

$314.524 \quad 123.620$

$444.929 \quad 249.490$

$792.815 \quad 232.480$

$674.926 \quad 671.226$

$673.241 \quad 236.798$

$1038.958 \quad 520.872$

$1597.179 \quad 892.487$

$593.085 \quad 279.047$

$441.322 \quad 123.879$

$832.005 \quad 275.940$

$805.800 \quad 184.433$

$1586.089 \quad 704.399$

$554.190 \quad 127.132$

362.856166 .581

$532.739 \quad 155.901$

$264.326 \quad 126.256$

$176.342 \quad 37.514$

$346.701 \quad 89.230$

232.986 79.968

$192.244 \quad 114.282$

$556.135 \quad 138.899$

$366.434 \quad 124.228$

$180.850 \quad 56.825$

$207.883 \quad 80.978$

$206.500 \quad 77.121$

$2094.616 \quad 633.015$

$251.620 \quad 80.336$

$331.455 \quad 56.661$
Method te
ip 35 ig sWh

Culvert Max Druo

9

$1084.104 \quad 662.767$

$2960.096 \quad 1662.400$

$15823.740 \quad 8213.175$

$9197.370 \quad 4274.625$

\begin{tabular}{l}
$1380.692 \quad 572.047$ \\
\hline
\end{tabular}

$947.896 \quad 368.799$

$875.199 \quad 516.191$

$3948.429 \quad 1184.145$

$547.547 \quad 215.173$

$2192.967 \quad 1137.884$

$338.611 \quad 105.840$

$1602.717 \quad 957.498$

$2273.971 \quad 1509.656$

8004.8693975 .487

$2163.731 \quad 1086.460$

$2126.443 \quad 1058.752$

$2108.350 \quad 1076.276$

$1714.003 \quad 881.616$

$1125.355 \quad 279.732$

$13014.684 \quad 1927.912$

$981.315 \quad 385.695$

$1389.167 \quad 778.409$

$2473.584 \quad 725.338$

$2105.769 \quad 2094.224$

$2100.511 \quad 738.808$

$3241.549 \quad 1625.122$

$4951.999 \quad 2784.558$

$1850.426 \quad 870.625$

$1376.923 \quad 386.504$

$2595.856 \quad 860.933$

$2514.096 \quad 575.432$

$4948.597 \quad 2: 97.723$

1729.072 396.653

$1132.112 \quad 519.732$

$1662.142 \quad 486.410$

$824.696 \quad 393.919$

$550.186 \quad 117.043$

$1081.706 \quad 278.398$

$726.916 \quad 249.500$

$\mathbf{5 9 9 . 8 0 0} 335.559$

$1735.141 \quad 433.333$

$1143.273 \quad 387.591$

$564.251 \quad 177.294$

$648.595 \quad 232.651$

$644.279 \quad 240.619$

$6535.203 \quad 1975.005$

$793.056 \quad 250.649$

$1034.139 \quad 176.781$ 
TABLE C-E. Pu-239 Estinates Ordered by Culvert/ Methods 11,t2

\begin{tabular}{|c|c|c|c|c|}
\hline \multicolumn{2}{|c|}{ Culvert Pad } & \multirow{2}{*}{$\begin{array}{c}\text { Recorded } \\
\text { Culvert } \\
g\end{array}$} & $\begin{array}{l}\text { Mass } \\
\text { Max Orue }\end{array}$ & \multirow{2}{*}{ Meas/Proj } \\
\hline 1 & 1 & & 9 & \\
\hline 470 & 13 & 334.901 & 80.860 & 2.344 \\
\hline 472 & 13 & 324.490 & 94.620 & 2.126 \\
\hline 475 & 13 & 105.977 & 92.740 & 1.724 \\
\hline 479 & 13 & 345.430 & 96.750 & 1.014 \\
\hline 480 & 13 & 343.640 & 70.990 & 2.730 \\
\hline 481 & 13 & 343.477 & 74.280 & 10.341 \\
\hline 482 & 13 & 341.354 & 71.346 & 4.010 \\
\hline 484 & 13 & 322.785 & 154.000 & 0.811 \\
\hline 488 & 13 & 329.822? & 178.900 & 3.045 \\
\hline 489 & 13 & 355.619 & 155.860 & 0.432 \\
\hline 490 & 13 & 333.991 & 178.260 & 2.664 \\
\hline 491 & 13 & 349.800 & 140.180 & 0.840 \\
\hline 492 & 10 & 308.824 & 175.780 & 3.164 \\
\hline 493 & 13 & 340.105 & 187.040 & 1.803 \\
\hline 494 & 13 & 238.244 & 169.690 & 3.136 \\
\hline 498 & 13 & 53.400 & 35.300 & 0.385 \\
\hline 501 & 10 & 346.830 & 181.540 & 2.116 \\
\hline 502 & 13 & 131.580 & 94.130 & 1.542 \\
\hline 503 & 10 & 321.610 & 151.570 & 2.967 \\
\hline 504 & 10 & 328.440 & 169.960 & 1.587 \\
\hline 505 & 13 & 355.340 & 165.750 & 3.425 \\
\hline 506 & 10 & 608.096 & 149.180 & 0.718 \\
\hline 507 & 13 & 355.056 & 179.710 & 38.305 \\
\hline 508 & 13 & 267.526 & 70.240 & 1.066 \\
\hline 509 & 13 & 339.232 & 62.190 & 1.072 \\
\hline 510 & 13 & 694.000 & 134.590 & 1.071 \\
\hline 513 & 13 & 689.950 & 144.820 & 2.715 \\
\hline 514 & 10 & 333.900 & 176.300 & 2.200 \\
\hline 515 & 10 & 325.730 & 170.180 & 6.943 \\
\hline 516 & 10 & 333.290 & 174.700 & 7.067 \\
\hline 517 & 13 & 335.320 & 167.710 & 0.895 \\
\hline 518 & 10 & 320.040 & 163.990 & 5.597 \\
\hline 919 & 13 & 335.320 & 172.310 & 0.582 \\
\hline 520 & 13 & 219.900 & 179.270 & 0.452 \\
\hline 521 & 13 & 241.970 & 183.260 & 4.359 \\
\hline 522 & 10 & 247.510 & 181.610 & 0.697 \\
\hline 523 & 10 & 685.250 & 130.660 & 1.149 \\
\hline \$26 & 13 & 245.400 & 175.980 & 4.003 \\
\hline 527 & 13 & 267.410 & 183.290 & 6.992 \\
\hline 528 & 10 & 972.150 & 141.810 & 1.525 \\
\hline 529 & 13 & 322.100 & 162.020 & 9.831 \\
\hline 530 & 13 & 318.510 & 176.540 & 3.356 \\
\hline 531 & 13 & 313.710 & 174.470 & 1.532 \\
\hline 532 & 13 & 913.870 & 135.450 & 0.556 \\
\hline 533 & 13 & 225.070 & 173.530 & 1.202 \\
\hline 534 & 10 & 279.040 & 155.390 & 1.317 \\
\hline 535 & 13 & 230.510 & 167.090 & 2.198 \\
\hline 536 & 13 & 231.510 & 177.780 & 0.721 \\
\hline
\end{tabular}

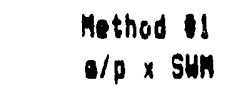

Culvert Max oruo

$$
99
$$

$785.008 \quad 189.536$

$689.866 \quad 201.162$

$182.704 \quad 159.884$

$350.266 \quad 98.105$

$938.137 \quad 193.803$

$3551.896 \quad 768.129$

$1368.830 \quad 296.097$

$261.779 \quad 124.894$

$1004.308 \quad 544.751$

$153.627 \quad 67.332$

$889.752 \quad 474.885$

$293.832 \quad 117.751$

$977.119 \quad 536.168$

$613.209 \quad 337.233$

$747.133 \quad 532.148$

$20.559 \quad 13.590$

$733.892 \quad 384.139$

$202.896 \quad 145.148$

$954.217 \quad 449.708$

$521.234 \quad 269.727$

$1217.039 \quad 567.694$

$436.613 \quad 107.111$

13600.4206893 .792

$295.183 \quad 74.876$

$363.657 \quad 66.668$

$743.274 \quad 144.146$

$1870.499 \quad 393.186$

$737.251 \quad 399.270$

2261.5431181 .560

2355.3601234 .605

$300.111 \quad 150.100$

1788.063916 .212

$195.156 \quad 100.284$

$99.395 \quad 81.030$

$1054.747 \quad 799.830$

$219.541 \quad 161.088$

$787.352 \quad 150.128$

$982.336 \quad 704.448$

1869.7311291 .564

$1482.529 \quad 216.260$

3166.5651592 .819

$1068.920 \quad 592.468$

$480.604 \quad 267.280$

$508.112 \quad 75.310$

$270.534 \quad 208.583$

$367.496 \quad 204.649$

$506.661 \quad 367.264$

$166.919 \quad 128.179$
Methoo 12

$0 / p \times 3$ sig $\times$ SWA

Culvert Max Drue

9 g

$2449.225 \quad 591.352$

$2152.381 \quad 627.626$

$570.038 \quad 498.837$

$1092.830 \quad 306.086$

$2926.988 \quad 604.664$

$11081.914 \quad 2396.564$

$4270.748 \quad 892.624$

$816.749 \quad 389.669$

$3133.441 \quad 1699.622$

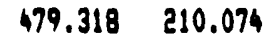

$2776.026 \quad 1481.640$

$916.756 \quad 367.384$

$3048.612 \quad 1735.244$

$1913.213 \quad 1052.167$

$2331.056 \quad 1660.301$

$64.144 \quad 42.402$

$2289.744 \quad 1198.313$

$633.037 \quad 452.863$

$2977.157 \quad 1403.090$

$1626.251 \quad 841.547$

$3797.163 \quad 1771.205$

1362.232 334.187

42433.31121477 .430

$899.770 \quad 233.613$

$1134.609 \quad 208.003$

$2319.015 \quad 449.735$

$5935.959 \quad 1226.741$

$2300.224 \quad 1214.524$

7056.0153696 .466

7340.7253851 .967

$936.348 \quad 468.313$

$5578.758 \quad 2958.582$

$608.887 \quad 312.897$

$310.112 \quad 252.814$

$3290.811 \quad 2492.351$

$684.969 \quad 502.595$

$2456.539 \quad 468.400$

$3064.889 \quad 2197.878$

$5833.560 \quad 3999.479$

$4625.490 \quad 674.732$

$9879.693 \quad 4969.594$

$3335.029 \quad 1848.501$

$1499.484 \quad 833.939$

$1595.309 \quad 234.968$

$844.067 \quad 650.779$

$1146.587 \quad 638.504$

$1580.782 \quad 1145.863$

$520.786 \quad 399.920$ 
TABLE C-2. PU-239 Estieates Ordered by Culvert/ Methods 11,12

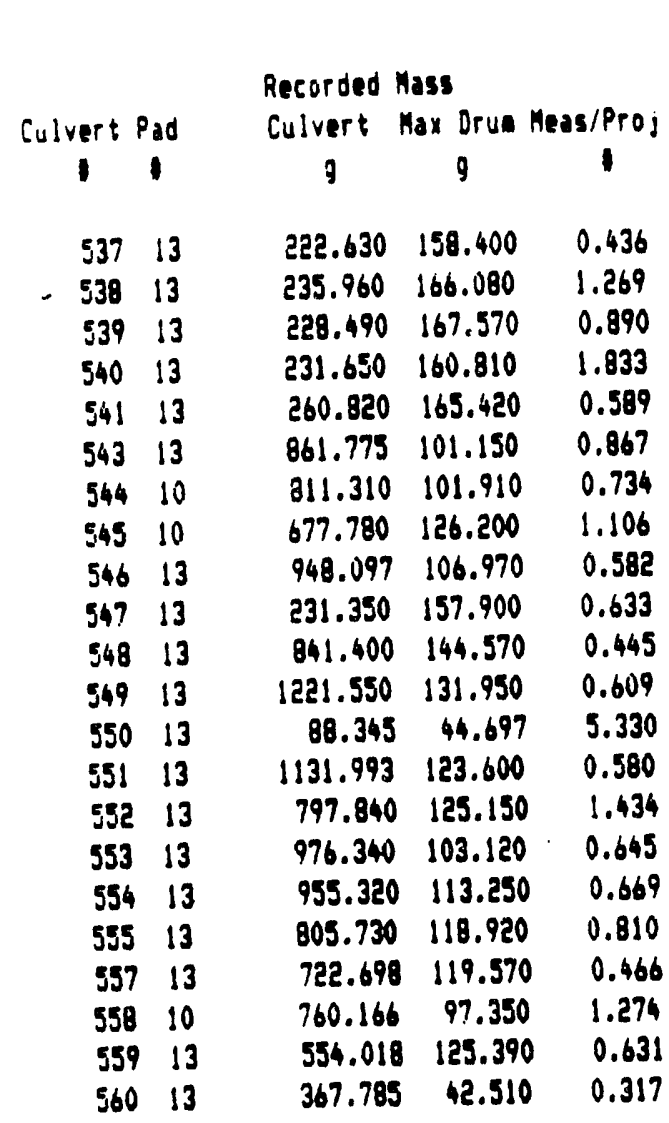

\begin{tabular}{|c|c|}
\hline \multicolumn{2}{|c|}{$\begin{array}{l}\text { Hethod II } \\
1 / p \times \text { SWI }\end{array}$} \\
\hline Culvert & Max Drus \\
\hline 9 & 9 \\
\hline 97.067 & 69.062 \\
\hline 299.433 & 210.756 \\
\hline 203.396 & 149.137 \\
\hline 424.614 & 294.765 \\
\hline 153.623 & 97.432 \\
\hline 747.159 & 87.697 \\
\hline 595.502 & 74.802 \\
\hline 749.625 & 139.577 \\
\hline 551.792 & 62.257 \\
\hline 146.445 & 99.951 \\
\hline 374.423 & 64.334 \\
\hline 743.924 & 80.358 \\
\hline 470.879 & 238.235 \\
\hline 656.556 & 71.688 \\
\hline 1144.103 & 3179.465 \\
\hline 629.739 & 66.512 \\
\hline 639.109 & 75.764 \\
\hline 652.641 & 96.323 \\
\hline 336.777 & 55.720 \\
\hline 968.451 & 124.024 \\
\hline 349.589 & 579.121 \\
\hline 116.588 & $8 \quad 13.476$ \\
\hline
\end{tabular}

\begin{tabular}{|c|c|}
\hline $\begin{array}{l}\text { Method } \\
\text { as } \times 35 i g \\
\text { ulvert }\end{array}$ & $\begin{array}{l}\text { I2 } \\
\times \text { SWh } \\
\text { Hax Drue }\end{array}$ \\
\hline 9 & 9 \\
\hline $\begin{array}{l}302.848 \\
934.232 \\
634.471\end{array}$ & $\begin{array}{l}215.475 \\
657.557 \\
465.308\end{array}$ \\
\hline $\begin{array}{r}1324.797 \\
479.304\end{array}$ & $\begin{array}{l}919.666 \\
303.999\end{array}$ \\
\hline $\begin{array}{l}2331.136 \\
1897.965\end{array}$ & $\begin{array}{l}273.615 \\
233.382\end{array}$ \\
\hline 2338.829 & 435.481 \\
\hline 1721.592 & 194.240 \\
\hline $\begin{array}{r}456.907 \\
1168.200\end{array}$ & $\begin{array}{l}311.846 \\
200.721\end{array}$ \\
\hline 2321.043 & 250.716 \\
\hline 1469.142 & 743.293 \\
\hline $\begin{array}{l}2048.455 \\
3569.600\end{array}$ & $\begin{array}{l}223.667 \\
559.931\end{array}$ \\
\hline 1964.787 & 207.519 \\
\hline 1994.020 & 236.384 \\
\hline 2036.241 & 300.535 \\
\hline 1050.745 & 173.845 \\
\hline $\begin{array}{l}3021.569 \\
1090.706\end{array}$ & $\begin{array}{l}386.955 \\
246.858\end{array}$ \\
\hline 363.754 & 42.044 \\
\hline
\end{tabular}


TABLE C-2. Pu-239 Estunates Drdered by Culvert/ Methods 13.84

Recorded Mass

\begin{tabular}{|c|c|c|c|c|}
\hline \multicolumn{2}{|c|}{ Culvert Pad } & \multirow{2}{*}{$\begin{array}{c}\text { Culvert } \\
9\end{array}$} & \multicolumn{2}{|c|}{ Max Drus Meas/Proj } \\
\hline 1 & 1 & & 9 & 1 \\
\hline 272 & 13 & 299.027 & 182.810 & 1.162 \\
\hline 321 & 10 & 323.805 & 181.850 & 2.930 \\
\hline 324 & 13 & 339.472 & 176.200 & 14.940 \\
\hline 332 & 13 & 288.188 & 133.940 & 10.229 \\
\hline 352 & 6 & 329.263 & 136.420 & 1.346 \\
\hline 354 & 6 & 180.841 & 70.360 & 1.680 \\
\hline 367 & 6 & 167.871 & 99.010 & 1.671 \\
\hline 370 & 6 & 216.070 & 64.800 & 5.857 \\
\hline 374 & 6 & 73.848 & 36.880 & 1.870 \\
\hline 384 & 6 & 195.460 & 101.420 & 3.596 \\
\hline 385 & 6 & 192.240 & 44.460 & 0.763 \\
\hline 390 & 6 & 301.462 & 180.100 & 1.704 \\
\hline 391 & 6 & 269.640 & 179.010 & 2.703 \\
\hline 392 & 6 & 351.124 & 174.380 & 7.307 \\
\hline 393 & 6 & 356.008 & 178.760 & 1.948 \\
\hline 394 & 6 & 330.690 & 164.650 & 2.061 \\
\hline 395 & 6 & 358.680 & 183.100 & 1.884 \\
\hline 396 & 6 & 350.357 & 180.210 & 1.568 \\
\hline 397 & 6 & 291.585 & 72.480 & 1.237 \\
\hline 399 & 6 & 342.056 & 50.670 & 12.195 \\
\hline 400 & 6 & 161.460 & 63.460 & 1.948 \\
\hline 401 & 6 & 84.780 & 47.540 & 5.248 \\
\hline 402 & 6 & 146.709 & 43.020 & 5.404 \\
\hline 404 & 6 & 131.873 & 131.150 & 5.118 \\
\hline 405 & 6 & 144.970 & 50.990 & 4.644 \\
\hline 409 & 6 & 182.690 & 91.590 & 5.687 \\
\hline 412 & 6 & 154.470 & 86.860 & 10.275 \\
\hline 413 & 6 & 286.100 & 134.610 & 2.073 \\
\hline 413 & 6 & 233.380 & 65.510 & 1.891 \\
\hline 417 & 6 & 184.890 & 61.320 & 4.500 \\
\hline 418 & 6 & 340.000 & 77.820 & 2.370 \\
\hline 420 & 6 & 309.360 & 137.390 & 5.127 \\
\hline 423 & 6 & 199.780 & 45.830 & 2.774 \\
\hline 426 & 6 & 109.327 & 50.190 & 3.319 \\
\hline 427 & 13 & 151.346 & 44.290 & 3.520 \\
\hline 428 & 13 & 122.034 & 58.290 & 2.166 \\
\hline 432 & 13 & 175.290 & 37.290 & 1.006 \\
\hline 433 & 13 & 153.204 & 39.430 & 2.263 \\
\hline 434 & 13 & 94.990 & 32.600 & 2.453 \\
\hline 437 & 13 & 206.270 & 122.620 & 0.932 \\
\hline 439 & 13 & 239.610 & 59.840 & 2.321 \\
\hline 443 & 13 & 352.340 & 119.450 & 1.040 \\
\hline 444 & 13 & 126.380 & 39.710 & 1.631 \\
\hline 453 & 13 & 363.432 & 141.570 & 0.572 \\
\hline 454 & 13 & 323.667 & 120.880 & 0.638 \\
\hline 455 & 13 & 344.396 & 104.080 & 6.082 \\
\hline 458 & 13 & 113.037 & 36.090 & 2.226 \\
\hline 461 & 13 & 305.770 & 52.270 & 1.084 \\
\hline
\end{tabular}

Method 13

a/p(Pu239) $\times$ SUN

Culvert Max Drue

99

$492.017 \quad 300.794$

$1343.428 \quad 754.474$

7181.5443727 .518

4174.1911940 .022

$626.622 \quad 259.621$

$430.199 \quad 167.378$

$397.206 \quad 234.271$

$1791.979 \quad 537.420$

$248.502 \quad 97.655$

$995.270 \quad 516.424$

$153.677 \quad 48.035$

$727.387 \quad 434.557$

$1032.033 \quad 685.151$

3632.9791804 .260

$982.001 \quad 493.086$

965.078490 .511

$956.866 \quad 488.464$

$777.893 \quad 400.118$

$510.738 \quad 126.955$

$5906.664 \quad 874.976$

$445.366 \quad 175.046$

$630.014 \quad 353.278$

$1122.627 \quad 329.192$

955.695950 .456

$953.309 \quad 335.305$

$1471.165 \quad 737.555$

2247.4461263 .761

$839.009 \quad 395.130$

$624.911 \quad 175.413$

$1178.119 \quad 390.731$

$1141.013 \quad 261.158$

$2245.902 \quad 997.428$

784.733180 .020

$513.805 \quad 235.878$

754.357 220.756

$374.285 \quad 178.779$

$249.700 \quad 53.119$

$490.928 \quad 126.350$

$399.908 \quad 113.234$

272.217 161.823

$787.487 \quad 196.666$

$518.870 \quad 175.907$

256.083 80.464

$294.362 \quad 114.665$

$292.403 \quad 109.204$

$2965.977 \quad 896.349$

$356.294 \quad 113.756$

$469.340 \quad 80.232$
Method 14

D/p(Pu239) $\times 35 i g(P u 239) \times$ SH Culvert Max Drue

99

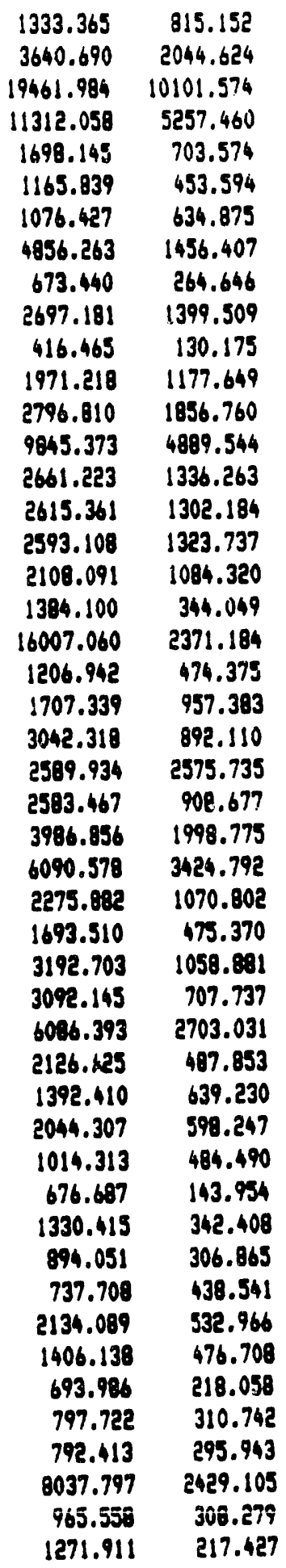


TABLE C-2. Pu-239 Estieates Ordered by Culvert/ Methods 13,14

\begin{tabular}{|c|c|c|c|c|c|c|c|c|}
\hline & & Recorded $n$ & Mass & & $\begin{array}{l}\text { Method } \\
\text { /p (Puz39) }\end{array}$ & 13 & $\begin{array}{l}\text { Method } \\
\text { Pu2391 } \times 35 \text { ig }\end{array}$ & Pue39) $\times 54$ \\
\hline Culvert $P$ & & Culvert & Max Drue & leasiProj & Culvert & Max Drue & Culvert & Max Orua \\
\hline 1 & 1 & 9 & 9 & 1 & 9 & 9 & 9 & 9 \\
\hline$\$ 70$ & 13 & 334.901 & 80.860 & 2.344 & 1111.571 & 268.383 & 3012.358 & 727.317 \\
\hline 472 & 13 & 324.490 & 94.620 & 2.126 & 976.850 & 284.846 & 2647.263 & 771.931 \\
\hline 475 & 13 & 105.977 & 92.740 & 1.724 & 258.709 & 226.395 & 701.102 & 613.532 \\
\hline 479 & 13 & 345.430 & 96.750 & 1.014 & 495.977 & 138.916 & 1344.097 & 376.462 \\
\hline 480 & 13 & 343.640 & 70.990 & 2.730 & 1329.402 & 274.425 & 3599.970 & 743.691 \\
\hline 481 & 13 & 343.477 & 74.280 & 10.341 & 5029.484 & 1087.671 & 13629.902 & 2947.589 \\
\hline 482 & 13 & 341.354 & 71.346 & 4.010 & 1938.263 & 405.114 & 5252.692 & 1097.859 \\
\hline 484 & 13 & 322.785 & 154.000 & 0.811 & 370.679 & 176.850 & 1004.539 & 479.263 \\
\hline 488 & 13 & 329.822 & 178.900 & 3.045 & 1422.100 & 771.367 & 3853.891 & 2090.404 \\
\hline 489 & 13 & 355.619 & 155.860 & 0.432 & 217.536 & 95.341 & 589.524 & 258.375 \\
\hline 490 & 13 & 333.991 & 178.260 & 2.664 & 1259.889 & 672.437 & 3414.299 & 1822.303 \\
\hline 491 & 13 & 349.800 & 140.180 & 0.840 & 416.066 & 166.736 & 1127.539 & 451.854 \\
\hline 492 & 10 & 308.824 & 175.780 & 3.164 & 1383.601 & 787.534 & 3749.558 & 2134.217 \\
\hline 493 & 13 & 390.105 & 187.040 & 1.803 & 869.304 & 477.522 & 2353.105 & 1294.085 \\
\hline 494 & 13 & 239.244 & 169.690 & 3.136 & $1057.94 !$ & 753.521 & 2867.019 & 2042.043 \\
\hline 498 & 13 & 53.400 & 35.300 & 0.385 & 29.112 & 19.244 & 78.892 & 52.152 \\
\hline 501 & 10 & 346.830 & 181.540 & 2.116 & 1039.191 & 543.940 & 2816.209 & 1474.078 \\
\hline 502 & 13 & 131.580 & 94.130 & 1.542 & 287.301 & 205.530 & 778.586 & 356.987 \\
\hline 503 & 10 & 321.610 & 151.570 & 2.967 & 1351.171 & 636.787 & 3661.674 & 1725.692 \\
\hline 504 & 10 & 328.440 & 169.960 & 1.587 & 738.068 & 381.933 & 2000.164 & 1035.038 \\
\hline 505 & 13 & 355.340 & 165.750 & 3.425 & 1723.328 & 803.854 & 4670.219 & 2178.445 \\
\hline 506 & 10 & 608.096 & 149.180 & 0.718 & 618.244 & 151.670 & 1675.441 & 411.024 \\
\hline 507 & 13 & 355.056 & 179.710 & 38.305 & 19258.195 & $\$ 9747.449$ & 52189.708 & 26415.586 \\
\hline 508 & 13 & 267.526 & 70.240 & 1.066 & 403.819 & 106.024 & 1094.349 & 287.326 \\
\hline 509 & 13 & 339.232 & 62.190 & 1.072 & 514.938 & 94.401 & 1395.482 & 255.828 \\
\hline 510 & 13 & 694.000 & 134.590 & 1.071 & 1052.476 & 204.111 & 2952.210 & 553.140 \\
\hline 513 & 13 & 688.950 & 144.820 & 2.715 & 2648.627 & 556.752 & 7177.779 & 1508.797 \\
\hline 514 & 10 & 333.900 & 176.300 & 2.200 & 1043.948 & 551.207 & 2829.098 & 1493.771 \\
\hline 515 & 10 & 325.730 & 170.180 & 6.943 & 3202.345 & 51673.089 & 8678.356 & 4534.070 \\
\hline 516 & 10 & 333.290 & 174.700 & 7.067 & 3335.190 & 1740.201 & 9038.366 & 4737.623 \\
\hline 517 & 13 & 355.320 & 167.710 & 0.095 & 424.958 & 212.542 & 1151.635 & 575.989 \\
\hline 518 & 10 & 320.040 & 163.990 & 5.587 & 2531.890 & 1297.356 & 6861.443 & 3515.836 \\
\hline 519 & 13 & 335.320 & 172.310 & 0.582 & 276.341 & 1142.003 & 748.885 & 384.827 \\
\hline 520 & 13 & 219.900 & 179.270 & 0.452 & 140.743 & 114.739 & 381.414 & 310.941 \\
\hline 521 & 13 & 241.970 & 183.260 & 4.359 & 1493.522 & 21131.144 & 4047.445 & 3065.400 \\
\hline 522 & 10 & 247.510 & 181.610 & 0.807 & 310.871 & 1228.101 & 842.459 & 618.133 \\
\hline 523 & 10 & 685.250 & 130.660 & 1.149 & 1114.891 & 1212.592 & 3021.354 & 576.096 \\
\hline 526 & 13 & 249.400 & 175.980 & 4.003 & 1390.998 & 997.498 & 3769.578 & 2703.2220 \\
\hline 527 & 13 & 267.410 & 183.290 & 6.992 & 2647.539 & 91814.694 & 7174.830 & 4917.821 \\
\hline 528 & 10 & 972.150 & 141.810 & 1.525 & 2099.261 & 1306.225 & 5689.997 & 829.868 \\
\hline 529 & 13 & 322.100 & 0162.020 & 9.831 & 4483.856 & 62255.431 & 12151.250 & 6112.218 \\
\hline 530 & 13 & 318.510 & 176.540 & 3.356 & 1513.590 & $0 \quad 938.935$ & 4101.829 & 2273.514 \\
\hline 531 & 13 & 313.710 & $0 \quad 174.470$ & 1.532 & 680.535 & 5378.480 & 1844.249 & 1025.680 \\
\hline 532 & 13 & 913.870 & 135.450 & 0.556 & 719.486 & $6 \quad 106.639$ & 1949.808 & 288.992 \\
\hline 533 & 13 & 225.070 & 173.530 & 1.202 & 393.076 & $6 \quad 295.354$ & 1038.137 & 800.408 \\
\hline 534 & 10 & 279.040 & 155.390 & 1.317 & 520.374 & - 289.782 & 1410.213 & 785.310 \\
\hline 535 & 13 & 230.510 & $0 \quad 167.090$ & อ์.198 & $7 i 7.435$ & E 520.046 & 1944.241 & 1409.322 \\
\hline 536 & 13 & 231.510 & 177.780 & 0.721 & 236.357 & 7181.502 & 640.527 & 491.870 \\
\hline & & & & & & -1 & & \\
\hline
\end{tabular}


TABLE C-2. Pu-239 Estinates Ordered by Culvert/ Methods 13,14

\begin{tabular}{|c|c|c|c|c|}
\hline \multicolumn{2}{|c|}{ Culvert pad } & \multirow{2}{*}{$\begin{array}{c}\text { Recorded } \\
\text { Culvert } \\
9\end{array}$} & $\begin{array}{l}\text { Mass } \\
\text { Hax Drue }\end{array}$ & Meas/Proj \\
\hline 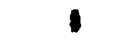 & 1 & & 9 & 1 \\
\hline 537 & 13 & 222.630 & 158.400 & 0.436 \\
\hline 538 & 13 & 235.960 & 166.080 & 1.269 \\
\hline 539 & 13 & 2? & 167.570 & 0.890 \\
\hline 540 & 13 & 231.650 & 160.810 & 1.833 \\
\hline 541 & 13 & 260.820 & 165.420 & 0.989 \\
\hline 543 & 13 & 861.775 & 101.150 & 0.867 \\
\hline 544 & 10 & 811.310 & 101.910 & 0.734 \\
\hline 345 & 10 & 677.780 & 126.200 & 1.106 \\
\hline 546 & 13 & 948.097 & 106.970 & $0 . \$ 88$ \\
\hline 547 & 13 & 231.350 & 157.900 & 0.633 \\
\hline 548 & 13 & 241.400 & 144.570 & 0.445 \\
\hline 549 & 13 & 1221.550 & 131.950 & 0.609 \\
\hline 590 & 13 & 89.345 & 49.697 & 5.330 \\
\hline 551 & 13 & 1131.993 & 123.600 & 0.580 \\
\hline 552 & 13 & 797.840 & 125.150 & 1.434 \\
\hline 553 & 13 & 976.340 & 103.120 & 0.645 \\
\hline S54 & 13 & 955.320 & 113.250 & 0.669 \\
\hline 355 & 13 & 005.730 & 118.920 & 0.810 \\
\hline 554 & 13 & 722.698 & 119.570 & 0.466 \\
\hline 558 & 10 & 760.166 & 97.350 & 1.274 \\
\hline 559 & 13 & 554.018 & 125.390 & 0.631 \\
\hline 560 & 13 & 367.785 & 42.310 & 0.317 \\
\hline
\end{tabular}

\begin{tabular}{|c|c|}
\hline \multicolumn{2}{|c|}{$\begin{array}{l}\text { Method } 13 \\
1 / \text { (Pu239) } \times \text { Sun }\end{array}$} \\
\hline Culvert & Max Drue \\
\hline 9 & 9 \\
\hline 137.446 & 97.792 \\
\hline 423.997 & 298.430 \\
\hline 287.952 & 211.178 \\
\hline 601.254 & 417.387 \\
\hline 217.539 & 137.964 \\
\hline 1057.977 & 124.179 \\
\hline 843.230 & 105.920 \\
\hline 1061.469 & 197.641 \\
\hline 781.338 & 88.155 \\
\hline 207.365 & 141.530 \\
\hline 530.183 & 91.096 \\
\hline 1053.396 & 113.786 \\
\hline 666.764 & 337.341 \\
\hline 929.683 & 101.510 \\
\hline 1620.049 & 254.123 \\
\hline 891.711 & 94.186 \\
\hline 904.978 & 107.298 \\
\hline 924.140 & 136.396 \\
\hline 476.877 & 78.899 \\
\hline 1371.327 & 175.618 \\
\hline 495.013 & 1112.035 \\
\hline & \\
\hline
\end{tabular}

\begin{tabular}{|c|c|}
\hline $\begin{array}{r}\text { Method } \\
\text { o/pipue391 } \times 35 i g\end{array}$ & Pue391 $\times 54$ \\
\hline Culvert & Max Orue \\
\hline 9 & 9 \\
\hline 372.480 & 265.017 \\
\hline 1149.033 & 808.745 \\
\hline 780.351 & 572.294 \\
\hline 1629.399 & 1131.118 \\
\hline 589.507 & 373.883 \\
\hline 2867.118 & 336.525 \\
\hline 2285.154 & 287.042 \\
\hline 2976.580 & 535.608 \\
\hline 2117.426 & 238.901 \\
\hline 561.960 & 383.547 \\
\hline 1436.796 & 246.871 \\
\hline 2854.704 & 308.361 \\
\hline 1806.932 & 914.193 \\
\hline 2519.442 & 275.093 \\
\hline 4390.333 & 608.672 \\
\hline 2416.536 & 255.232 \\
\hline 2452.492 & 290.735 \\
\hline 2504.420 & 369.634 \\
\hline 1292.336 & 213.816 \\
\hline 3716.297 & 475.924 \\
\hline 1341.485 & 303.616 \\
\hline 7.390 & 51.711 \\
\hline
\end{tabular}


TABLE C-2. Pu-239 Esticates Ordered by Culvert/ Methods 15,16

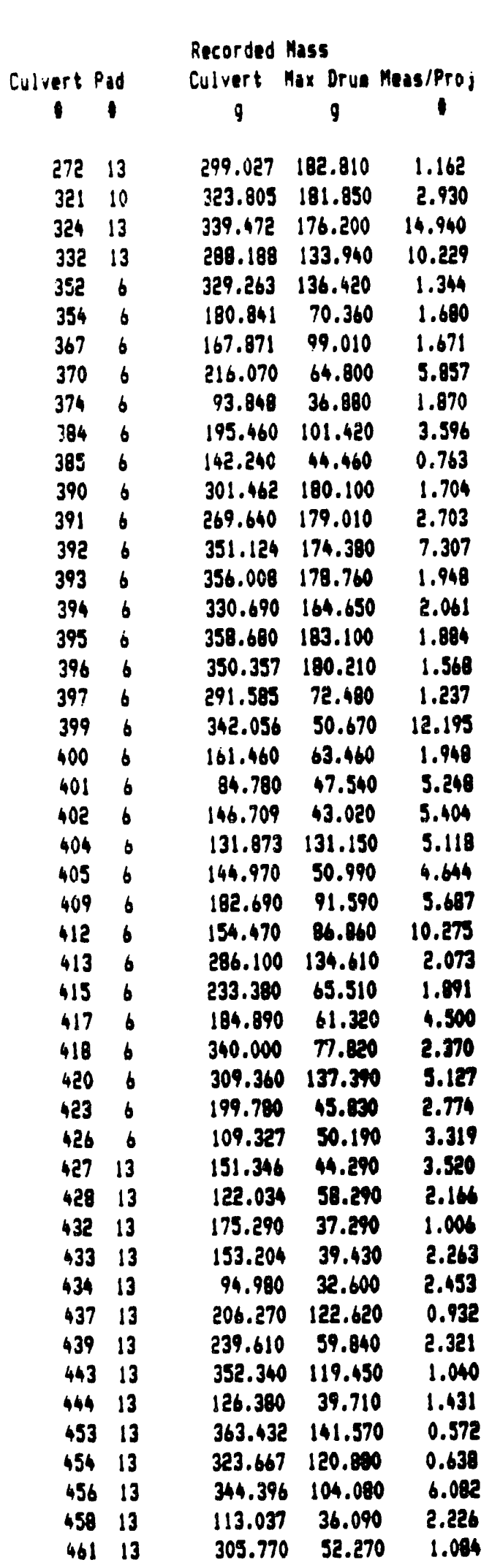

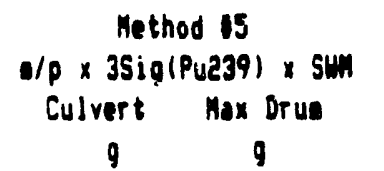

$\begin{array}{rr}941.642 & 575.672 \\ 2571.109 & 1443.944 \\ 13744.339 & 7133.890 \\ 7989.741 & 3712.896 \\ 1199.255 & 496.874 \\ 823.333 & 320.335 \\ 760.189 & 448.358 \\ 3429.565 & 1028.536 \\ 475.594 & 186.897 \\ 1904.789 & 988.354 \\ 294.114 & 91.931\end{array}$

$1392.103 \quad 831.673$

$1975.148 \quad 1311.272$

6952.9473453 .068

$1879.395 \quad 963.699$

$1847.006 \quad 919.621$

$1831.291 \quad 934.043$

1488.765765 .763

$977.472 \quad 242.973$

$11304.421 \quad 1674.565$

$852.360 \quad 335.010$

$1205.748 \quad 676.118$

2J48.530 630.021

1829.0491819 .022

1824.489641 .721

$2815.576 \quad 1411.564$

4301.2562418 .639

1607.261756 .216

1195.991356 .713

2254.734 747.797

$2183.718 \quad 499.815$

$4298.300 \quad 1909.420$

$1501.854 \quad 344.529$

$993.341 \quad 451.433$

$1443.720 \quad 422.491$

$716.322 \quad 342.154$

$477.896 \quad 101.662$

$939.559 \quad 241.814$

$631.392 \quad 216.713$

$520.990 \quad 309.704$

$1507.125 \quad 376.398$

$993.035 \quad 336.658$

$490.103 \quad 153.996$

$563.363 \quad 219.450$

$559.614 \quad 200.999$

$5676.411 \quad 1715.469$

$691.891 \quad 217.711$

$898.242 \quad 153.550$

\begin{tabular}{|c|c|}
\hline \multicolumn{2}{|c|}{$\begin{array}{l}\text { Nethod } 16 \\
13 / \sqrt{n} \text { SUn }\end{array}$} \\
\hline Ivert & Hax Druo \\
\hline 9 & 0 \\
\hline 1286.493 & 1159.193 \\
\hline 1319.507 & 1158.524 \\
\hline 1340.857 & 1154.824 \\
\hline 1272.394 & 1145.607 \\
\hline 1326.909 & 1144.890 \\
\hline 1157.034 & 914.680 \\
\hline 1150.180 & 1188.425 \\
\hline 1188.015 & 842.400 \\
\hline 1202.804 & 479.440 \\
\hline 1168.967 & 1182.693 \\
\hline 1143.997 & 577.980 \\
\hline 19.681 & 1157.334 \\
\hline 18.923 & 1156.613 \\
\hline 1356.923 & 1153.722 \\
\hline 1363.699 & 1156.449 \\
\hline 1320.851 & 1148.676 \\
\hline 1367.415 & 1159.397 \\
\hline 355.861 & 1157.400 \\
\hline 1276.793 & 942.240 \\
\hline 1344.407 & 658.710 \\
\hline 147.364 & 824.990 \\
\hline .140 & 618.080 \\
\hline 1143.905 & 559.260 \\
\hline 1146.371 & 1146.676 \\
\hline 43.925 & 662.870 \\
\hline & 1190.670 \\
\hline 1145.169 & 1129.180 \\
\hline & 1145.392 \\
\hline 1206.248 & 851.630 \\
\hline 0.680 & 797.160 \\
\hline 1341.591 & 1011.660 \\
\hline 1300.130 & 1144.667 \\
\hline 72.671 & 595.790 \\
\hline 67.344 & 652.470 \\
\hline 4.521 & 575.770 \\
\hline 2.399 & 757.770 \\
\hline 4.267 & 484.770 \\
\hline 1144.800 & 512.590 \\
\hline 9.386 & 423.800 \\
\hline 1178.540 & 1151.909 \\
\hline 1213.200 & 777.92 \\
\hline 1358.608 & 1154.71 \\
\hline 1149.212 & 516.23 \\
\hline 1374.041 & 1144.047 \\
\hline & 1153.38 \\
\hline 1347.628 & 1177.007 \\
\hline & 469.170 \\
\hline & \\
\hline
\end{tabular}

Method 16

Culvert hax Druo

$1319.507 \quad 1158.524$

$1272.394 \quad 1145.607$

$1326.909 \quad 1144.890$

$1157.834 \quad 914.680$

1180.015 (1108.425

$1202.804 \quad 479.440$

$1168.967 \quad 1182.693$

$1143.997 \quad 577.980$

$1248.923 \quad 1156.613$

$1356.923 \quad 1153.722$

$1363.699 \quad 1156.449$

1320.851 1148.676

$1367.615 \quad 1159.397$

$1276.703 \quad 942.240$

$1344.407 \quad 658.710$

$1147.364 \quad 824.980$

$1102.140 \quad 618.020$

$1146.371 \quad 1146.676$

$1143.925 \quad 662.870$

$1159.109 \quad 1190.670$

$1145.169 \quad 1129.180$

$1269.709 \quad 1145.392$

$1160.690 \quad 797.160$

$1341.591 \quad 1011.660$

$1300.130 \quad 1144.667$

$1172.671 \quad 595.790$

$1167.344 \quad 652.470$

$1144.521 \quad 575.770$

$1152.399 \quad 757.770$

IIX.267 424.770

$1199.396 \quad 423.800$

$1178.540 \quad 1151.909$

$1213.200 \quad 777.920$

$1149.212 \quad 516.230$

$1374.041 \quad 1144.047$

1319.321 1153.395

$1162.090 \quad 469.170$ 
TABLE C-2. Pu-239 Estiates Ordered by Culvert/ Methods 15,16

\begin{tabular}{|c|c|c|c|c|}
\hline Ivert & Pad & $\begin{array}{l}\text { Recorded } \\
\text { Culvert }\end{array}$ & $\begin{array}{l}\text { Mass } \\
\text { Yax Drue }\end{array}$ & as/Proj \\
\hline 1 & 1 & 9 & 9 & 1 \\
\hline 470 & 13 & 334.901 & 90.860 & 2.344 \\
\hline 472 & 13 & 324.490 & 94.620 & 2.126 \\
\hline 475 & 13 & 105.977 & 92.740 & 1.724 \\
\hline 479 & 13 & 345.430 & 96.750 & 1.014 \\
\hline 480 & 13 & 343.640 & 70.990 & 2.730 \\
\hline 481 & 13 & 343.477 & 74.280 & 10.341 \\
\hline 482 & 13 & 341.354 & 71.346 & 4.010 \\
\hline 484 & 13 & 322.785 & 154.000 & 0.811 \\
\hline 488 & 13 & 329.822 & 178.900 & 3.045 \\
\hline 489 & 13 & 355.619 & 155.860 & 0.432 \\
\hline 490 & 13 & 333.991 & 178.260 & 2.664 \\
\hline 491 & 13 & 349.800 & 140.180 & 0.840 \\
\hline 492 & 10 & 308.824 & 175.780 & 3.164 \\
\hline 493 & 13 & 340.105 & 187.040 & 1.803 \\
\hline 494 & 13 & 238.244 & 169.690 & 3.136 \\
\hline 498 & 13 & 53.400 & 35.300 & 0.385 \\
\hline 501 & 10 & 346.830 & 181.540 & 2.116 \\
\hline 502 & 13 & 131.580 & 94.130 & 1.542 \\
\hline 503 & 10 & 321.610 & 151.570 & 2.967 \\
\hline 504 & 10 & 328.440 & 169.960 & 1.587 \\
\hline 505 & 13 & 355.340 & 165.750 & 3.425 \\
\hline 506 & 10 & 608.096 & 149.180 & 0.718 \\
\hline 507 & 13 & 355.056 & 179.710 & 39.305 \\
\hline 508 & 13 & 267.526 & 70.240 & 1.066 \\
\hline 509 & 13 & 339.232 & 62.190 & 1.072 \\
\hline 510 & 13 & 694.000 & 134.590 & 1.071 \\
\hline 513 & 13 & 689.950 & 144.820 & 2.715 \\
\hline 514 & 10 & 333.900 & 176.300 & 2.200 \\
\hline 515 & 10 & 325.730 & 170.180 & 6.943 \\
\hline 316 & 10 & 333.290 & 174.700 & 7.067 \\
\hline 517 & 13 & 335.320 & 167.710 & $0.6 r s$ \\
\hline 518 & 10 & 320.040 & 163.990 & 5.57 \\
\hline 519 & 13 & 335.320 & 172.310 & 0.52 \\
\hline 520 & 13 & 219.900 & 179.270 & 0.452 \\
\hline $52 !$ & 13 & 241.970 & 18.260 & 4.309 \\
\hline 522 & 10 & 247.510 & 181.610 & 0.897 \\
\hline 523 & 10 & 685.250 & 130.660 & 1.149. \\
\hline 526 & 13 & 245.400 & 175.90 & 4.003 \\
\hline 527 & 13 & 267.410 & 183.290 & 6.992 \\
\hline 528 & 10 & 972.150 & 141.810 & 1.523 \\
\hline 529 & 13 & 322.100 & 162.020 & 9.831 \\
\hline 530 & 13 & 318.510 & 176.540 & 3.356 \\
\hline 531 & 13 & 313.710 & 174.470 & 1.532 \\
\hline 532 & 13 & 913.870 & 135.450 & 0.556 \\
\hline 533 & 13 & 225.070 & 173.530 & 1.202 \\
\hline 534 & 10 & 279.040 & 155.390 & 1.317 \\
\hline 535 & 13 & 230.510 & 167.090 & 2.198 \\
\hline 536 & 13 & 231.510 & 177.780 & 0.721 \\
\hline
\end{tabular}

\begin{tabular}{|c|c|c|c|}
\hline $\begin{array}{r}\text { Hetho } \\
\text { ip } \times 3 \text { Sig } 1 \text { P }\end{array}$ & $\begin{array}{l}d 05 \\
\text { u2391 } \times \text { sun }\end{array}$ & $\begin{array}{l}\text { Weth } \\
13 / \sqrt{1}\end{array}$ & Sin \\
\hline Culvert & Max Drus & Culvert & Max Drus \\
\hline 9 & 9 & 9 & 9 \\
\hline 2127.372 & 513.642 & 1334.596 & 1051.180 \\
\hline 1869.536 & 545.149 & 1320.434 & 1200.456 \\
\hline 495.129 & 433.285 & 1173.331 & 1205.620 \\
\hline 949.221 & 265.863 & 1349.054 & 1194.348 \\
\hline 2542.352 & 523.205 & 1346.587 & 922.870 \\
\hline 9625.637 & 2081.631 & 1346.362 & 965.640 \\
\hline 3709.529 & 775.324 & 1343.442 & 927.498 \\
\hline 709.420 & 338.463 & 1318.129 & 1145.058 \\
\hline 2721.675 & 1476.274 & 1327.669 & 1156.541 \\
\hline 416.330 & 182.468 & 1363.158 & 1145.526 \\
\hline 2411.220 & 1286.937 & 1333.352 & 1156.125 \\
\hline 796.295 & 319.106 & 1355.090 & 1144.193 \\
\hline 2647.993 & 1507.215 & 1299.417 & 1154.566 \\
\hline 1661.797 & 913.802 & 1341.726 & 1162.269 \\
\hline 2024.731 & 1442.121 & 1211.660 & 1151.105 \\
\hline 55.715 & 36.830 & 694.200 & 458.900 \\
\hline 1988.848 & 1041.016 & 1350.985 & 1158.311 \\
\hline 349.849 & 393.352 & 1146.493 & 1201.937 \\
\hline 2585.928 & 1218.709 & 1316.542 & 1144.560 \\
\hline 1412.545 & 730.959 & 1325.790 & 1151.247 \\
\hline 3298.177 & 1539.450 & 1362.771 & 1149.170 \\
\hline 1183.221 & 290.271 & 1726.815 & 1144.205 \\
\hline 36857.138 & 18653.075 & 1362.376 & 1157.074 \\
\hline 772.845 & 202.914 & 1246.308 & 913.120 \\
\hline 985.510 & 180.669 & 1340.527 & 808.470 \\
\hline 2014.273 & 390.635 & 1851.646 & 1145.398 \\
\hline 5069.053 & 1065.533 & 1844.321 & 1143.923 \\
\hline 1997.951 & 1054.923 & 1333.220 & J154.806 \\
\hline 6129.713 & 3202.027 & 1322.113 & 1151.343 \\
\hline 6300.027 & 3245.779 & 1382.395 & 1153.913 \\
\hline 813.302 & 406.772 & 1395.169 & $\$ 150.101$ \\
\hline 4845.652 & 2482.935 & 1314.426 & 1148.390 \\
\hline 528.873 & 271.771 & 1335.169 & 1152.527 \\
\hline 269.360 & 219.591 & 1891.896 & 1156.783 \\
\hline 2858.365 & 2164.030 & 1215.891 & 1159.510 \\
\hline 594.957 & 436.549 & 1222.260 & 1158.359 \\
\hline 2133.723 & 406.840 & 1838.952 & 1146.895 \\
\hline 2662.131 & 1909.054 & 1219.820 & 1154.698 \\
\hline 5066.970 & 3473.038 & 1246.164 & 1159.532 \\
\hline 4017.653 & sng.045 & 2E51.411 & 1144.027 \\
\hline 8581.391 & 4316.538 & 1317.204 & 1147.581 \\
\hline 2896.772 & 1605.589 & 1312.367 & 1155.083 \\
\hline 1302.436 & 724.351 & 1305.931 & 1153.776 \\
\hline 1376.983 & 204.091 & 2169.306 & 1145.145 \\
\hline 733.148 & 565.260 & i iิ7.280ิ & 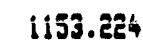 \\
\hline 995.913 & 554.398 & 1260.708 & 1145.401 \\
\hline 1373.051 & 995.285 & 1203.109 & 1149.800 \\
\hline 452.350 & 347.366 & 1204.198 & 1155.817 \\
\hline
\end{tabular}

$$
\text { C-15 }
$$


TABLE C-2. Pu-239 Estieates Ordered by Culvert/ Methods 15,16

\begin{tabular}{|c|c|c|c|c|}
\hline \multicolumn{2}{|c|}{ Culvert Pad } & \multirow{2}{*}{$\begin{array}{c}\text { Recorded } \\
\text { Culvert } \\
9\end{array}$} & Mass & \multirow{2}{*}{ Mers/Pro } \\
\hline 1 & 1 & & 9 & \\
\hline 537 & 13 & 222.630 & 158.400 & 0.436 \\
\hline 538 & 13 & 235.960 & 166.080 & 1.269 \\
\hline 539 & 13 & 228.490 & 167.570 & 0.890 \\
\hline 540 & 13 & 231.650 & 160.810 & 1.833 \\
\hline 541 & 13 & 260.820 & 165.420 & 0.589 \\
\hline 543 & 13 & 861.775 & 101.150 & 0.867 \\
\hline 544 & 10 & 811.310 & 101.910 & 0.734 \\
\hline 545 & 10 & 677.780 & 126.200 & 1.106 \\
\hline 546 & 13 & 948.097 & 106.970 & 0.582 \\
\hline 547 & 13 & 231.350 & 157.900 & 0.633 \\
\hline 548 & 13 & 841.400 & 144.570 & 0.445 \\
\hline 549 & 13 & 1221.550 & 131.950 & 0.609 \\
\hline 550 & 13 & 88.345 & 44.697 & 5.330 \\
\hline 551 & 13 & 1131.993 & 123.600 & 0.580 \\
\hline 352 & 13 & 797.840 & 125.150 & 1.434 \\
\hline 553 & 13 & 976.340 & 103.120 & 0.645 \\
\hline 554 & 13 & 955.320 & 113.230 & 0.669 \\
\hline 555 & 13 & 805.730 & 118.920 & 0.810 \\
\hline 557 & 13 & 722.698 & 119.570 & 0.466 \\
\hline 958 & 10 & 760.166 & 97.350 & 1.274 \\
\hline 559 & 13 & 554.018 & 125.390 & 0.631 \\
\hline 560 & 13 & 367.785 & 42.510 & 0.317 \\
\hline
\end{tabular}

\begin{tabular}{|c|c|}
\hline \multirow{2}{*}{\multicolumn{2}{|c|}{$\begin{array}{c}\text { Method } 55 \\
1 p \times 3 S i g(P u 239) \times \text { SWl }\end{array}$}} \\
\hline & \\
\hline 9 & 9 \\
\hline 263.051 & 187.159 \\
\hline $0 . . .464$ & 571.147 \\
\hline 551.093 & 404.162 \\
\hline 1150.705 & 798.812 \\
\hline 416.318 & 264.042 \\
\hline 2024.801 & 237.659 \\
\hline 1613.809 & 202.713 \\
\hline 2031.483 & 378.254 \\
\hline 1495.358 & 168.715 \\
\hline 396.865 & 270.866 \\
\hline 1014.686 & 174.344 \\
\hline 2016.034 & 217.769 \\
\hline 1276.092 & 645.617 \\
\hline 1779.267 & 194.274 \\
\hline 3100.518 & 486.350 \\
\hline 1706.594 & 180.249 \\
\hline 1731.986 & 205.321 \\
\hline 1768.658 & 261.041 \\
\hline 912.666 & 151.000 \\
\hline 2624.504 & 336.105 \\
\hline 947.376 & 214,418 \\
\hline 315.953 & 36.519 \\
\hline
\end{tabular}

\begin{tabular}{cc}
\multicolumn{2}{c}{ Method 16} \\
$13 / \sqrt{n}$ & SuH \\
Culvert & Max Orus \\
9 & 9 \\
& 9 \\
1194.719 & 1146.283 \\
1209.104 & 1149.323 \\
1200.926 & 1150.033 \\
1204.351 & 1147.119 \\
1238.101 & 1149.020 \\
2093.718 & 1183.307 \\
2021.194 & 1181.5997 \\
1829.111 & 1149.327 \\
2217.156 & 1171.525 \\
1204.023 & 1146.123 \\
2064.468 & 1143.922 \\
2603.106 & 1146.340 \\
1148.485 & 581.061 \\
2477.529 & 1151.142 \\
2001.792 & 1150.023 \\
2257.372 & 1178.985 \\
2227.449 & 1161.805 \\
2013.159 & 1155.235 \\
1893.237 & 1154.599 \\
1947.432 & 1192.721 \\
1640.104 & 1149.860 \\
1380.127 & 552.630
\end{tabular}


TABLE C-2. Pu-239 Estiaates Ordered by Culvert/ Mathods 17,10

\begin{tabular}{|c|c|c|c|c|c|c|c|c|}
\hline & & & Mass & & $\begin{array}{l}\text { Metho } \\
\text { Refined }\end{array}$ & $17 \sqrt{n} \sin$ & & $\begin{array}{l}\text { od } 18 \\
11 \times \text { SUH }\end{array}$ \\
\hline Culvert & & Culvert & Hax Orus & leas/Proj & Culvert & Hax Drue & Culvert & Max Orua \\
\hline 1 & 1 & 9 & 9 & 1 & 9 & 9 & 9 & 9 \\
\hline 272 & 13 & 299.027 & 182.810 & 1.162 & 1186.353 & 1045.079 & 602.942 & 383.170 \\
\hline 321 & 10 & 323.805 & 181.850 & 2.930 & 1220.660 & 1044.191 & 616.807 & 382.887 \\
\hline 324 & 13 & 339.472 & 176.200 & 14.940 & 1242.668 & 1059.137 & 689.352 & 381.127 \\
\hline 332 & 13 & 289.180 & 133.940 & 10.229 & 1171.590 & 1014.975 & 643.308 & 360.742 \\
\hline 352 & 6 & 329.263 & 136.420 & 1.344 & 1228.303 & 1015.463 & 718.039 & 362.394 \\
\hline 354 & 6 & 180.841 & 70.360 & 1.680 & 1043.266 & 914.680 & 491.553 & 281.838 \\
\hline 367 & 6 & 167.871 & 99.010 & 1.671 & 1032.295 & 1032.324 & 459.798 & 328.082 \\
\hline 370 & 6 & 216.070 & 64.800 & 5.857 & 1080.000 & 842.400 & 366.283 & 269.886 \\
\hline 374 & 6 & 93.848 & 36.880 & 1.870 & 1040.830 & 479.440 & 290.580 & 188.907 \\
\hline 384 & b & 195.460 & 101.420 & 3.596 & 1057.490 & 1029.076 & 504.380 & 331.024 \\
\hline 385 & 6 & 142.240 & 44.460 & 0.763 & 1017.189 & 577.980 & 416.732 & 214.894 \\
\hline 390 & 6 & 301.462 & 880.100 & 1.704 & 1189.693 & 1042.593 & 623.831 & 382.360 \\
\hline 391 & 6 & 269.640 & 179.010 & 2.703 & 1146.773 & 1041.612 & 537.995 & 382.024 \\
\hline 392 & 6 & 351.124 & 174.380 & 7.307 & 1259.159 & 1037.575 & 660.011 & 380.522 \\
\hline 393 & 6 & 396.008 & 178.760 & 1.948 & 1266.099 & 1041.399 & 658.146 & 381.946 \\
\hline 394 & 6 & 330.690 & 164.650 & 2.061 & 1230.306 & 1029.850 & 652.409 & 376.944 \\
\hline 395 & 6 & 358.680 & 183.100 & 1.884 & 1269.900 & 1045.349 & 631.601 & 393.254 \\
\hline 396 & 6 & 350.357 & 180.210 & 1.568 & 1258.070 & 1042.693 & 631.894 & 392.394 \\
\hline 397 & 6 & 291.585 & 72.480 & 1.237 & 1176.199 & 942.240 & 683.206 & 286.101 \\
\hline 399 & 6 & 342.056 & 50.670 & 12.195 & 1246.316 & 658.710 & 764.294 & 233.782 \\
\hline 400 & 6 & 161.460 & 63.460 & 1.948 & 1027.570 & 824.990 & 423.813 & 266.828 \\
\hline $4 \hat{u} 1$ & 6 & 84.780 & 47.540 & 5.248 & 1062.086 & 618.020 & 315.631 & 224.516 \\
\hline $40 E$ & 6 & 146.709 & 43.020 & 3.404 & 1019.019 & 559.260 & 433.726 & 210.216 \\
\hline 404 & 6 & 131.873 & 131.150 & 3.118 & 1014.693 & 1014.623 & 360.045 & 358.797 \\
\hline 405 & b & 144.970 & 50.990 & 4.644 & 1018.257 & 662.870 & 427.082 & 234.701 \\
\hline 409 & 6 & 182.690 & 91.590 & 3.687 & 1044.968 & 1045.290 & 505.077 & 318.213 \\
\hline 412 & 6 & 154.470 & 86.860 & 10.279 & 1023.097 & 1056.391 & 454.553 & 311.226 \\
\hline 413 & 6 & 286.100 & 134.610 & 2.073 & 1168.767 & 1015.091 & 612.583 & 361.196 \\
\hline 415 & 6 & 233.380 & 65.510 & 1.091 & 1100.534 & 851.630 & 594.029 & 271.677 \\
\hline 417 & 6 & 184.890 & 61.320 & 4.500 & 1047.031 & 797.160 & 509.641 & 261.797 \\
\hline 418 & 6 & 340.000 & 77.820 & 2.370 & 1243.413 & 1011.660 & 769.093 & 296.169 \\
\hline 420 & 6 & 309.360 & 137.390 & 3.127 & 1200.575 & 1015.693 & 676.768 & 363.021 \\
\hline 423 & 6 & 199.780 & 45.030 & 2.774 & 1061.990 & 595.790 & 519.761 & 219.230 \\
\hline 426 & 6 & 109.327 & 50.190 & 3.319 & 1021.115 & 652.470 & 335.192 & 232.393 \\
\hline 427 & 13 & 191.346 & b 44.290 & 3.520 & 1021.315 & 579.770 & 423.446 & 214.348 \\
\hline 428 & 13 & 122.034 & 50.290 & 2.166 & 1015.112 & 757.770 & 365.721 & 234.345 \\
\hline 432 & 13 & 175.290 & 37.290 & 1.006 & 1038.352 & 404.770 & 460.997 & 190.402 \\
\hline 433 & 13 & 153.204 & 39.430 & 2.263 & 1022.343 & 512.590 & 447.460 & 198.033 \\
\hline 434 & 13 & 94.980 & 32.600 & 2.453 & 1038.770 & 423.800 & 312.946 & 178.654 \\
\hline 437 & 13 & 206.270 & 122.620 & 0.932 & 1068.992 & 1014.997 & 475.766 & 392.233 \\
\hline 439 & 13 & 239.610 & $0 \quad 59.840$ & 2.321 & 1108.206 & 777.920 & 588.247 & 258.206 \\
\hline 443 & 13 & 352.340 & 119.450 & 1.040 & 1260.803 & 1015.773 & 715.361 & 349.535 \\
\hline 444 & 13 & 126.380 & $0 \quad 39.710$ & 1.431 & 1014.543 & 516.230 & 353.672 & 199.011 \\
\hline 453 & 13 & 363.432 & 141.570 & 0.572 & 1276.673 & 1086.959 & 743.760 & 365.605 \\
\hline 454 & 13 & 323.667 & $7 \quad 120.880$ & 0.638 & 1220.467 & 1015.376 & 715.335 & 330.771 \\
\hline 456 & 13 & 344.396 & 6104.080 & 6.082 & 1249.623 & 1025.962 & 750.430 & 334.139 \\
\hline 458 & 13 & 113.037 & $7 \quad 36.090$ & 2.226 & 1018.601 & 469.170 & 344.841 & 185.997 \\
\hline 461 & 13 & 305.770 & 52.270 & 1.084 & 1195.619 & 679.510 & 713.229 & 238.328 \\
\hline
\end{tabular}


TABLE C-2. Pu-239 Estinates Ordered by Cuivert/ Methods 17,68

\begin{tabular}{|c|c|c|c|c|}
\hline \multicolumn{2}{|c|}{ Culvert Pad } & \multirow{2}{*}{$\begin{array}{c}\text { Recorded } \\
\text { Culvert } \\
9\end{array}$} & Mass & as/Proj \\
\hline 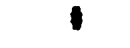 & 1 & & 9 & 1 \\
\hline 470 & 13 & 334.901 & 80.860 & 2.344 \\
\hline 472 & 13 & 324.490 & 94.620 & 2.126 \\
\hline 475 & 13 & 105.977 & 92.740 & 1.724 \\
\hline 479 & 13 & 345.430 & 96.750 & 1.016 \\
\hline 480 & 13 & 343.640 & 70.990 & 2.730 \\
\hline 481 & 13 & 343.477 & 74.290 & 10.341 \\
\hline 489 & 13 & 341.354 & 71.346 & 4.010 \\
\hline 484 & 13 & 322.795 & 154.000 & 0.811 \\
\hline 488 & 13 & 329.822 & 178.900 & 3.045 \\
\hline 489 & 13 & 355.619 & 155.860 & 0.432 \\
\hline 490 & 13 & 333.991 & 178.260 & 2.664 \\
\hline 491 & 13 & 349.800 & 140.180 & 0.840 \\
\hline 492 & 10 & 308.824 & 175.790 & 3.164 \\
\hline 493 & 13 & 340.105 & 187.040 & 1.803 \\
\hline 494 & 13 & 239.244 & 169.690 & 3.136 \\
\hline 498 & 13 & 53.400 & 35.300 & 0.385 \\
\hline 501 & 10 & 346.030 & 181.540 & 2.116 \\
\hline 502 & 13 & 131.580 & 94.130 & 1.542 \\
\hline 503 & 10 & 321.610 & 151.570 & 2.967 \\
\hline 504 & 10 & 328.440 & 169.960 & 1.587 \\
\hline 505 & 13 & 355.340 & 165.750 & 3.425 \\
\hline 506 & 10 & 608.096 & 149.180 & 0.718 \\
\hline 507 & 13 & 355.056 & 179.710 & 30.305 \\
\hline 508 & 13 & 267.526 & 70.240 & 1.066 \\
\hline 509 & 13 & 339.232 & 62.190 & 1.072 \\
\hline 510 & 13 & 694.0000 & 134.590 & 1.071 \\
\hline 513 & 13 & 689.950 & 144.020 & 2.715 \\
\hline 584 & 10 & 333.900 & 176.300 & 2.200 \\
\hline 515 & 10 & 325.730 & 170.180 & 6.943 \\
\hline 516 & 10 & 333.290 & 174.700 & 7.067 \\
\hline 517 & 13 & 335.330 & 167.710 & 0.875 \\
\hline 518 & 10 & 320.040 & 163.990 & 5.577 \\
\hline 519 & 13 & 335.320 & 172.310 & 0.32 \\
\hline 520 & 13 & 219.900 & 179.270 & 0.452 \\
\hline 521 & 13 & 241.970 & 183.260 & 4.359 \\
\hline 522 & 10 & 247.510 & 101.610 & 0.87 \\
\hline 523 & 10 & 6005.250 & 130.660 & 1.149 \\
\hline 526 & 13 & 245.400 & 175.900 & 4.003 \\
\hline 527 & 13 & 267.410 & 183.290 & 6.992 \\
\hline 528 & 10 & 972.150 & 141.810 & 1.523 \\
\hline 529 & 13 & 322.100 & 162.020 & 9.831 \\
\hline 530 & 13 & 318.510 & 176.540 & 3.356 \\
\hline 531 & 13 & 313.710 & 174.470 & 1.532 \\
\hline 532 & 13 & 913.870 & 135.450 & 0.556 \\
\hline 533 & 13 & 223.070 & 173.530 & 1.202 \\
\hline 534 & 10 & 279.040 & 155.390 & 1.387 \\
\hline 535 & 13 & 230.510 & 167.090 & 2.198 \\
\hline 536 & 13 & 231.510 & 177.780 & 0.721 \\
\hline
\end{tabular}

\begin{tabular}{|c|c|c|c|}
\hline \multicolumn{2}{|c|}{$\begin{array}{l}\text { Method } 17 \\
\text { Refined } 13 / \sqrt{\pi} \text { SWh }\end{array}$} & \multicolumn{2}{|c|}{$\begin{array}{l}\text { Method } 18 \\
\text { Cut Hodel } \times \text { SWN }\end{array}$} \\
\hline Ivert & Max Drua & Culvert & hax Orus \\
\hline 9 & 9 & 9 & 9 \\
\hline 1236.226 & 1051.180 & 767.257 & 301.498 \\
\hline 1221.618 & 1039.412 & 734.762 & 322.397 \\
\hline 1024.022 & 1042.961 & 341.922 & 319.827 \\
\hline 1251.088 & 1035.774 & 762.060 & 325.210 \\
\hline 1248.556 & 922.870 & 768.340 & 293.121 \\
\hline 1248.323 & 965.640 & 777.547 & 289.599 \\
\hline 1245.325 & 927.499 & 772.994 & 203.840 \\
\hline 1219.235 & 1022.801 & 672.874 & $372.27 !$ \\
\hline 1229.087 & 1041.514 & 639.536 & 381.990 \\
\hline 1265.544 & 1023.911 & 671.374 & 373.150 \\
\hline 1234.945 & 1040.944 & 661.080 & 381.789 \\
\hline 1257.280 & 1016.409 & 720.960 & 364.766 \\
\hline 1199.834 & 1030.773 & 602.856 & 380.999 \\
\hline 1243.561 & 1049.009 & 670.942 & 394.359 \\
\hline 1106.513 & 1033.715 & 503.134 & 378.873 \\
\hline 694.200 & 458.900 & 224.959 & 183.047 \\
\hline 1253.070 & 1043.906 & 690.512 & 382.795 \\
\hline 1014.663 & 1040.306 & 401.938 & 321.735 \\
\hline 1217.594 & 1021.036 & 659.416 & 371.078 \\
\hline 1227.149 & 1033.931 & 667.293 & 378.971 \\
\hline 1265.148 & 1030.667 & 689.907 & 377.390 \\
\hline 1631.432 & 1020.192 & 1008.174 & 369.855 \\
\hline 1264.744 & 1042.241 & 694.445 & 302.241 \\
\hline 1143.997 & 913.120 & 653.717 & 281.592 \\
\hline 1242.329 & 800.470 & 756.584 & 263.865 \\
\hline 1755.735 & 1015.000 & 1248.087 & 361.182 \\
\hline 1748.446 & 1010.194 & 1239.544 & 367.489 \\
\hline 1234.817 & 1039.224 & 618.104 & 381.160 \\
\hline 1223.353 & 1034.107 & 613.406 & 379.051 \\
\hline 1233.939 & 1037.840 & 617.402 & 300.630 \\
\hline 1236.815 & 1032.160 & 652.610 & 378.135 \\
\hline 1215.404 & 1029.367 & 610.500 & 376.679 \\
\hline 1236.815 & 1035.842 & 662.690 & 379.811 \\
\hline 1084.433 & 1041.845 & 471.976 & 382.105 \\
\hline 1111.147 & 1045.498 & 512.732 & 383.300 \\
\hline 1118.117 & 1043.970 & 523.491 & 392.816 \\
\hline 1743.108 & 1014.503 & 1228.065 & 350.446 \\
\hline 1115.451 & 1030.946 & 529.553 & 381.055 \\
\hline 1143.834 & 1045.526 & 549.223 & 393.309 \\
\hline 2152.474 & 1017.036 & 1602.303 & 365.748 \\
\hline 1218.278 & 1027.960 & 612.314 & 375.869 \\
\hline 1213.273 & 1039.432 & 612.442 & 381.238 \\
\hline 1206.600 & 1037.652 & 647.173 & 390.552 \\
\hline 2070.099 & 1015.233 & 1525.082 & 361.756 \\
\hline 1090.521 & $10 \overline{36} 6.800$ & 996.550 & 360.2333 \\
\hline 1159.273 & 1023.626 & 583.311 & 372.931 \\
\hline 097.046 & 1031.603 & 506.473 & 377.899 \\
\hline 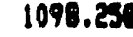 & & 500.331 & 381.63 \\
\hline
\end{tabular}

$c-18$ 
TABLE C-2. Pu-239 Estieates Ordered by Culvert/ Methods 17,10

\begin{tabular}{|c|c|c|c|c|}
\hline \multirow{2}{*}{\multicolumn{2}{|c|}{ Culvert Pad }} & \multirow{2}{*}{$\begin{array}{c}\text { Recorded } \\
\text { Culvert } \\
9\end{array}$} & \multirow{2}{*}{$\begin{array}{l}\text { Mass } \\
\text { Max Drue } \\
9\end{array}$} & \multirow{2}{*}{$\begin{array}{c}\text { Meas/Proj } \\
\end{array}$} \\
\hline & & & & \\
\hline 537 & 13 & 222.630 & 158.400 & 0.436 \\
\hline 538 & 13 & 235.960 & 166.080 & 1.269 \\
\hline 539 & 13 & 228.490 & 167.570 & 0.890 \\
\hline 540 & 13 & 231.650 & 160.810 & 1.833 \\
\hline 541 & 13 & 260.820 & 165.420 & 0.589 \\
\hline 543 & 13 & 861.775 & 101.150 & 0.867 \\
\hline 544 & 10 & 811.310 & 101.910 & 0.734 \\
\hline 545 & 10 & 677.780 & 126.200 & 1.106 \\
\hline 546 & 13 & 948.097 & 106.970 & 0.582 \\
\hline 547 & 13 & 231.350 & 157.900 & 0.633 \\
\hline 548 & 13 & 841.400 & 144.570 & 0.445 \\
\hline 549 & 13 & 1221.550 & 131.950 & 0.609 \\
\hline 550 & 13 & 88.345 & 44.697 & 5.330 \\
\hline 551 & 13 & 1131.993 & 123.600 & 0.580 \\
\hline 552 & 13 & 797.840 & 125.150 & 1.434 \\
\hline 553 & 13 & 976.340 & 103.120 & 0.645 \\
\hline 554 & 13 & 955.320 & 113.250 & 0.669 \\
\hline 555 & 13 & 805.730 & 118.920 & 0.810 \\
\hline 557 & 13 & 722.698 & 119.570 & 0.466 \\
\hline 558 & 10 & 760.166 & 97.350 & 1.274 \\
\hline 559 & 13 & 554.018 & 125.390 & 0.631 \\
\hline 560 & 13 & 367.785 & 42.510 & 0.317 \\
\hline
\end{tabular}

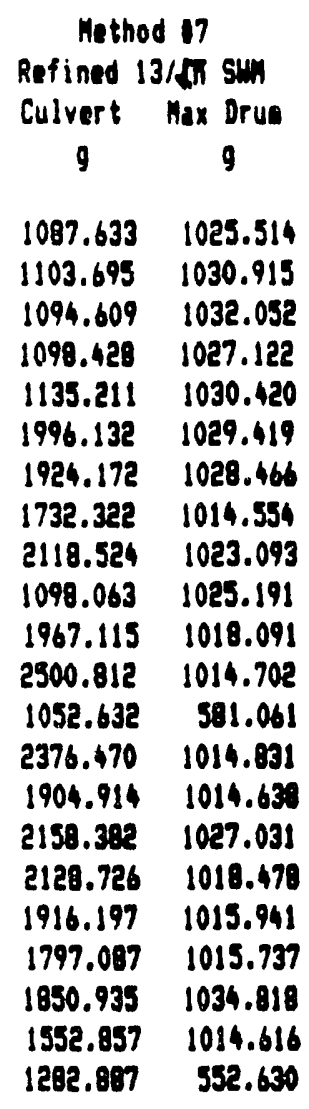

Method 18

Cut Model $x$ Sum

Culvert Max Drus

99

$511.010 \quad 374.307$

$524.943 \quad 377.509$

$509.744 \quad 378.082$

523.752 375.358

$573.800 \quad 377.250$

$1495.595 \quad 330.701$

$1424.606 \quad 331.608$

$1229.215 \quad 355.107$

\begin{tabular}{l}
$1597.867 \quad 337.350$ \\
\hline
\end{tabular}

$524.706 \quad 374.083$

$1428.424 \quad 367.348$

1911.045359 .365

$324.005 \quad 215.653$

$1811.928 \quad 353.037$

1385.422 354.282

$1636.326 \quad 333.027$

$1593.637 \quad 343.811$

$1409.733 \quad 349.070$

$1280.645 \quad 349.640$

1354.301 325.983

$1048.328 \quad 354.472$

$784.770 \quad 208.532$ 
TABLE C-2. Pu-239 Estieates Ordered by Cuivert/ Method 19

\begin{tabular}{|c|c|c|c|c|c|c|}
\hline \multirow{2}{*}{\multicolumn{2}{|c|}{ Eulvert Pad }} & \multirow{2}{*}{$\begin{array}{c}\text { Recorded } \\
\text { Culvert } \\
9\end{array}$} & $\begin{array}{l}\text { Mass } \\
\text { Max Drue }\end{array}$ & Meas/Proj & \multicolumn{2}{|c|}{$\begin{array}{c}\text { Method } 09 \\
\text { Conservative Cut Model x Sum } \\
\text { Culvert Max Drue }\end{array}$} \\
\hline & & & 9 & 1 & 9 & 9 \\
\hline 272 & 13 & 299.027 & 182.810 & 1.162 & 850.101 & 574.755 \\
\hline 321 & 10 & 323.805 & 181.850 & 2.930 & 856.962 & 574.331 \\
\hline 324 & 13 & 339.472 & 176.200 & 14.940 & 961.124 & 571.690 \\
\hline 332 & 13 & 298.188 & 133.940 & 10.229 & 911.529 & 541.113 \\
\hline 352 & 6 & 329.263 & 136.420 & 1.344 & 1000.590 & 543.591 \\
\hline 354 & 6 & 180.841 & 70.360 & 1.680 & 699.891 & 422.757 \\
\hline 367 & 6 & 167.871 & 99.010 & 1.671 & 664.427 & 492.124 \\
\hline 370 & 6 & 216.070 & 64.800 & 5.857 & 802.336 & 404.828 \\
\hline 374 & 6 & 93.848 & 36.880 & 1.870 & 414.529 & 283.361 \\
\hline 384 & 6 & 199.460 & 101.420 & 3.596 & 718.907 & 496.537 \\
\hline 385 & 6 & 142.240 & 44.460 & 0.763 & 592.980 & 322.341 \\
\hline 390 & 6 & 301.462 & 180.100 & 1.704 & 881.497 & 573.541 \\
\hline 391 & 6 & 269.640 & 179.010 & 2.703 & 762.085 & 573.036 \\
\hline 392 & 6 & 351.124 & 174.380 & 7.307 & 933.466 & 570.793 \\
\hline 393 & 6 & 356.008 & 178.760 & 1.948 & 931.237 & 572.919 \\
\hline 394 & 6 & 330.690 & 164.650 & 2.061 & 925.486 & 565.416 \\
\hline 395 & 6 & 358.680 & 183.100 & 1.884 & 901.477 & 574.881 \\
\hline 396 & 6 & 350.357 & 180.210 & 1.568 & 900.945 & 573.591 \\
\hline 397 & 6 & 291.585 & 72.480 & 1.237 & 954.912 & 429.152 \\
\hline 399 & 6 & 362.056 & 50.670 & 12.195 & 1048.213 & 350.673 \\
\hline 400 & 6 & 161.460 & 63.460 & 1.948 & 396.991 & 400.243 \\
\hline 401 & 6 & 84.780 & 47.540 & 5.248 & 462.760 & 336.774 \\
\hline 402 & 6 & 146.709 & 43.020 & 5.404 & 619.647 & 315.323 \\
\hline 404 & 6 & 131.873 & 131.150 & 5.118 & 539.403 & 538.196 \\
\hline 405 & 6 & 144.970 & 50.990 & 4.644 & 611.903 & 352.052 \\
\hline 409 & 6 & 182.690 & 91.590 & 5.687 & 726.591 & 477.320 \\
\hline 412 & 6 & 154.470 & 86.860 & 10.275 & 662.540 & 466.839 \\
\hline 413 & 6 & 286.100 & 134.610 & 2.073 & 871.491 & 541.793 \\
\hline 415 & 6 & 233.380 & 65.510 & 1.891 & 834.806 & 407.215 \\
\hline 417 & 6 & 194.890 & 61.320 & 4.500 & 723.729 & 392.693 \\
\hline 418 & b & 340.000 & 77.820 & 2.370 & 1067.627 & $44 . .254$ \\
\hline 420 & 6 & 309.360 & 137.390 & 3.127 & 948.992 & 544.531 \\
\hline 423 & 6 & 199.700 & 45.830 & 2.774 & 728.403 & 328.856 \\
\hline 426 & 6 & 109.327 & 50.190 & 3.319 & $400.26 !$ & 348.590 \\
\hline 427 & 13 & 151.346 & 44.290 & 3.590 & 599.265 & 321.522 \\
\hline 428 & 13 & 122.034 & 58.290 & 2.166 & 524.501 & 381.518 \\
\hline 432 & 13 & 175.290 & 37.290 & 1.006 & 645.2266 & 285.603 \\
\hline 433 & 13 & 153.204 & 39.430 & 2.263 & 637.333 & 297.050 \\
\hline 434 & 13 & 94.980 & 32.600 & 2.453 & 449.620 & 258.991 \\
\hline 437 & 13 & 206.270 & 122.620 & 0.932 & 676.717 & 528.350 \\
\hline 439 & 13 & 239.610 & 59.840 & 2.321 & 818.945 & 307.309 \\
\hline 443 & 13 & 352.340 & 119.450 & 1.040 & 992.569 & 524.303 \\
\hline 444 & 13 & 126.380 & 39.710 & 1.431 & 499.601 & 298.517 \\
\hline 453 & 13 & 363.432 & 141.570 & 0.572 & 1029.237 & 540.407 \\
\hline 459 & 13 & 323.667 & iĉ. & 0.638 & 995.290 & 596.156 \\
\hline 456 & 13 & 344.396 & 104.080 & 6.082 & 1044.188 & 501.198 \\
\hline 458 & 13 & 113.037 & 36.090 & 2.226 & 492.174 & 270.996 \\
\hline 461 & 13 & 305.770 & 52.270 & 1.084 & 987.535 & 357.491 \\
\hline & & & & & $C-20$ & \\
\hline
\end{tabular}


TABLE C-2. Pu-239 Estiestes Ordered by Culvert/ Method 19

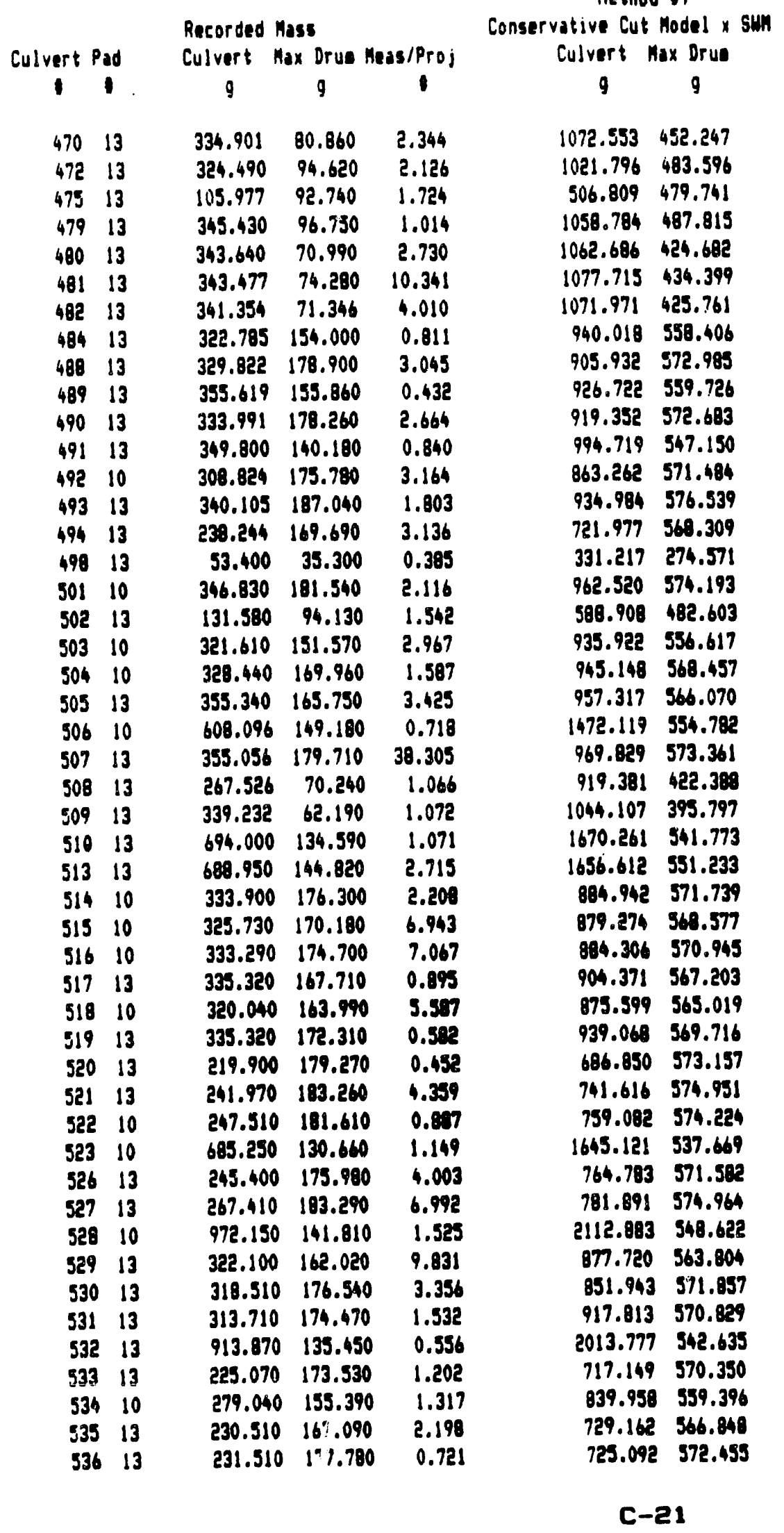


TABLE C-2. Pu-239 Estioates Ordered by Culvert/ Mathod 19

\begin{tabular}{|c|c|c|c|c|c|c|}
\hline \multicolumn{2}{|c|}{ Culvert Pad } & \multirow{2}{*}{$\begin{array}{c}\text { Recorded } \\
\text { Culvert } \\
g\end{array}$} & $\begin{array}{l}\text { Mass } \\
\text { Max Orue }\end{array}$ & Meas/Proj & \multicolumn{2}{|c|}{$\begin{array}{c}\text { Conservative Cut Model } x \text { Sum } \\
\text { Culvert Max Drue }\end{array}$} \\
\hline 1 & 1 & & 9 & 1 & 9 & 9 \\
\hline 537 & 13 & 222.630 & 158.400 & 0.436 & 740.609 & 561.460 \\
\hline 539 & 13 & 235.960 & 166.080 & 1.269 & 759.327 & 566.263 \\
\hline 539 & 13 & 229.490 & 167.570 & 0.890 & 738.422 & 567.123 \\
\hline 540 & 13 & 231.650 & 160.810 & 1.833 & 757.992 & 563.037 \\
\hline 541 & 13 & 260.820 & 165.420 & 0.589 & 819.189 & 565.875 \\
\hline 543 & 13 & 861.775 & 101.150 & 0.867 & 1967.029 & 496.051 \\
\hline 544 & 10 & 811.310 & 101.910 & 0.734 & 1889.883 & 497.412 \\
\hline 545 & 10 & 677.780 & 126.200 & 1.106 & 1649.039 & 532.660 \\
\hline 546 & 13 & 948.097 & 106.970 & 0.582 & 2105.327 & 506.025 \\
\hline 547 & 13 & 231.350 & 157.900 & 0.633 & 753.206 & 561.125 \\
\hline 548 & 13 & 841.400 & 144.570 & 0.445 & 1891.461 & 351.021 \\
\hline 549 & 13 & 1221.550 & 131.950 & 0.609 & 2487.807 & 539.047 \\
\hline 550 & 13 & 88.345 & 44.697 & 5.330 & 473.781 & 323.480 \\
\hline 551 & 13 & 1131.993 & 123.600 & 0.580 & $=367.773$ & I 529.556 \\
\hline 552 & 13 & 797.840 & 125.150 & 1.434 & 1840.592 & 531.423 \\
\hline 553 & 13 & 976.340 & 103.120 & 0.645 & 2153.907 & 499.541 \\
\hline 534 & 13 & 955.320 & 113.250 & 0.669 & 2102.160 & 515.716 \\
\hline 555 & 13 & 805.730 & 118.920 & 0.810 & 1873.650 & 523.604 \\
\hline 557 & 13 & 722.699 & 119.570 & 0.466 & 1705.279 & 324.460 \\
\hline 558 & 10 & 760.166 & 97.350 & 1.274 & 1800.305 & 480.975 \\
\hline 559 & 13 & 554.018 & 125.390 & 0.631 & 1414.037 & 531.700 \\
\hline 560 & 13 & 367.795 & 42.510 & 0.317 & 1066.422 & 312.797 \\
\hline
\end{tabular}



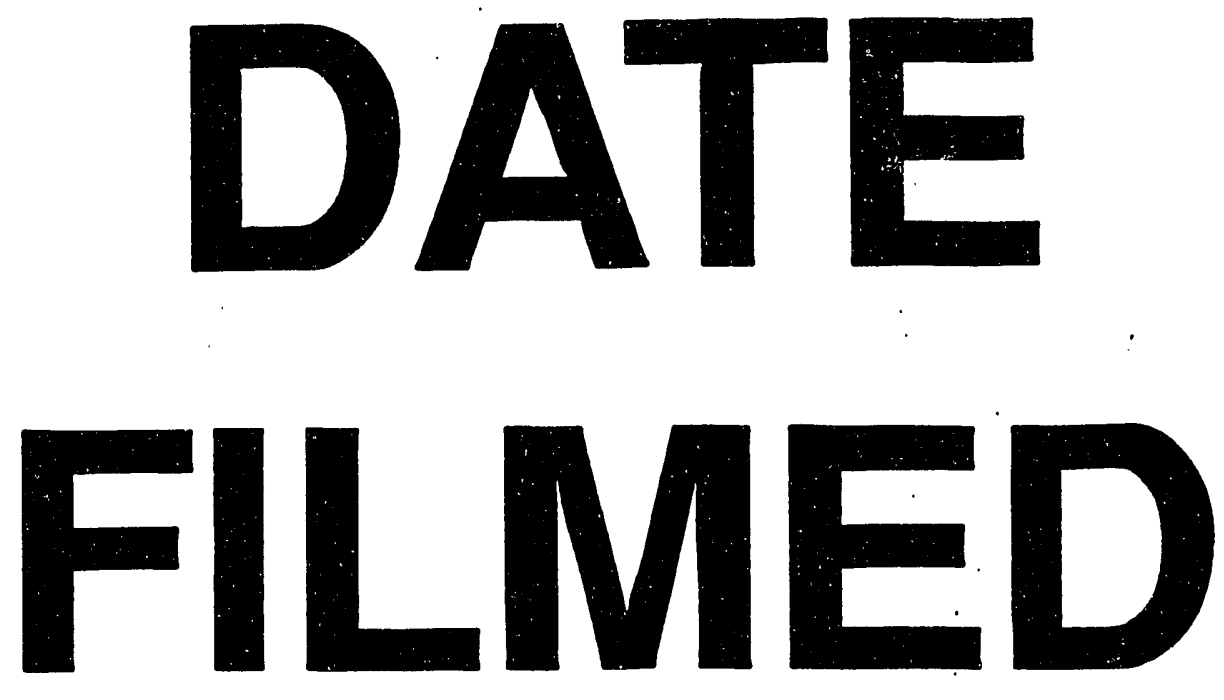

$10 / 6 / 93$
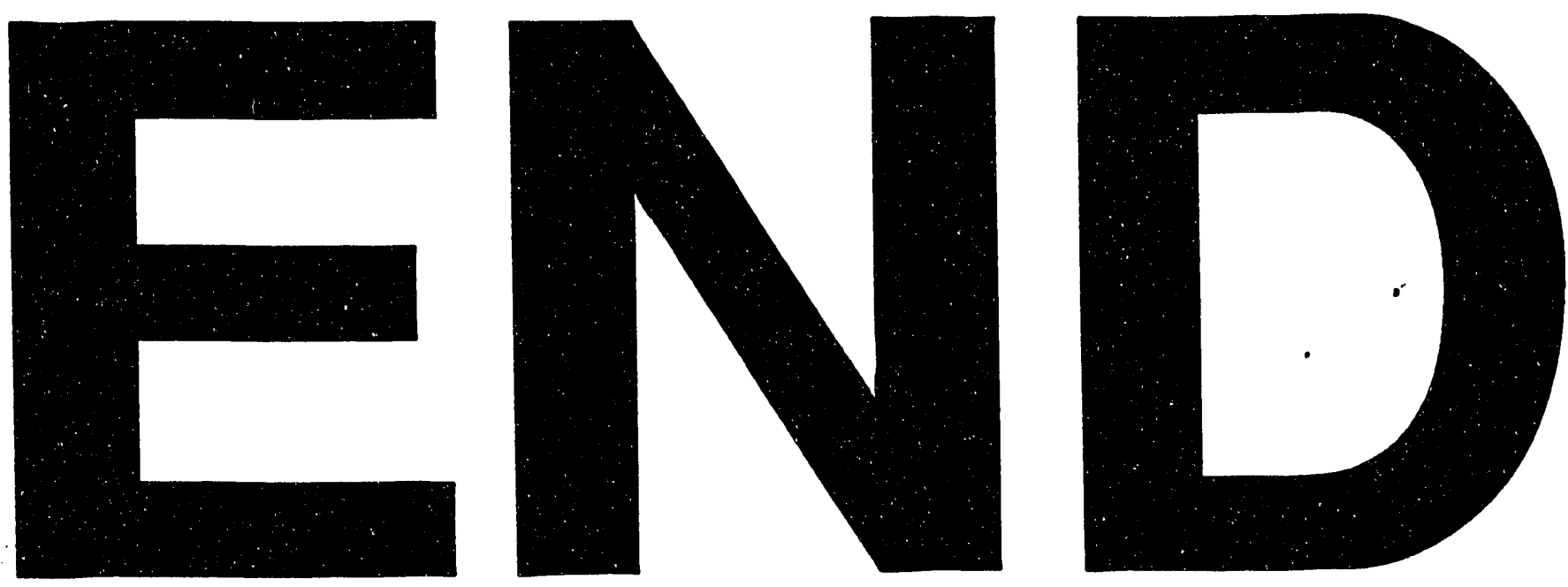
